\title{
Carbon Nanotube-based Vectors for Delivering Immunotherapeutics and Drugs
}

\author{
Alberto Bianco, Wei Wu, Giorgia Pastorin, Cédric Klumpp, \\ Lara Lacerda, Charalambos D. Partidos, Kostas Kostarelos, \\ and Maurizio Prato
}

3.1

Introduction

Administration of drugs is very often limited by problems of insolubility, inefficient distribution, lack of selectivity and side-effects raising health concerns. Currently, most of these problems are the subject of very intense studies, aiming to improve efficiency, availability and toxicity profiles. In addition, cell membranes that act as barriers can pose a problem in drug delivery by selectively allowing only certain structures to pass based on hydrophilicity:hydrophobicity ratios. Among the currently available delivery systems, which include liposomes, emulsions, polymers and microparticles [1-3], carbon nanotubes (CNTs) have recently gained high popularity as potential drug carriers, therapeutic agents and for applications in diagnosis [4-10].

CNTs possess a unique and fascinating one-dimensional nanostructure, which imparts intriguing properties to the nanomaterial, such as tremendous strength [11], high thermal conductivity [12] and amazing electronic properties ranging from metallic to semiconducting [13-16]. These all-carbon hollow graphitic tubes with high aspect and nanoscale diameter [17] can be classified by their structure into two main types: single-walled CNTs (SWNTs), which consist of a single layer of graphene sheet seamlessly rolled into a cylindrical tube, and multiwalled CNTs (MWNTs), which comprise multiple layers of concentric cylinders with a space of about $0.34 \mathrm{~nm}$ between the adjacent layers (Fig. 3.1) [18].

Several techniques, e.g. arc-discharge [19], laser ablation [20], chemical vapor deposition (CVD) [21] or the gas-phase catalytic process (HiPCO) [22], have been used to synthesize CNTs. However, up to now, the CNTs prepared by all currently known methods are mixtures of different tubes with a broad distribution in diameter and chirality, and often contaminated by impurities (mainly including amorphous carbon and catalyst particles). Various methods have been developed to purify CNTs, such as oxidation of contaminants [23-28], microfiltration [29], chromatographic procedures [30,31] and microwave irradiation [32-34]. 


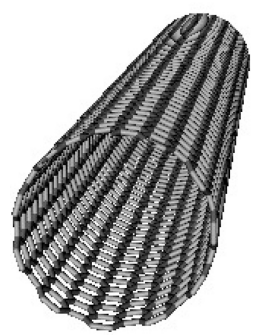

SWNT

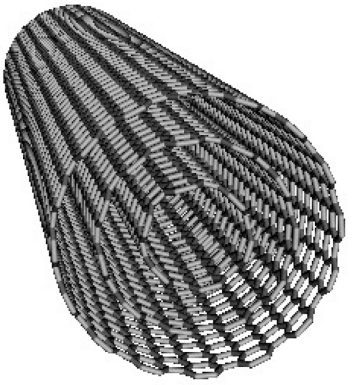

MWNT

Figure 3.1. Molecular structures of defect-free SWNTs (left) and MWNTs (right) with open ends.

One important feature of CNTs is that this material is practically insoluble in both aqueous and polar/nonpolar organic solvents. Although this characteristic has hindered their chemical manipulation and potential applications in many fields, it has stimulated research in their chemical and physical functionalization.

A great effort has been invested in the search for new ways to chemically derivatize the CNTs. Although their tips are very reactive, similar to fullerenes, their sidewalls are much more inert toward chemical reagents. For this reason, there are not so many methods exhibiting general applicability.

Both covalent and noncovalent functionalization approaches are currently known that are very helpful in disentangling the CNT bundles, but which have different impacts on their electronic properties.

\section{2}

\section{Chemical Functionalization of CNTs}

\subsection{1}

\section{Noncovalent Functionalization}

The methods of functionalization of CNTs based on noncovalent interaction can be performed without destroying the intrinsic $\mathrm{sp}^{2}$-hybridized structure of the nanotube sidewall, so that the original electronic structure and properties of CNTs can be preserved. Different kinds of noncovalent functionalization have been explored.

\subsubsection{1 $\pi-\pi$ Stacking Interactions}

The noncovalent functionalization of CNTs could be achieved by $\pi-\pi$ stacking interactions between conjugated molecules and the graphitic sidewall of CNTs. Compounds with the pyrene moiety, e.g. $N$-succinimidyl-1-pyrenebutanoate (Fig. 3.2), could be adsorbed irreversibly onto the surface of SWNTs through $\pi-\pi$ interaction [35]. Furthermore, via the succinimidyl ester group on this bifunctional anchor, 
<smiles>O=C(CCCc1ccc2ccc3cccc4ccc1c2c34)ON1C(=O)CCC1=O</smiles>

$N$-succinimidyl-1pyrenebutanoate

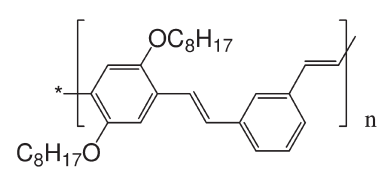

PmPV

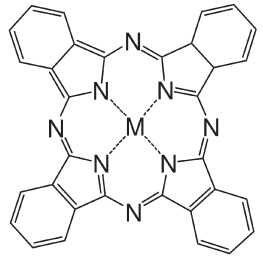

phthalocyanine $(\mathrm{M}=2 \mathrm{H})$ or its coordination complex $(M=$ metal $)$

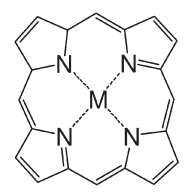

porphyrin $(M=2 H)$ or its coordination complex $(M=$ metal $)$

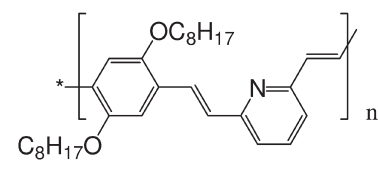

PPyPV

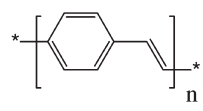

PPV<smiles>CC(=[Tl])c1ccccc1</smiles>

PPA

Figure 3.2. Typical molecules that can noncovalently modify CNTs via $\pi-\pi$ stacking interaction.

various molecules with primary or secondary amines [such as ferritin, streptavidin (SA) or biotin-polyethyleneoxide-amine] were covalently attached to the activated pyrene by nucleophilic attack of the amino group [35]. Using a similar strategy, some other biomolecules (e.g. protein and DNA) [36-38] and gold nanoparticles [39] were also coupled to CNTs.

Through the $\pi-\pi$ stacking interactions, other classes of molecules, including phthalocyanines [40-42], porphyrins [43-53] and their derivatives, have been immobilized onto the surface of CNTs (Fig. 3.2). It was demonstrated that this kind of composite could display photoinduced charge transfer from the dye molecules to CNTs $[42,45]$. The selective interaction between the porphyrin derivative and CNTs was also discovered [46]. The use of Raman spectroscopy, near-infrared (NIR) absorption and buck conductivity has shown that porphyrin derivatives could be selectively adsorbed onto semiconducting nanotubes in a solubilized sample. This is a convenient method to separate the semiconductive CNTs from metallic CNTs.

Polymers with conjugated structures could also be coupled to CNTs by $\pi-\pi$ forces (Fig. 3.2) [54-75]. The strong interaction between the conjugated polymer and the nanotube remarkably increased CNT dispersibilty [54, 61, 66-68]. Some conjugated polymers have been used to purify CNTs by efficient phase separation from the main impurity, consisting of amorphous graphitic shells [62, 64, 65]. In this way, amorphous carbon impurities tend to sediment out of solution, whereas the nanotubes stay in suspension. In addition, this kind of composite has potential applications in the optoelectronic field because of energy transfer from the excited conjugated polymer to the nanotubes [55-60, 63, 66, 69-75]. 


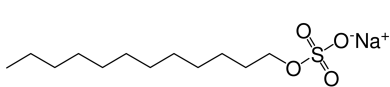

SDS

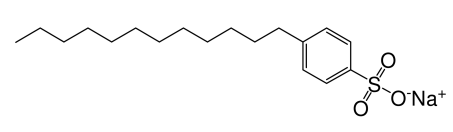

SDBS

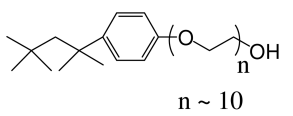

Triton X-100

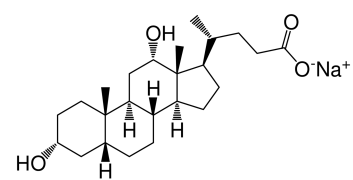

DOC<smiles>C=CCC1CCC(OS(=O)(=O)O)CC1</smiles>

PSS

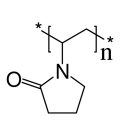

PVP

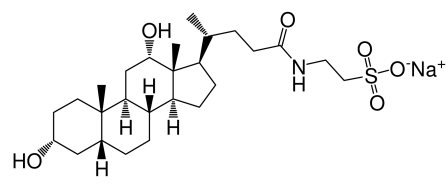

TDOC

Figure 3.3. Typical molecules that can noncovalently modify CNTs via hydrophobic interactions.

\subsubsection{Hydrophobic Interactions}

Another method of noncovalent functionalization of CNTs involves association of CNTs with amphiphilic molecules through hydrophobic interactions in aqueous media. In this system, the amphiphilic molecules interact noncovalently with the aromatic surface of CNTs using their hydrophobic parts, while exposing the hydrophilic parts to the aqueous solution to minimize the hydrophobic interface between the nanotubes and their polar environment.

Through hydrophobic interactions, water-soluble polymers polyvinylpyrrolidone (PVP) and polystyrenesulfonate (PSS) (Fig. 3.3) wrapped helically around the surface of SWNTs helped to dissolve the nanotubes in water [76]. The association between the polymer and SWNTs, which is reversible by changing the solvent system, was very robust, independent of the presence of excess of polymer in solution and uniform along the surface of the nanotubes.

Surfactants were also conjugated to CNTs via hydrophobic interactions. So far, various anionic, nonionic and cationic surfactants have been used to suspend CNTs in aqueous medium (Fig. 3.3) [77-81]. Among them, bile salt surfactants such as deoxycholic acid (DOC) and taurodeoxycholic acid (TDOC) have been found to be very efficient in solubilizing SWNTs. This is because the aggregation was further prevented by the coulombic repulsion between surfactant-coated SWNTs [81]. In addition, if aromatic moieties in the hydrophobic part of the amphiphilic molecule were present, particularly strong interactions between the molecule and the CNTs could be established. This kind of aggregates forms additional $\pi-\pi$ stacking between the aromatic part of the molecule and the graphitic sidewalls of CNTs while exposing the hydrophilic groups to the aqueous solution. As an example, sodium dodecylbenzene sulfonate (SDBS) presented an increased ability in suspending CNTs in water [80]. Some of the surfactants including so- 
dium dodecyl sulfate (SDS), SDBS, DOC or TDOC were found to be very effective in dispersing individually SWNTs [79-81]. This provided the possibility to study the properties of individual SWNTs and further manipulate single tubes [82-86].

Hydrophobic interactions were also used to couple biomolecules to CNTs. In particular, an amphiphilic peptide was wrapped around the SWNT surface. The peptide was able to adopt an $\alpha$-helical structure in aqueous solution, exposing the hydrophobic face of the helix to the nanotube surface $[87,88]$. Atomic force microscopy (AFM), transmission electronic microscopy (TEM), and absorption and Raman spectroscopy proved that the SWNTs were debundled by the peptide. The peptide-coated nanotubes were assembled into macromolecular structure through charged peptide-peptide interactions between adjacent peptide-wrapped nanotubes. The size and morphology of the supermolecular structure can be regulated by controlling the factors that affect peptide-peptide interactions. It was also demonstrated that the ability to disperse individual SWNTs increased with increasing the amount of aromatic residues inside the peptide sequence [89]. In a similar manner, different proteins have also been adsorbed onto the surface of SWNTs and uptaken by mammalian cells (see Section 3.4) [90].

Another interesting approach involved the conjugation of single-stranded DNA with SWNTs resulting in helical wrapping around the surface of the tube exposing the hydrophilic sugar-phosphate backbone towards the exterior [91, 92]. Using this strategy, individually dispersed nanotubes in solution were obtained. CNT wrapping by single-stranded DNA was strongly dependent on the DNA sequence. Moreover, the dependence of the electrostatic properties of the DNA-CNT hybrid on the tube diameter and electronic properties enable nanotube separation by anionexchange chromatography.

In addition to a direct interaction with CNTs, biomolecules have also been attached to SWNTs via amphiphilic molecules as a bifunctional linker. For instance, phospholipid molecules with phospholipid (PL)-poly(ethylene glycol) (PEG) chains and terminal amine (PL-PEG-NH$)$ were noncovalently conjugated to SWNTs. PL alkyl chains were adsorbed to the surface of SWNTs via hydrophobic interactions while the PEG chain extended into the aqueous phase for SWNTs dispersion. After incorporation of a heterobifunctional crosslinker sulfosuccinimidyl 6-(3'-[2-pyridyldithio]propionamido)hexanoate (sulfo-LC-SPDP), the functionalized SWNTs $(f$-SWNTs) were coupled with DNA and RNA via disulfide linkage. The complexes were subsequently delivered to cells (see Section 3.7) [93].

\subsection{2}

\section{Covalent Functionalization}

The characteristics of CNTs such as low curvature, low solubility and bundling tendency make these carbon nanomaterials relatively inert to chemical treatment. So far, a number of routes to covalent functionalization of CNTs have been developed. According to the location of the functional groups, the strategies to covalently functionalize CNTs can be classified into two main types: (i) defect functionalization, 
and (ii) sidewall functionalization. The covalent functionalization of nanotubes is more robust and better controllable compared to functionalization based on noncovalent methods.

\subsubsection{Defect Functionalization}

CNTs synthesized by any available method are not free of defects. The intrinsic defects include five- or seven-membered rings called Stone-Wales defects, $\mathrm{sp}^{3}$ hybridized defects and vacancies in the $\mathrm{sp}^{2}$-hybridized six-membered ring carbon structure of the sidewall $[94,95]$. A limited number of defects can be tolerated by CNTs without losing their macroscopic electronic and mechanical properties [9698]. In addition, the tips of the tubes, forming a hemispherical fullerene, have stronger reactivity than the sidewalls because of their higher curvature [99, 100]. When treated with strong oxidizing agents such as nitric acid, $\mathrm{KMnO}_{4} / \mathrm{H}_{2} \mathrm{SO}_{4}$, $\mathrm{O}_{2}, \mathrm{~K}_{2} \mathrm{Cr}_{2} \mathrm{O}_{7} / \mathrm{H}_{2} \mathrm{SO}_{4}$ or $\mathrm{OsO}_{4}$, CNTs could be opened and cut into short tubes. In the meantime defects were introduced around the CNT surface [28, 95, 100, 101]. Moreover, oxygenated functional groups such as carboxylic acid, ketone, alcohol and ester groups were generated by the oxidization process to the ends and the defect sites of the nanotubes [102]. These functional groups were very important to further functionalize CNTs. Sonication could also produce defects on the sidewall of CNTs that were eager for further chemical reactions [103-106].

Using the nanotube-bound carboxylic acid groups introduced by oxidization treatment, further functionalization was performed via amidation, esterification or the zwitterionic $\mathrm{COO}^{-} \mathrm{NH}_{3}{ }^{+}$formation. Before covalent modification, the carboxylic acids are often activated by thionyl chloride, carbodiimide [e.g. $\mathrm{N}$-(3dimethylaminopropyl)- $N^{\prime}$-ethylcarbodiimide (EDC) or $N, N^{\prime}$-dicyclohexylcarbodiimide (DCC)] or $\mathrm{N}$-hydroxysuccinimide (NHS), to get highly reactive intermediate groups (Scheme 3.1). Esterification was achieved by the nucleophilic substitution reaction of nanotube carboxylate salt with alkyl halides [107]. The functionalization of CNTs via nanotube carboxylic acids, located at the ends or pre-existing defects of CNTs, preserved the essential features of the CNT electronic structure as well as the bulk properties of the material [102, 108].

The first shortened soluble SWNTs were obtained through carboxylic amidation using octadecylamine [102]. Since then, various lipophilic and hydrophilic dendrons have been attached to CNTs via amide or ester linkages, which significantly improved the solubility of CNTs in organic or aqueous solvents [109]. These groups could be subsequently removed under basic or acidic hydrolysis conditions [110]. In addition, following this functionalization process, CNT bundles were largely exfoliated into individual nanotubes [96]. This enabled further manipulation and investigation of the spectroscopic properties of individual SWNTs.

Via amidation or esterification, polymers like poly-propionyl-ethylenimine-coethylenimine (PPEI-EI), poly-n-vinylcarbazole (PVK-PS) and PEG were grafted to the surface of CNTs [111]. Another approach called "graft from" was developed to attach polymer to CNTs. The polymerization initiators were first covalently bound to CNTs and then the nanotube-based macroinitiators were exposed to monomers to accomplish the polymerization. In particular, polymer poly- $n$-butyl methacry- 


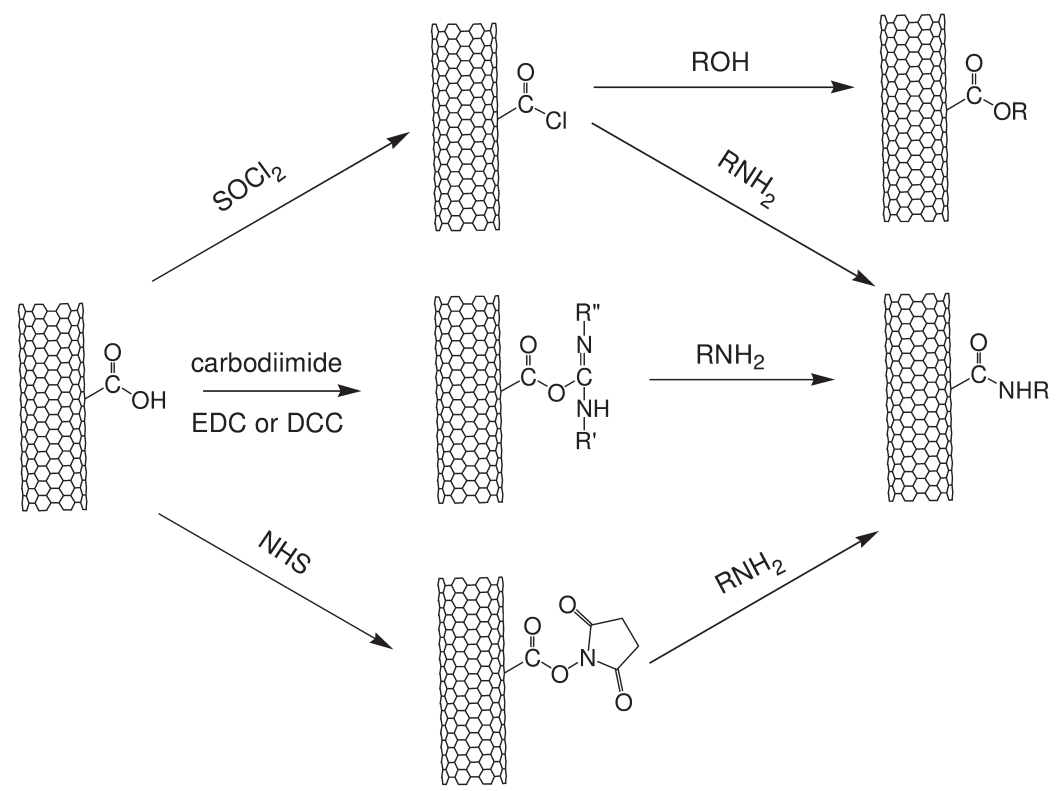

Scheme 3.1. Typical CNT carboxylic acid derivatization routes.

late (PnBMA), poly-methyl methacrylate (PMMA) and copolymer PMMA-b-polyhydroxyethyl methacrylate (PHEMA) have been coupled to CNTs via atom transfer radical polymerization (ATRP) [112, 113].

Defect functionalization was used to link biological molecules to CNTs via stable covalent bonds. For example, $f$-SWNTs and $f$-MWNTs with bovine serum albumin (BSA) were synthesized via diimide-activated amidation at ambient condition. It was found that the protein bound to nanotubes remained active [114]. SA (a protein with potential clinical applications in anticancer therapy) was complexed to SWNTs prefunctionalized with biotin through EDC activated amidation [115]. Similarly, using the biotin-SA interaction, a biotinylated DNAzyme was covalently attached to MWNTs prefunctionalized with SA via amide linkage. The nanotubebound DNAzymes displayed highly active and classical enzymatic behavior [116].

DNA was also bound to CNTs via amide linkage [117, 118]. DNA-CNT conjugates were hybridized with their complementary sequences and this hybridization was apparently reversible upon a denaturation process. The derived single-strand DNA-CNTs could be reused in a second-round of hybridization. In another case, DNA recognition was achieved by peptide nucleic acid (PNA) $f$-SWNTs, in which PNA was attached to SWNTs via NHS activated SWNTs [119].

\subsubsection{Sidewall Functionalization}

The sidewalls of CNTs have an aromatic, six-membered ring structure. So far, various kinds of reactions of the sidewall have been developed such as fluorina- 
tion, radical addition, nucleophilic addition, electrophilic addition and cycloaddition [120]. There are two principal sources of molecular strain that affect the reactivity in nonplanar conjugated molecules: (i) pyramidalization of the conjugated carbon atom and (ii) $\pi$-orbital misalignment between adjacent pairs of conjugate carbon atoms. Unlike fullerene, in which the strain is primarily from pyramidalization, $\pi$-orbital misalignment is the main source of the strain for the sidewalls of CNTs. Since $\pi$-orbital misalignment, as well as pyramidalization, scales inversely with nanotube diameter, nanotubes with a smaller diameter display a higher chemical reactivity [99]. Differing from defect reactions, sidewall reactions disrupted the conjugated structure of CNTs, as monitored by Raman or absorption spectroscopy. In the Raman spectrum of pristine SWNTs, three main characteristic modes were disclosed: (i) the radial breathing $\left(\omega_{\mathrm{r}}\right)$ below $350 \mathrm{~cm}^{-1}$, (ii) the tangential $\left(\omega_{\mathrm{t}}\right)$ mode at $1550-1600 \mathrm{~cm}^{-1}$ and (iii) the disorder $\left(\mathrm{sp}^{3}\right)$ mode at $1250-1450 \mathrm{~cm}^{-1}$. The radial breathing mode was demonstrated to be in strong relationship with the diameter of the nanotube [121]. The relative intensity of the disorder mode was related to the amount of $\mathrm{sp}^{3}$-hybridized carbon atoms in the SWNTs and thus provided direct information of the extent of sidewall functionalization, in which the carbons linked to functional groups were converted from $\mathrm{sp}^{2}$-hybridized into $\mathrm{sp}^{3}$ hybridized carbon [122]. The absorption spectrum reflected the sidewall covalent modification of SWNTs. The disruption of the conjugated structure caused by the reaction led to the loss of optical transitions between van Hove singularities in the electronic density of state (DOS) of CNTs, which was detected as the loss of the structure of the absorption spectrum [123].

3.2.2.2.1 Fluorination The fluorination of SWNTs was accomplished through the reaction of SWNTs with elemental fluorine at temperatures ranging from 150 to $600{ }^{\circ} \mathrm{C}$ [124]. By controlling the reaction conditions such as temperature and time, the stoichiometry could be regulated. In some cases, a stoichiometry of $\mathrm{C}_{2} \mathrm{~F}$ was obtained (see Scheme 3.3). The investigation of absorption and Raman spectra indicated the electronic perturbation of fluorinated SWNTs. The fluorination allowed exfoliation of SWNTs bundles into individual nanotubes and remarkably improved the solubility of SWNTs in tetrahydrofuran (THF), dimethylformamide (DMF) and various alcohols [125]. The C-F bonds were very sensitive to the treatment with hydrazine, which allowed almost complete recovery of the conductivity and the spectroscopic properties of the pristine SWNTs [124]. It was demonstrated that the Fermi energy level of fluorinated SWNTs, as well as the conduction band energy, were significantly shifted to lower values compared to those of the pristine SWNTs. This revealed that fluorinated CNTs were better electron acceptors than pristine nanotubes, and thus displayed higher chemical reactivity to strong nucleophilic reagents like Grignard, alkyllithium reagents and metal alkoxides (Scheme 3.2). The same result was reached by exploiting the eclipsing strain effect that weakened the $\mathrm{C}-\mathrm{F}$ bonds in fluorinated CNTs relative to the $\mathrm{C}-\mathrm{F}$ bond in alkyl fluorides [126, 127]. It was proposed that the substitution of fluorine by nucleophilic reagents proceeds via a concerted allylic displacement [126]. 


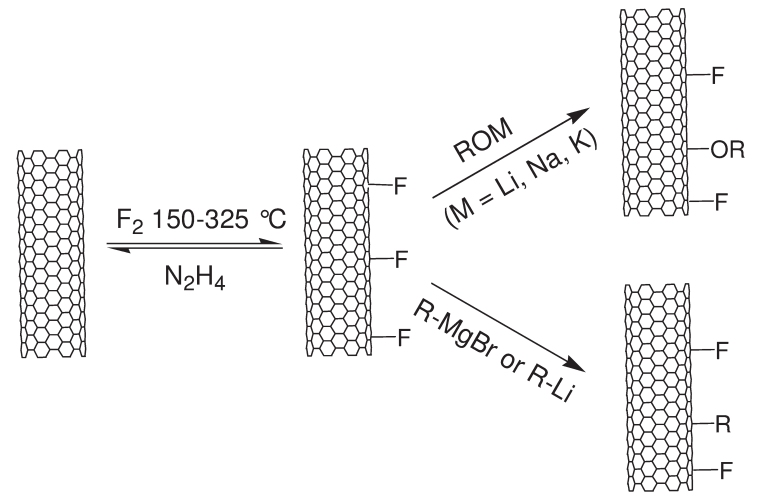

Scheme 3.2. Fluorination of CNTs and further modification routes.

3.2.2.2.2 Radical Addition The addition of radicals to SWNTs was carried out using different radical sources including perfluorinated alkyl radicals photoinduced from perfluoroalkyl iodide [128], aryl radicals generated by one-electron reduction of the diazonium salt [129-131], radicals produced by decomposition of benzoyl peroxide in the presence of alkyl iodides [132], or directly produced by decomposition of benzoyl or lauroyl peroxide [133].

The functionalization of SWNTs with diazonium reagents was achieved by three different methods: electrochemical reaction [119], thermochemical reaction in solvent [130] and using a solvent-free system [131] (Scheme 3.3). The resultant SWNTs displayed very high degree of functionalization. It was also demonstrated that metallic SWNTs showed higher reactivity in these types of reactions than semiconductive SWNTs, which would allow CNT separation [134].

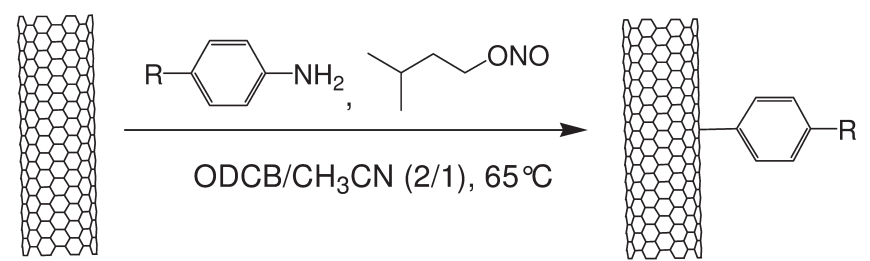

$\mathrm{R}=$ halogen, $\mathrm{CO}_{2} \mathrm{CH}_{3}, \mathrm{NO}_{2}$, tert-butyl, $\mathrm{COOH}$,

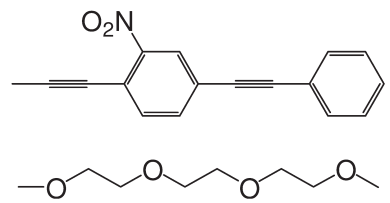

Scheme 3.3. Example of a strategy to functionalize SWNTS with diazonium compounds. ODCB $=$ orthodichlorobenze. 
3.2.2.2.3 Nucleophilic and Electrophilic Addition Due to the high electron affinity imparted by the curvature of sidewall [135], CNTs were reacted with strong nucleophilic reagents such as nucleophilic carbene [128], sec-butyllithium [136], polymeric carbanions [137] and Birch reduction reagents (lithium/1,2-diaminoethane [108] or lithium/ammonia [138]) to form various $f$-CNTs (Scheme 3.4).

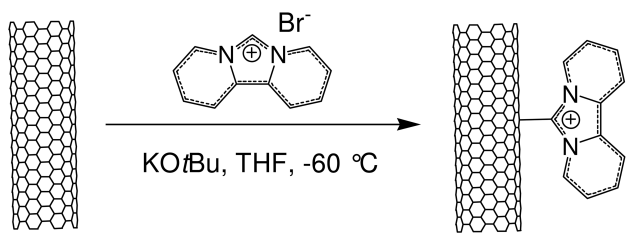

Scheme 3.4. Reaction of SWNTs with nucleophilic carbene.

In addition, the electrophilic addition was also achieved by the reaction of chloroform with the sidewall of CNTs in the presence of Lewis acid [139].

3.2.2.2.4 Cycloaddition Various cycloaddition reactions to CNTs have been developed, including [2+1] cycloaddition of dichlorocarbene [108], nitrenes [128] and bromomalonates under Bingel reaction conditions [140], [4+2] Diels-Alder cycloaddition of o-quinodimethane performed under microwave irradiation [141], $[3+2]$ cycloaddition of azido groups under ultraviolet (UV) irradiation [142], and azomethine ylides [143]. The 1,3-dipolar addition of azomethine ylides is particularly versatile for the functionalization of CNTs [143-145]. This strategy is suitable for different types of CNTs (e.g. pristine and purified SWNTs or MWNTs), and involves the in situ generation of an azomethine ylide through the decarboxylation of an immonium salt derived from condensation of a $\alpha$-amino acid and an aldehyde in the presence of CNTs. This afforded functionalization of CNTs with the 2substituted pyrrolidine (Scheme 3.5).

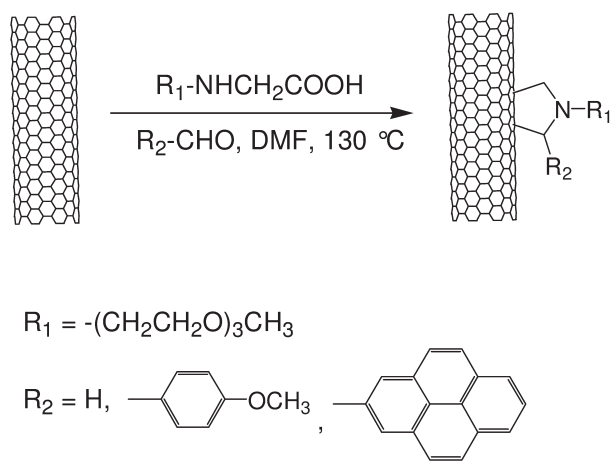

Scheme 3.5. 1,3-Dipolar cycloaddition reaction of azomethine ylides to SWNTs. 
The CNTs modified by this method possessed a very high degree of functionalization and improved solubility in organic or aqueous solvents [143, 146]. The disruption of the aromatic structure of the sidewalls of the $f$-SWNTs was proven by absorption spectroscopy [143]. This functionalization technique was also used to purify CNTs [147]. Protected amino groups were introduced onto the surface of CNTs via 1,3-dipolar cycloaddition of azomethine ylides [143, 148]. For instance, $f$-CNTs with N-protected glycine were achieved using N-protected amino acid, which were subsequently used to link biomolecules (e.g. bioactive peptides) by fragment condensation or selective chemical ligation (see Section 3.5) [148, 149].

3.2.2.2.5 Multifunctionalization of CNTs The first multifunctionalization of CNTs was achieved using a vertically aligned MWNT membrane. One method involved the protection of the sidewalls of CNTs with polystyrene in the process of plasma oxidation that produced carboxylate derivatization. Under this process, aligned MWNT membranes functionalized with carboxylic acid groups at the terminal parts were obtained. Thereafter, bifunctional CNTs with thiol groups on one end and carboxylic groups on the other end were accomplished by floating on top of a 2-aminoethanethiol reaction solution one side of the oxidized CNTs membrane [150]. Another approach was carried out by floating directly one side of an aligned MWNTs membrane on $3^{\prime}$-azido-3'-deoxythymidine (AZT) solution in ethanol under UV irradiation and, after removal of absorbed AZT molecules by washing with ethanol, laying the unmodified side on the surface of a perfluorooctyl iodide solution in 1,1,2,2-tetrachloroethane (TEC) under UV irradiation. Thus, bifunctionalized MWNTs with AZT molecules and perfluorooctyl chains were obtained [151].

These two methods of CNT bifunctionalization are quite complicated and limited to aligned MWNTs. Using a different method, Wu and coworkers introduced an orthogonal protecting methodology into the chemical modification of nanotube to achieve the multifunctionalization of CNTs [152]. In particular, diaminotriethylene glycol chains mono-protected by phthalimide were linked to the carboxylic acids of oxidized MWNTs. In a second step, a suitable N-substituted glycine with a diaminotriethylene glycol chain mono-protected by tert-butyloxycarbonyl (Boc) was introduced via 1,3-dipolar cycloaddition (Scheme 3.6). Since the phthalimide is stable to harsh acidic conditions and orthogonal to the Boc, the selection and control of attachment of different molecules was possible [152]. In this case, CNTs containing both fluorescein and amphotericin B (AmB) were prepared, and bioactivity of the conjugates was studied (see Section 3.6) [152]. This method of bifunctionalization is general and suitable for different types of CNTs.

In summary, the functionalization and consequent applications of CNTs have been dramatically increased in the last few years. The chemical modification of CNTs cannot only endow these intriguing nanomaterials with various functions, but also extend their potential applications to different fields of research. 


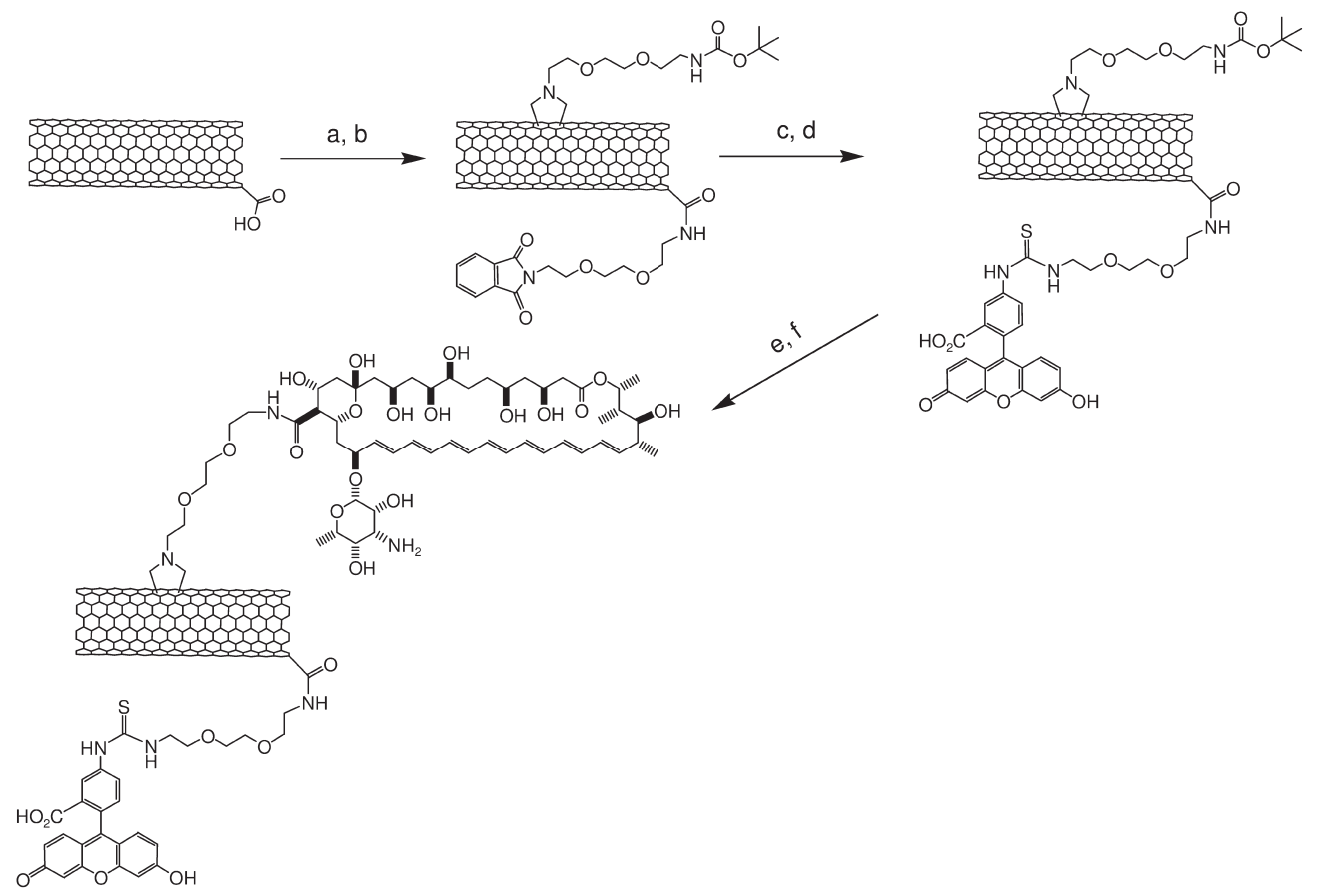

Scheme 3.6. One of the routes to the (f) Fmoc-AmB, HOBt/EDC $\times \mathrm{HCl} / D I P E A$, bifunctionalization of CNTs. (a) Neat $(\mathrm{COCl})_{2}$; DMF; $25 \%$ piperidine in DMF. Boc $=$ tertPht- $\mathrm{N}\left(\mathrm{CH}_{2} \mathrm{CH}_{2} \mathrm{O}\right)_{2}-\mathrm{CH}_{2} \mathrm{CH}_{2}-\mathrm{NH}_{2}$, dry THF, butyloxycarbonyl; DIPEA = diisopropylethylreflux; (b) Boc-NH- $\left(\mathrm{CH}_{2} \mathrm{CH}_{2} \mathrm{O}\right)_{2}-\mathrm{CH}_{2} \mathrm{CH}_{2}$ amine; $\mathrm{FMOC}=$ fluorenyl-methyloxycarbonyl; $\mathrm{NHCH}{ }_{2} \mathrm{COOH} /\left(\mathrm{CH}_{2} \mathrm{O}\right)_{n}, \mathrm{DMF}, 125^{\circ} \mathrm{C}$; FITC = fluorescein isothiocyanate; HOBt $=$ (c) hydrated $\mathrm{NH}_{2}-\mathrm{NH}_{2}$, EtOH, reflux; 1-hydroxybenzo-triazole; Pht $=$ phthalimide.

\section{3}

\section{CNTs in Diagnosis}

A biosensor can be defined as the spatial combination of a biological recognition element and a transduction process into an electrical signal [153]. One of the most used recognition element, due to its high chemical specificity and inherent biocalalytic signal amplification, is an enzyme. Other elements like antibodies, nucleic acid and aptamers are also commonly incorporated into biosensing devices. An important issue in the elaboration of new sensors for application in living systems is to avoid invasive tools, which may cause trauma [154]. In this context, the development of electrical instrumentations has paved the way for miniaturization of noninvasive biosensors. This type of device requires an electronic conductor and a binding agent for recognition [155]. Due to their particular structure [156, 157], CNTs are very promising for the development of new alternative biosensors. The 
aromatic carbon structure of CNTs is characterized by a $(m, n)$ lattice vector in the graphene plane. The two indices determine the diameter and chirality of the nanotubes. When $n=m$, the rolling process leads to an armchair tube with a metallic behavior. When $n-m=3 i$, where $i$ is an integer, the nanotubes adopt a zigzag conformation and behave as semimetallic species. Finally, when $n-m \neq 3 i$, the resulting nanotubes are chiral and semiconductor. Semiconducting nanotubes represent about two-thirds of the SWNTs, whereas metallic tubes represent about one-third. These properties could be exploited for the fabrication of new electronic devices containing CNTs such as field-effect transistors (FETs), nanoelectrode arrays (NEAs), nanoelectrode ensembles (NEEs) or screen-printed electrodes (SPEs) [158-167]. FET devices need semiconductor-type nanotubes. Currently, no method of production permits us to obtain a specific type of nanotubes. Some studies were carried out on the separation or selection of semiconducting and metallic nanotubes [168-171].

This section will describe the utilization of CNTs in FETs and in modified electrodes (NEAs, NEEs and SPEs). Initially, the methods of preparation of the devices will be addressed and then their applications in the field of biosensing will be illustrated.

\subsection{1}

\section{CNTs in FETs}

The FET is a transistor that relies on an electric field to control the shape and hence the conductivity of a channel in a semiconductor material. Basically, two metal electrodes called the source and drain are connected by the channel, and a third component (the gate) is separated from the channel by a thin insulator film. The latter, usually made up of $\mathrm{Si}$, is replaced by semiconducting SWNTs in CNTbased FETs $[158,164]$. There are two types of FETs: (i) p-type and (ii) n-type. If a negative charge is placed on the gate and the applied voltage exceeds a certain threshold, then a hole current flows in a p-type system. For a n-type FET, the current flows when a positive charge is present on the gate and the voltage exceeds the threshold [166].

\subsubsection{Fabrication}

As CNTs are still emerging in the field of electronic devices, the protocols for their preparation are not yet optimized. A CNT-based FET was built by positioning a semiconducting SWNT between two metal electrodes. Typically, as-prepared SWNTs were purified by acid treatment to remove metal particles, which can interfere with the electronic properties of the nanotubes. Other, more elaborate techniques to obtain highly pure nanotubes (up to $95 \%$ wt) consisted of heating as-grown HiPCO SWNTs in wet air in the presence of $\mathrm{H}_{2} \mathrm{O}_{2}$, followed by acid treatment, magnetic fractionation and vacuum annealing [168]. Subsequently, the nanotubes were dispersed in an organic (dichloromethane) or aqueous solution with a surfactant like sodium dodecyl benzene sulfonate $[164,168]$. The suspension was then deposited on a substrate constituted of a degenerately doped, oxidized silicon 


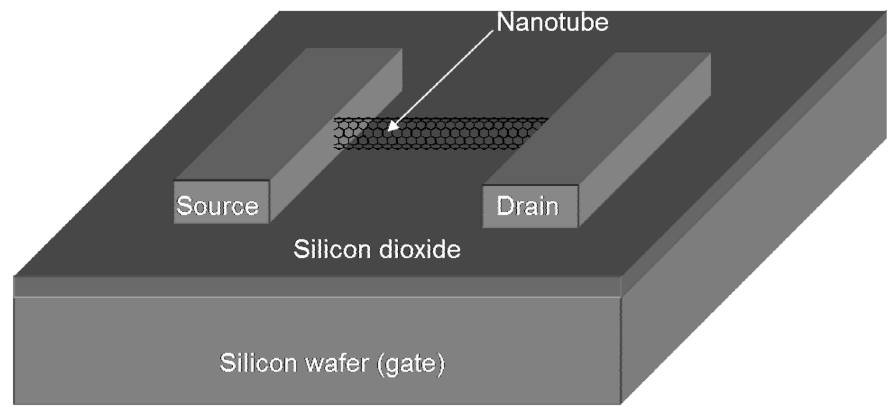

Figure 3.4. A typical CNT-based FET. The nanotube serves as a semiconductor between the source and the drain electrode. The silicon wafer in this case is used as a back gate.

wafer. An alternative technique consisted on the growth of SWNTs directly on the $\mathrm{SiO}_{2} / \mathrm{Si}$ water by chemical vapor deposition (CVD) [36, 172-176]. Once the SWNTs were deposited, the electrodes were fabricated with electron beam lithography, followed by thermal evaporation and lift-off. The degenerately doped silicon was used as back gate electrode. At this stage, the channel was composed of a simple SWNTs or a small bundle with properties ranging from semiconducting to metallic behavior (Fig. 3.4). To select only semiconducting SWNTs, a source-drain current $I$ was applied at different bias voltage $V_{\mathrm{b}}$ and gate voltage $V_{\mathrm{g}}$. Typically, the $I-V_{\mathrm{g}}$ curve at low voltage bias shows a low source-drain resistance and almost no gate response for metallic nanotubes [168]. These types of CNT FET devices behave as p-type FETs with holes as dominant carriers. However, by using a network of SWNTs between the drain and the source, the network exhibited a semiconductor-like conductance as semiconducting SWNTs represented about two-thirds of the tubes [176]. Efforts have been made to improve them, thus now they can be built with a $g_{m}$ transconductance of $2300 \mu \mathrm{S} \mu \mathrm{m}^{-1}$ whereas a $g_{m}$ of $650 \mu \mathrm{S} \mu \mathrm{m}^{-1}$ was obtained for the same device based on silicon. Moreover, the parasitic contact resistance changed from more than 1 to $100 \mathrm{k} \Omega$ or above [166]. In addition, a method to select semiconducting SWNTs by current-induced electrical breakdown was developed. This technique permitted a direct current-induced oxidation only at the metallic SWNT component of the CNT bundle by previously depleting semiconducting SWNTs with the gate [177].

Even at this early stage of development, CNT-based FETs have been shown to outperform the corresponding Si-based devices. Their applications in sensing can therefore offer considerable improvements.

\subsubsection{FET Biosensors}

CNTs have already been successfully employed for sensing chemical species. In fact, molecules were adsorbed onto the surface of nanotubes. The fringing electric field radiating from the CNT surface polarized the molecules, increasing the capac- 
ity of the system. Different chemical vapors including $\mathrm{NO}_{2}$ and $\mathrm{NH}_{3}$, and a wide range of chemicals were detected [35, 160, 178-181]. A more sophisticated system based on a single-strand DNA-SWNT-FET was designed. The source-drain current was a function of the chemical environment and was modulated by the DNA sequence. In fact, depending on the DNA sequence covering the nanotube, the response for a same gas can be different in both sign and magnitude. Thus, the selection of a DNA sequence can enhance the detection of a specific gas and can serve for the design of "molecular noses" able to detect one molecule in a strong and variable background. The sensor had a rapid response and was also selfregenerating as it could undergo 50 gas exposure cycles [174].

In the field of biosensing, CNT-based FETs appeared as promising devices. Glucose biosensors are particularly requested. In industrialized countries, about $4 \%$ of the population is prone to diabetes. Thus, the selective determination of blood glucose is of crucial importance. In vivo monitoring requires a biosensor with longterm stability, selectivity and sensitivity in the millimolar range. Usually, the sensor for this type of application requires to couple the enzyme glucose oxidase to the electrochemical transducer. In the case of a CNT-based FET, it was possible to link noncovalently the enzyme via a pyrene moiety [35]. 1-Pyrenebutanoic acid succinimidyl ester was adsorbed onto the nanotube surface by strong van der Waals interactions. The enzyme was subsequently reacted with the active ester, thus forming a covalent linkage. The quantity of enzyme deposited on the CNT support was about one enzyme molecule every $12 \mathrm{~nm}$ of nanotube. Such FET allowed the detection of $\mathrm{pH}$ changes down to 0.1 , by measuring the difference of conductance. Similarly, the CNT sensor could detect the activity of the enzyme in the presence of glucose down to $0.03 \mathrm{mM}$ [36]. This technique was also applied to the recognition of proteins by using biomimetic sensors. One example concerned the sensing of thrombin via an aptamer [172]. An aptamer is an artificial oligonucleotide that can bind any kind of entity (e.g. metal ions, small organic molecules, proteins and/or cells). The affinity, selectivity and specificity are equal or superior to those of antibodies. Practically, the immobilization of thrombin aptamer was achieved by first covering the nanotube in the FET with carbodiimidazole (CDI)-Tween. Tween possess a hydrophobic part, which bound noncovalently to the tube, while the CDI moiety allowed covalent fixation of the aptamer. The measurement of the conductance permitted the detection of thrombin in the millimolar range. The selectivity appeared very high in comparison to elastase. Elastase is another serine protease with an isoelectric point ( $\mathrm{pI}$ ) and molecular weight similar to thrombin. However, no changes in the conductance were observed in its presence. Although the specificity and selectivity could be very high, the mechanism of electrical conductance changes is still not well understood. Dai and coworkers fabricated three different types of devices to better comprehend this phenomenon [175]. The first device consisted of a system with unmodified CNTs and $\mathrm{Pd} / \mathrm{Au}$ electrodes. The second had a methoxy(PEG)thiol covering the metal electrodes to block nonspecific protein adsorption. The third tool was modified at the electrode and the nanotube was coated with Tween 20. The conductance measurements were performed in the presence of different proteins including BSA, human serum albumin (HAS), human cho- 
rionic gonadotropin (hCG), $\alpha$-hCG, human immunoglobulin $\mathrm{G}$ (hIgG) and avidin. Unspecific binding led to a decrease of conductance on the first device, a change was detected only for avidin on the second and any change at all was observed on the third. All the proteins used have a $\mathrm{pI}$ around 5-7, meaning that at physiological $\mathrm{pH}$ they are neutral or slightly charged. Avidin was an exception, because its $\mathrm{p} I$ is between 10 and 11, highlighting the importance of the positive charges. The advanced hypothesis for the mechanism of conductance modifications was that the variation originated from the metal-tube contact. These p-type devices always exhibit a decrease upon protein adsorption. This behavior was similar to a reduction of the work function of a metal. In the case of Pd electrodes, the Schottky barrier to the valence band of the nanotubes is mainly zero. The biomolecular adsorption increased this barrier. However, in the case of avidin, the charges on the CNT surface exerted gating effects or charge transfer causing variations in the electrical conductance.

The CNT-based FETs have also been used in an antibody-based sensor [175]. For example, the hCG- $\alpha$-hCG antigen-antibody system is currently used for clinical pregnancy tests. The hCG protein could be adsorbed and detected onto the nanotube FET. A signal was observed upon the addition of $\alpha$-hCG. This biosensor was capable of detecting species in the nanomolar range. The same comparison was done by using antibody-specific binding onto the tubes [176]. CNTs were first covered by Tween. Then U1A RNA splicing factor was linked to the Tween after activation with 1,1-carbonydiimidazole. U1A is a prominent autoantigen target in systemic lupus erythematosus. The measurements revealed the binding of the monoclonal antibody $10 \mathrm{E} 3$, which recognizes U1A specifically, at a concentration of $1 \mathrm{nM}$ or below. CNT-based FETs were also functionalized with hemagglutinins (HAs) [173]. Instead of binding the proteins directly to the nanotubes, they were attached on the reverse side of the silicon wafer (Fig. 3.5). The silicon wafer was oxidized with $\mathrm{H}_{2} \mathrm{SO}_{4}$ for the fixation of a dithiothreitol linker. Next, the introduction of a maleimide linker permitted the coupling of HA. The $I-V_{\mathrm{g}}$ curves measured in the presence of various concentrations of an antibody anti-HA showed a detection limit of approximately of $5 \times 10^{-8} \mathrm{mg} \mathrm{mL}^{-1}$. Comparing these results to the same experiment with an enzyme-linked immunoadsorbent assay (ELISA), the FET increased the limit of detection by three orders of magnitude.

Therefore, the preliminary results on CNT-based FETs displayed an increase in the sensitivity as well as better detection limits. The great advantage of these new FETs stems from their small size, because miniaturization is an important parameter for the development of biosensors able to work at the single-cell level.

\section{3 .2}

\section{CNT-based Electrodes}

The construction of nanoelectrodes is a great challenge to create miniaturized sensors. Reducing the size will enable us to detect species in microenvironments with high sensitivity. Thus, the utilization of nanomaterials is highly recommended. CNTs can be considered ideal candidates. 


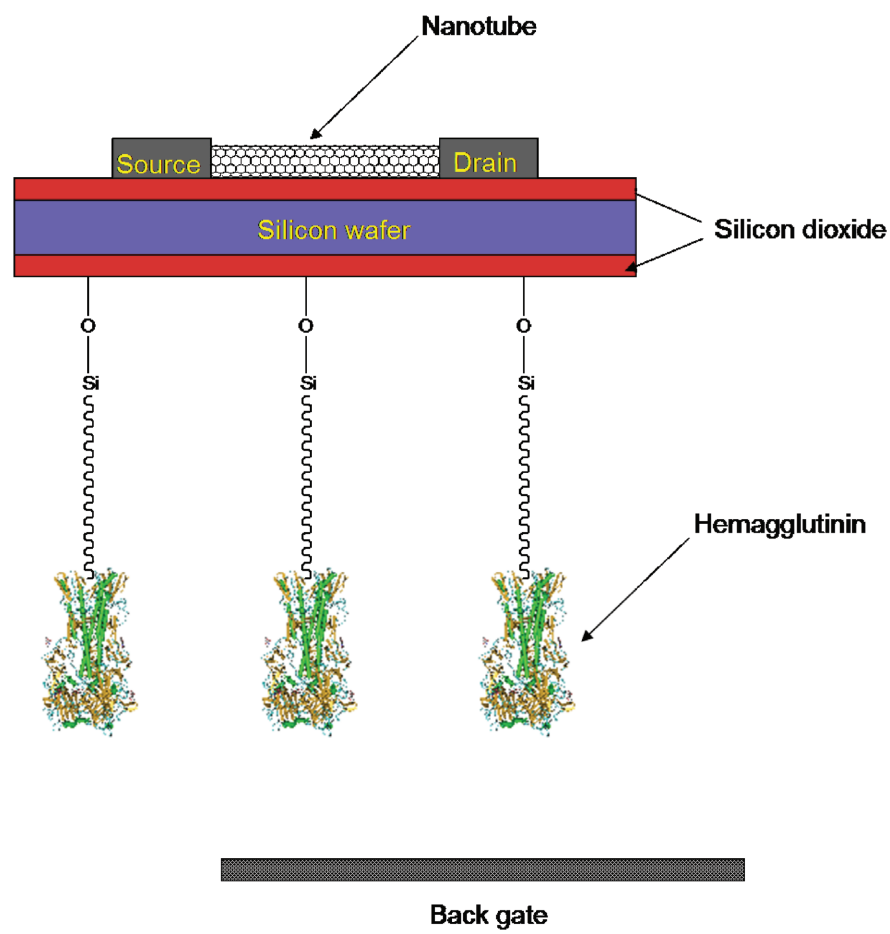

Figure 3.5. CNT-based FET functionalized on its reverse side. The silicon wafer is oxidized on the reverse side to allow the linkage with HA. The current is measured in air by applying a voltage to the back gate facing the reverse side.

\subsubsection{Fabrication}

Several techniques were used to prepare CNT-modified electrodes. One approach consisted on the covalent linkage of oxidized nanotubes to a metal electrode (usually $\mathrm{Au})[182,183]$. The purification of nanotubes by acid treatment shortened the nanotubes leading to free carboxylic functions mainly at the tips. An Au electrode was functionalized with a mixture of cysteamine and 2-thioethanol. The CNT coupling reaction was performed in the presence of an activator of the carboxylic groups (EDC or DCC). 2-Thioethanol was used to avoid nonspecific adsorption of the nanotubes onto the electrode surface as well as to prevent accumulation of the nanotubes on it. The obtained CNT array was further functionalized with any biological species to finalize the elaboration of the electrode (Fig. 3.6).

Another technique was based on the deposition of a metal film (usually Pt or Cr) on a Si wafer to serve as an electrical contact for the nanotubes. Then, a Ni catalyst was deposited on the top of the metal film and the nanotubes were grown by CVD $[165,184]$. The forest-like vertically aligned nanotube array was encapsulated by a dielectric film $\left(\mathrm{SiO}_{2}\right.$ or Epon 828 epoxy-based polymer), dramatically increasing the mechanical strength of the nanotube array, so that a chemical mechanical polish- 


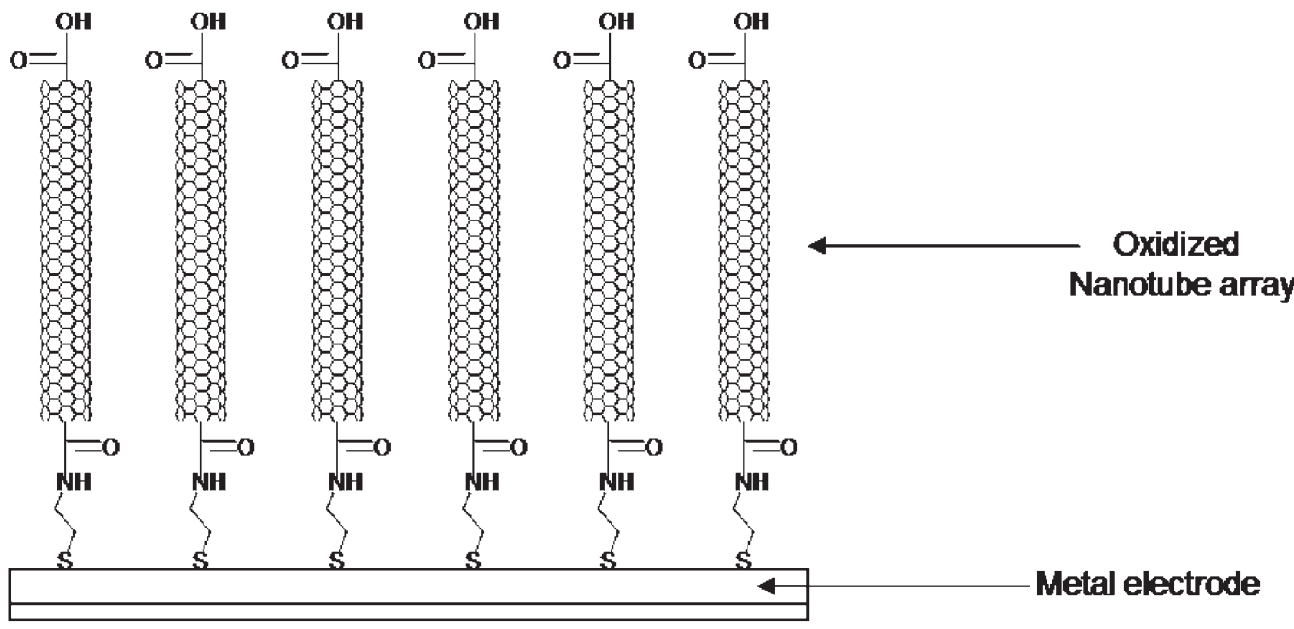

Figure 3.6. Nanoelectrode made of CNT arrays. The CNTs are disposed in a forest-like structure. The carboxylic groups on their tips are not hindered and can be easily functionalized.

ing process could be applied. This treatment oxidized the exposed end of the tubes and allowed control of the quantity of available nanotubes. Again, the nanotubes were ready to be further functionalized to create the nanoelectrode sensor (Fig. 3.7). A third approach to fabricate the electrodes was based on the utilization of the SPE technique $[185,186]$. The working and the reference electrodes were made of carbon paste. Three masks were used to form: (i) sliver conducting lead wires, (ii) the carbon film for electrochemical reactions and (iii) the insulating film. In the reaction compartment, the carbon paste film was modified by CNTs. Oxidized CNTs were dropped with a solution of $N$-cyclohexyl- $N^{\prime}-(\beta-[N$-methylmorpholino]ethyl)carbodiimide $p$-toluenesulfonate (CMC) to afford a hydrophilic polymer layer after drying in hot air. Alternatively, oxidized CNTs were dispersed in DMF and then incubated with EDC and NHS to be activated for the coupling of the bioactive molecule.

\subsubsection{Nanoelectrode Biosensors}

As mentioned for CNT-based FETs, the environment around the tubes changes their conductance. The measurement of the current will give direct information of the medium. A modified glassy carbon electrode was constructed to detect hydrogen peroxide. Nanotubes were first suspended in Nafion, which possess ionexchange, discriminative and biocompatibility properties [187]. The suspension was then simply deposited onto the electrode. In this case, cyclic voltammograms displayed oxidation and reduction currents, whereas in comparison no redox activity was observed for a simple glassy carbon electrode. Nevertheless, the preparation of biosensor required the immobilization of a biological entity. This can be done by linking the molecule to the free carboxylic groups of the nanotube tips. To control 


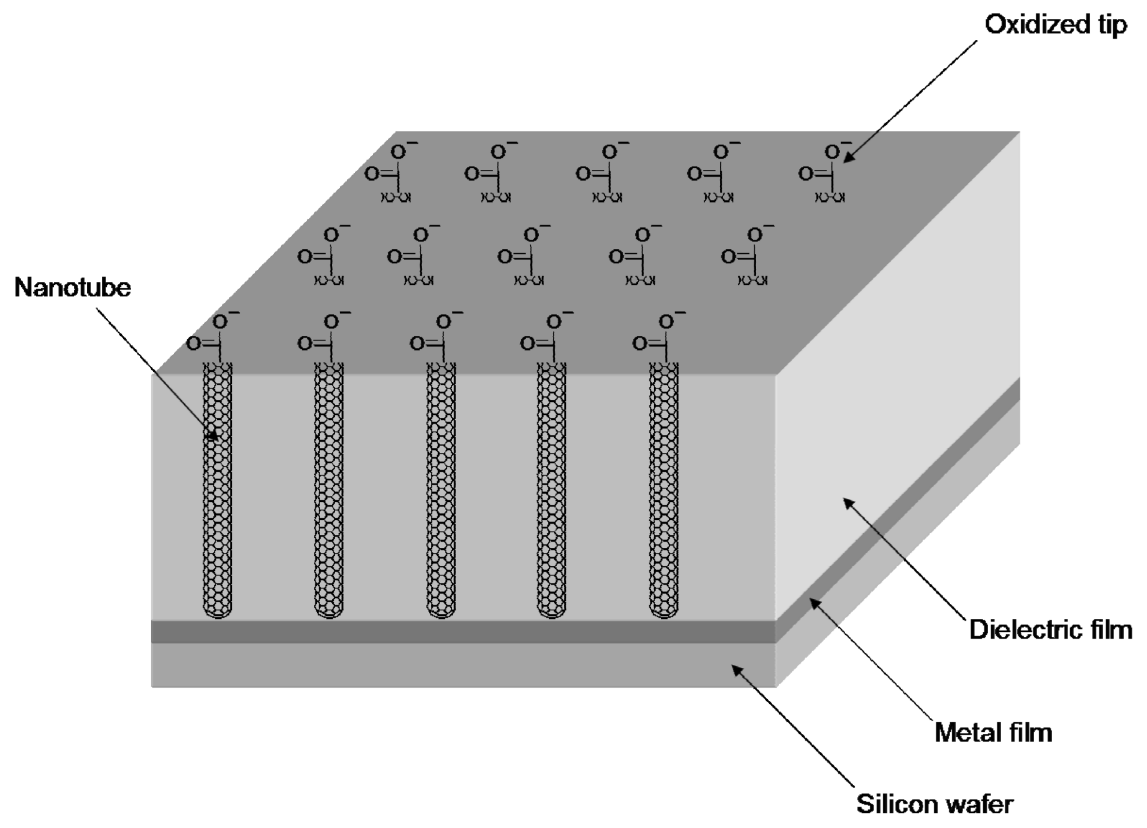

Figure 3.7. A nanoelectrode ensemble. The nanotubes are grown directly on the metal film via a catalyst (usually nickel). After deposition of the dielectric film, the number of nanotubes tips present on the surface can be selected by polishing. A weak polishing lets only the longest tubes appear with a low-density nanoelectrode array.

the specificity of the binding location, it is crucial to avoid any nonspecific absorption. Some reports described the interaction of proteins with nanotubes [188, 189]. For example, SA strongly bound to nanotubes [188]. Hence, the protection of the sidewall of the tube can be performed by wrapping a polymer like Triton X coadsorbed with PEG [189]. This provided an efficient barrier against protein adsorptions. As a consequence, specific immobilization of glucose oxidase at one tip of the nanotube was achieved via reconstitution of the apo-flavoenzyme glucose oxidase with the flavin adenine dinucleotide (FAD) cofactor [183]. The free amine of the FAD was coupled to the carboxylic end by activation with EDC. After addition of the apo-glucose oxidase, the glucose enzyme was reconstituted at the top of the tubes. The turnover rate of electrons transferred to the electrodes was 6-fold higher than for the active site of the glucose oxidase to its natural $\mathrm{O}_{2}$ electron acceptor. By controlling the length of the tubes in the array, the measurements of the current revealed that the electrons could be transported along distances greater than $150 \mathrm{~nm}$. Evidently, a shorter length enhances the electrocatalytic current. Another method used the nanoelectrode ensembles where the carboxylic end-groups of the nanotubes were directly coupled to the glucose oxidase [184]. This glucose sensor showed high selectivity towards the substrate. Indeed, a negligible signal was observed for ascorbic, uric acid and acetaminophen. The nanoelectrode gave a linear 
response up to $30 \mathrm{mM}$ glucose. For practical use, the required linear response is $15 \mathrm{mM}$. The detection limit of the system was $0.08 \mathrm{mM}$. These types of sensors could be extended to other enzymes, like microperoxidase MP-11 [182].

The utilization of nanotubes also permitted the development of nucleic acid sensors $[165,185]$. The free carboxylic functions on the carbon nanoelectrode were used to covalently link different $5^{\prime}$-amine modified oligonucleotides. In this manner, the oxidation of guanine bases could be monitored to detect DNA hybridization. Several ways were explored to construct this type of sensor. Initially, the sensors exploited the utilization of oligonucleotide probes in which guanines were replaced by nonelectroactive inosines to eliminate the redox background [165]. The complementary DNA sequence was instead modified with a 10-base polyguanine at the $3^{\prime}$ position. However, the background noise remained high because of the low oxidative current resulting from the small number of guanines. To circumvent this problem, a $\mathrm{Ru}(\mathrm{bpy})_{2}{ }^{3+}$ mediator was introduced to transfer the electrons from the base to the electrode. Polymerase chain reaction (PCR) amplicons were then detected. An improvement of at least 30 times was obtained in comparison to the use of the same kind of technique with a silane-modified electrode. In a similar approach, hybridization was observed with the single-strand binding (SSB) protein, which plays an important role in DNA replication [185]. The SSB protein binds specifically to the single-strand DNA, while it has almost no affinity toward double-strand DNA. The protein sequence comprises four tyrosines and four tryptophans. The electrochemical oxidation of these residues was measured when the protein was immobilized onto the electrode. Then, specific detection of singlestrand DNA in the medium was monitored by signal changes upon binding. At this stage of development, the performances of the biosensor remained constant for 1 week, but decreased 10-fold after 1 month and vanished after 2 months. A third technique of fabrication was applied to carbon nanoelectrodes for monitoring total cholesterol in blood [186]. Cholesterol oxidase, peroxidase, potassium ferrocyanide and threhalose dissolved in a buffer were deposited onto the reaction area of the electrode. Then, a hydrophilic polymer was applied to coat the rest of the electrode. Finally, cholesterol esterase, threhalose and Triton $\mathrm{X}$ in a phosphate buffer were deposited. The enzymatic cascade led to the formation of hydrogen peroxide, which was reduced by the ferrocyanide. The resulting current was recorded at various concentrations of cholesterol. While a nonlinear relationship was obtained between the cholesterol concentration and the current response for an unmodified electrode, an almost linear response was observed for a CNTmodified electrode. Moreover, the CNTs provided almost double the sensitivity, an acceptable repeatability over three consecutive assays, no interference effect from ascorbic and uric acids, and a stability at room temperature over 2 months.

In summary, CNTs are endowed with appropriate characteristics for the elaboration of biosensors. They possess high electronic conductivity and nanometric size. Miniaturization is an important parameter in the conception of more efficient sensors, which could be used to control biochemicals at the single-cell level. The current performance of nanotube-based biosensors has already overtaken the other sensors, but optimization still needs to be reached. Glucose biosensors are very 

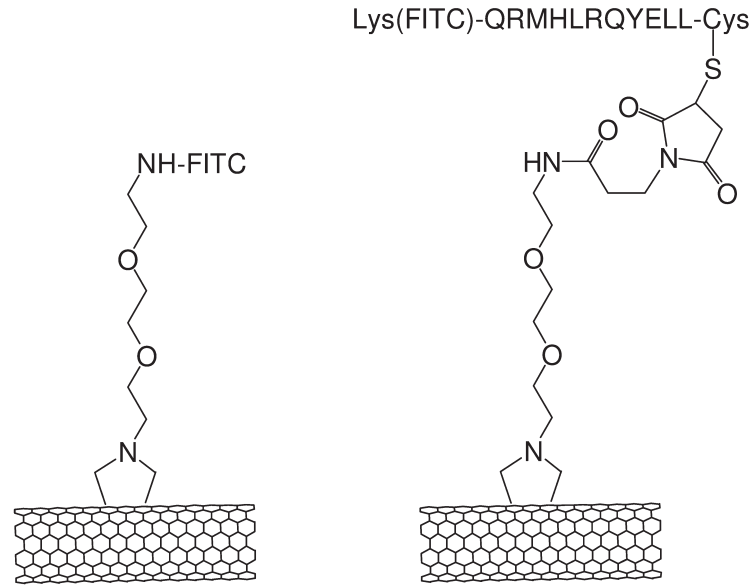

Figure 3.8. Molecular structure of FITC- (left) and fluorescent peptide-CNT (right) conjugates.

promising. However, numerous other oxidases exist and can be employed for the design of novel CNT-based biosensors. A bright future awaits these new sensors for pharmaceutical and clinical use.

\section{4}

\section{CNT Cell Uptake}

CNTs started to develop as new drug delivery systems because of their capacity to penetrate cell membranes and distribute into the cytoplasm and/or the nucleus.

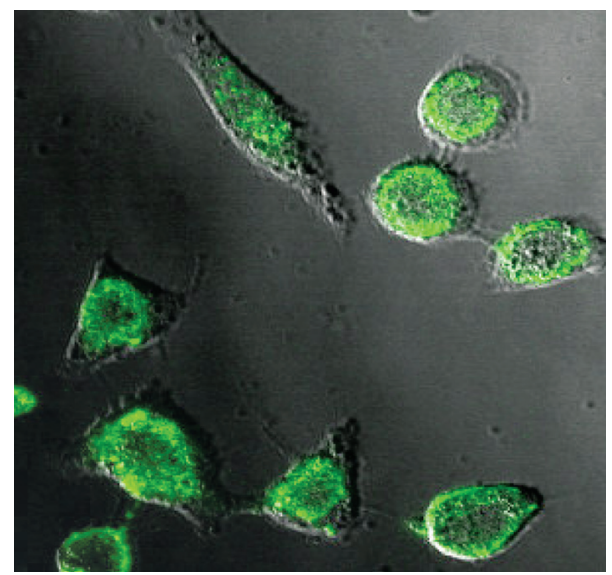

Figure 3.9. Confocal image of HeLa cells incubated with the fluorescent peptide-CNT conjugate. 
This behavior was observed for the first time in 2004 by Pantarotto and coworkers [190]. The amino groups of $f$-CNTs were coupled either to fluorescein isothiocyanate (FITC) or to a peptide bearing FITC on the side-chain of a lysine (Fig. 3.8).

Subsequently, fibroblasts were incubated with the fluorescent nanotubes. It was found that these tubes were easily internalized by the cells and could be detected in the cytoplasm and the nucleus using epifluorescence and confocal microscopy [190]. This penetrating capacity was also observed in other types of cells (Fig. 3.9).

The mechanism of uptake of this type of $f$-CNTs was energy independent and nonendocytotic. Indeed, the incubation of the fluorescent tubes with different types of cells in the presence of sodium azide or 2,4-dinitrophenol, well-known endocytosis inhibitors, did not block the penetration capacity of the tubes. The reduction of the temperature of incubation from 37 to $4{ }^{\circ} \mathrm{C}$ again did not affect cell uptake to a significant extent.

When the CNTs were devoid of the fluorescent moiety, they could be detected in the cells using transmission electron microscopy (TEM) [191]. Ammonium $f$ CNTs were incubated with HeLa cells. After washing, staining and fixing, the cells were embedded into a polymer that was cut into thin slices of $90 \mathrm{~nm}$ thicknesses using a diamond microtome. Each slice was deposited on a TEM grid and observed under the microscope. Functionalized nanotubes were visible in the cytoplasm and the nucleus. The tubes were also identified at the level of the cellular membrane in the process of crossing this barrier [191]. The shape of the tube was elongated, suggesting a behavior as a nanoneedle, capable of piercing the lipid bilayer of the membrane without provoking cell death. This mechanism, which can be defined as nanopenetration, was observed by Cai and coworkers, who developed an efficient molecular delivery technique called nanotube spearing [192]. In this case, CNTs filled with magnetic particles were cultured with MCF-7 cells. Under the action of a magnetic field, the suspended tubes were put in rotation to spear the cells. A second static magnetic field was applied under the plate where the cells were grown to pull the tubes through the cell membrane into the cytoplasm. Scanning electron microscopy showed the nanotubes crossing the cell membrane like tiny needles.

NIR fluorescence microscopy could be also used to detect CNTs in the cells [193]. Macrophages were able to phagocyte pristine CNTs without apparent toxic effects. Subsequently, the tubes were tracked into the cells by irradiation at 1100 $\mathrm{nm}$ and recovery of a fluorescence signal. This technique seems very promising since it could be extended to the visualization of CNTs in the tissue and the organs. However, only non- $f$-CNTs were used in this study and concerns are emerging about their toxicity once injected into a body (see Section 3.8).

An alternative pathway of penetration of CNTs into the cells was reported by Dai and coworkers. Oxidized CNTs were initially functionalized with biotin and then complexed to a fluorescent SA [115]. The protein-nanotube conjugates were taken up in an endocytosis-mediated mechanism, as they were localized into the endosomes. This behavior was also confirmed by complexing different proteins or nucleic acids to the nanotubes via noncovalent interactions $[90,194]$. HeLa and HL-60 
cell lines were treated with fluorescent BSA or SA, and a fluorescent 15-mer oligonucleotide at low temperature and in a adenosine triphosphate (ATP)-depleted environment [194]. Preincubation of the cells with sodium azide or cell culture performed at $4{ }^{\circ} \mathrm{C}$ clearly influenced nanotube uptake. In addition, it has been demonstrated that the endocytosis was clathrin dependent. To assess the role of clathrin, experiments were carried out in the presence of sucrose and potassium-depleted medium to disrupt the clathrin-coated vesicles. Under these conditions, the level of nanotube cellular uptake was drastically reduced. In parallel, it has also been demonstrated that the nanotubes were not internalized through the caveolae or lipid-raft pathway. In this case the cells were treated with filipin and nystatin, known to perturb the cholesterol distribution on the cell membrane, which is implicated in the lipid-raft mechanism. The two drugs did not hamper the uptake of the CNTs. Therefore, it could be concluded that $f$-CNTs complexed to proteins and nucleic acids penetrate following a clathrin-dependent endocytotoxic process. Elucidation of the different mechanism of cellular entry is crucial for the development of CNTs as delivery system for therapeutic molecules.

\section{5}

\section{CNTs as Delivery Devices for Antigens and Adjuvants}

The development of new delivery systems for the successful and effective administration of vaccines and immunotherapeutics still remains a great challenge. The listing of "delivery" among the top 10 biotechnologies required for improving global health has recently reinforced this view [195]. Among the novel delivery options, CNTs have emerged as a promising option for biomedical applications. This is because CNTs can enter into the cells and can be functionalized (see Section 3.4) $[148,190]$. The later property makes them soluble, nontoxic and permits modification of their surface [7]. Moreover, these molecules in the nanometer size range offer the control that modern drug delivery and targeting demands - control of the chemical nature of the carrier, control of the surface and, important in targeting, control of dimensions. CNTs can serve as vaccine delivery and adjuvant vehicles by virtue of their nanoparticulate nature. The hydrophobic nature of CNTs contributes to vaccine delivery capability by facilitating the interaction of CNTs with antigens or immunostimulatory molecules and uptake of the vaccine particles by immunocompetent cells.

\subsection{1}

\section{Interaction of $f$-CNTs with CpG Motifs and Potentiation of their Immunostimulatory Activity}

Immune responses to vaccine antigens are normally enhanced by immunostimulants called adjuvants. Recently, synthetic oligodeoxynucleotides (ODN) containing immunostimulatory $\mathrm{CpG}$ motifs (ODN CpG) have been considered as candidate adjuvants for vaccines or immunomodulators for therapeutic applications against 
tumors, allergy or to combat bioterrorist threats [196-199]. CpG motifs are unmethylated sequences that derive from bacterial DNA. The activation of the immune system by CpG motifs is a highly evolved defense mechanism, whose actual aim is to detect the microbial nucleic acid [200]. This can be achieved through the Toll-like receptor 9 [201], which belongs to the Toll family of pattern recognition receptors, conserved during the evolution in species from insects to humans [202]. CpG motifs induce B cell proliferation, antibody secretion and activate antigen-presenting cells (APCs) to express costimulatory molecules and secrete cytokines including, interleukin (IL)-12 and tumor necrosis factor (TNF)- $\alpha[200,203]$. In particular, the increased production of IL-12 promotes interferon (IFN)- $\gamma$ production by natural killer (NK) cells and T cells, and enhances the antigen-specific $\mathrm{T}$ cell proliferation and differentiation of naive $\mathrm{T}$ cells towards the $\mathrm{T}$ helper $\left(\mathrm{T}_{\mathrm{h}}\right) 1$ phenotype $[200,203]$. The triggering of the Toll-like receptor 9 by the ODN CpG is a critical event for the activation of innate immune system [203]. This requires the entry of ODN CpG into the cell for recognition by its receptor, which is expressed in endosomal compartments. Despite the potent immunostimulatory properties of ODN CpGs, their effect is short-lived because of their low uptake by the cells. In order to increase their biological properties, delivery of CpG using CNTs was explored. Therefore, ODN CpGs were first complexed with $f$-CNTs and their interaction analyzed [204], and then the immunostimulatory properties of the complexes were tested in vitro [204].

Cationic CNTs lend themselves as vectors for delivery because of their ability to form complexes with ODN CpG. Surface plasmon resonance (SPR) help in the understanding of the interaction that occurred between a $f$-CNT and ODN CpG to form complexes in real time, and gave an insight of how these molecules were bound [204]. Three types of $f$-CNTs were selected in the first series of experiments (Fig. 3.10).

Each $f$-CNT was attached onto the sensor chip by forming a stable amide bond between the amino groups on the tubes and the carboxylic functions on the chip's carboxylated dextran matrix, activated in turn with EDC and NHS. Following attachment, the increase in mass due to the interaction of $f$-CNTs with the ODN CpG 1668 present in the fluid phase was measured using the Biacore 3000 system.

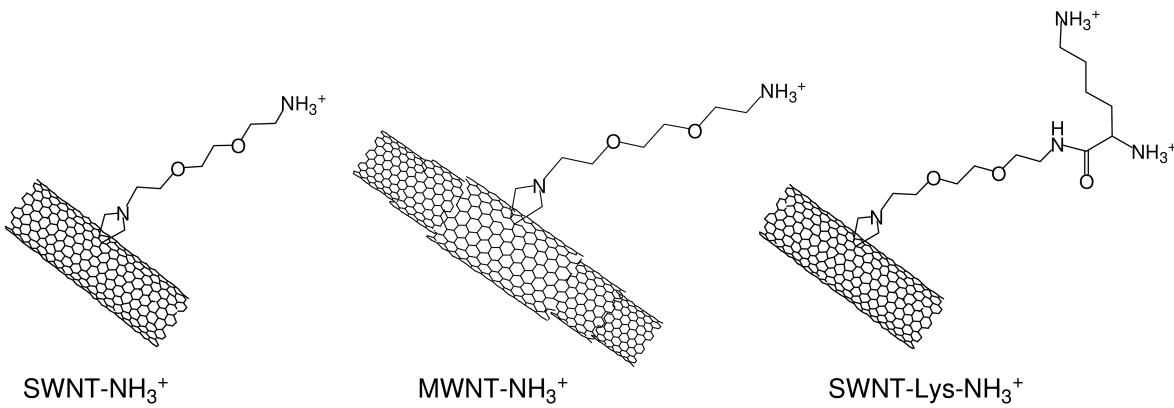

Figure 3.10. Molecular structures of ammonium $f$-CNTs for ODN CpG complexation. 
Although there were no significant differences between the affinity of binding between the two SWNT preparations and the ODN CpG 1668, the ODN CpG 1668 bound to the MWNT- $\mathrm{NH}_{3}{ }^{+}$formulation with much lower affinity. This difference was probably due to the relative dimensions and charge distributions of the two types of $f$-CNTs. Both SWNT-Lys- $\mathrm{NH}_{3}{ }^{+}$and $\mathrm{MWNT}-\mathrm{NH}_{3}{ }^{+}$displayed the same amount of positive charges. However, there must be an avidity effect, resulting from a double electrostatic interaction per ODN CpG molecule after their binding to SWNT-Lys- $\mathrm{NH}_{3}{ }^{+}$where the two ammonium groups on each lysine residue are in close proximity with respect to the single ammonium on the MWNT- $\mathrm{NH}_{3}{ }^{+}$.

Following the demonstration of complexation of the ODN CpGs with $f$-CNTs, their immunopotentiating effect was tested [204]. SWNTs were the CNTs of choice since they bound to ODN CpG 1668 with higher affinity than the MWNTs. After incubating the SWNT-Lys- $\mathrm{NH}_{3}{ }^{+}$at various excess ratios with a minimal immunostimulatory dose of the ODN CpG 1668, the complexes were added to a culture of naive mouse splenocytes. Complexes of SWNT-Lys- $\mathrm{NH}_{3}{ }^{+}$at 18:1 and 9:1 ratios over the ODN CpG 1668 increased its immunostimulatory properties by 58 and $45 \%$, respectively. There was no significant effect on immunostimulation when lower ratios of SWNT-Lys- $\mathrm{NH}_{3}{ }^{+} / \mathrm{ODN} \mathrm{CpG}$ were tested. Although the mechanism of this immunopotentiating effect is not quite clear, it could be argued that the high excess of SWNT-Lys-NH ${ }_{3}{ }^{+}$over the ODN CpG 1668 had a neutralizing effect of its negative charge. As a consequence, the repulsion forces by the negatively charged cell membrane were presumably reduced and therefore, the cellular uptake of ODN CpG 1668 was increased.

These preliminary findings pave the way for future in vivo experiments using animal models of disease or vaccination protocols to test the therapeutic or adjuvant potential of such complexes. Moreover, further studies will need to address whether serum proteins can alter the surface potential of CNTs, their size, the stability of complexes and the formation of aggregates.

\subsection{2}

Presentation and Immunogenic Potential of Peptide Antigens Attached onto $f$-CNTs

Peptides representing selected regions from the amino acid sequence of a protein antigen (epitopes) can be used as immunogens to induce peptide- and pathogenspecific B cell and $\mathrm{CD}^{+}\left(\mathrm{T}_{\mathrm{h}}\right)$ or cytotoxic CD8 ${ }^{+}$[cytotoxic T lymphocyte $\left.(\mathrm{CTL})\right] \mathrm{T}$ cell responses. Activated $\mathrm{CD}^{+}{ }^{+} \mathrm{T}$ cells help B cells to produce antibodies that neutralize viruses and bacterial toxins [205], enhance the magnitude of cytotoxic T cell responses to clear virus-infected cells [206], and regulate the immune responses to foreign antigens on the basis of the cytokine profile they secrete [207]. CD8 ${ }^{+} \mathrm{T}$ cells are the main effector cells responsible for the clearance of viral infections [208]. The development of such peptide vaccines requires a basic knowledge of the role of the various antigens of the pathogen in infection and immunity, the use of a cocktail of epitopes able to induce a broad range of protective antibody and $\mathrm{T}$ cell responses, and a delivery system for presentation of these epitopes to immunocompetent cells. 
B cell epitopes are mainly located on the surface of a protein antigen. Therefore, the native structure of the antigen is critical for recognition by antibodies. Immunization with flexible peptides normally induces a diverse set of antibody specificities that bind several different conformations of the peptide [209]. However, a subset of these antibodies can cross-react with the native protein, presumably because these peptides adopt a conformation similar to the native epitope [209]. Therefore, for a synthetic peptide vaccine to elicit a protective antibody response it is important the B cell epitope to be presented to the immune system at a conformation mimicking the native structure. The ability of $f$-CNTs to present a covalently linked synthetic peptide representing a neutralizing and protective B cell epitope from the foot-and-mouth disease virus (FMDV) corresponding to the 141-159 region of the VP1 viral envelope protein was tested [210]. $\mathrm{SWNTS}_{\mathrm{NH}}{ }^{+}$and SWNTs-Lys- $\mathrm{NH}_{3}{ }^{+}$modified with a maleimido group were used. This functionality allowed linking the FMDV peptide bearing an additional cysteine at the Nterminus necessary for a selective chemical ligation (Fig. 3.11).

To elucidate the structural and functional relationship between $f$-CNTs-linked peptide and peptide-specific polyclonal and monoclonal antibodies, the ELISA test and SPR were used. Both methods demonstrated that the SWNTs-linked peptide retained the structural features required for recognition by anti-FMDV peptide monoclonal and polyclonal antibodies [148, 211].

Since the FMDV peptide was not immunogenic (i.e. not capable of eliciting an immune response) in BALB/c mice (T cell help is required) [212] an immunization protocol that has been previously shown to overcome the requirement of coupling nonimmunogenic peptides to carrier proteins or $\mathrm{T}_{\mathrm{h}}$ epitopes was employed [213]. To this end, the SWNT-linked FMDV peptide was coimmunized with a protein antigen that provided T cell help, like ovalbumin (OVA) in a Freund's emulsion. After two injections, strong antipeptide antibody responses were induced that had significantly higher virus neutralizing capacity than the antibodies elicited after coimmunizing the free peptide with OVA [211]. This finding highlights the potential of $f$-CNTs to act as a delivery system capable of presenting critical epitopes at an

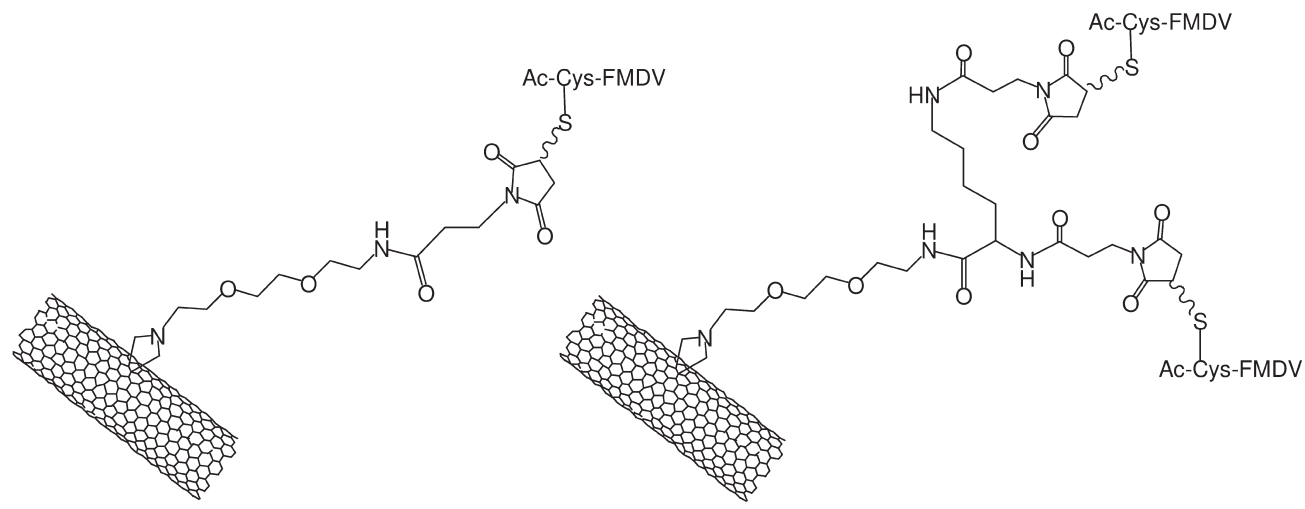

Figure 3.11. Molecular structures of FMDV peptide $f$-CNTs. 
appropriate conformation to elicit antibodies with the right specificity. Moreover, no antibody responses were induced against the $f$-CNTs, which could potentially hamper the successful outcome of the immunization procedure, particularly when several administrations are required [214].

Although the application of CNTs in the field of vaccine delivery is in its infancy, CNTs offer several attractive features, including the control one has over the primary nature of the system. They provide a platform for the attachment of adjuvants and antigens. Their potential use as vaccine delivery and adjuvant vehicles is likely to have a significant impact on the route that vaccines will be administered in the future and the required dose, conferring a competitive advantage in the market place. Obviously, their immunogenicity, toxicity, biodegradability, stability, biocompatibility, cost and consistent GMP manufacturing with readily scalable production processes has to be studied for each system and each application. These challenging issues should not inhibit research in examining the potential of CNTs to deliver vaccines since the most interesting and valuable delivery systems are yet to come.

\section{6}

\section{CNTs for Drug Delivery}

Drug delivery systems are necessary to improve the pharmacological profile and the therapeutic properties of administered drugs [1]. Among the wide variety of available delivery systems, CNTs may represent a promising alternative [215]. The application of $f$-CNTs as new nanovectors for drug delivery became possible soon after the demonstration of cellular uptake of this new material. However, only a few examples of delivery of therapeutic agents using CNTs are currently reported in the literature. Dai and coworkers have shown the potential of CNTs to transport proteins into the cells [90]. Single-walled CNTs were shortened to a length between 20 and $100 \mathrm{~nm}$ using strong acid conditions. This treatment also allowed the generation of carboxylic groups at the terminal parts of the tubes and at their defect sites. The carboxylated tubes were complexed with different types of proteins including SA, protein A, BSA and cytochrome $c$ (Fig. 3.12).

Mammalian cell lines were incubated with the complexes to study the capacity of CNTs to drive the adsorbed proteins into the cells. The complexes were localized in the endosomes and released into the cytoplasm by addition of chloroquine (a molecule able to destroy the endosomes). In the case of cytochrome $c$, it was verified that the protein exerted its biological function after liberation from the endosomal trap. Indeed, the cells entered into apoptosis. At the same time, it was shown that CNT-protein complexes were biocompatible by measuring cell proliferation.

In a different approach, Wu and coworkers used $f$-CNTs with AmB - one of the most effective antimycotic molecules for the treatment of chronic fungal infections (Fig. 3.13) [152].

MWNTs were treated with strong acid conditioned to reduce their length to about 180-940 $\mathrm{nm}$. The carboxylic groups were coupled with a phthalimide 


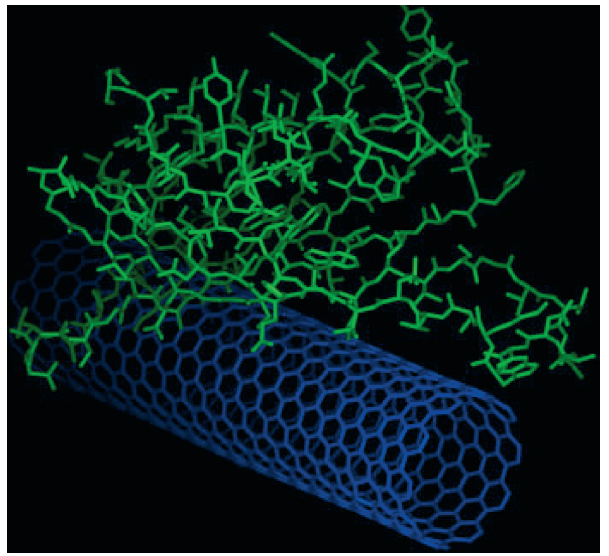

Figure 3.12. Molecular model of the complex between a shortened CNTs and SA.

mono-protected triethylene glycol diamine. Subsequently, the tubes underwent the 1,3-dipolar cycloaddition reaction to introduce a $\mathrm{N}$-functionalized pyrrolidine ring on the external walls of the tubes. A second Boc-protected amino group was therefore introduced on the nanotubes. The two protecting groups are orthogonal and permitted to modify the tubes with a fluorescent probe to follow the cell internalization of the conjugate and the active drug AmB to exert its antifungal activity. It

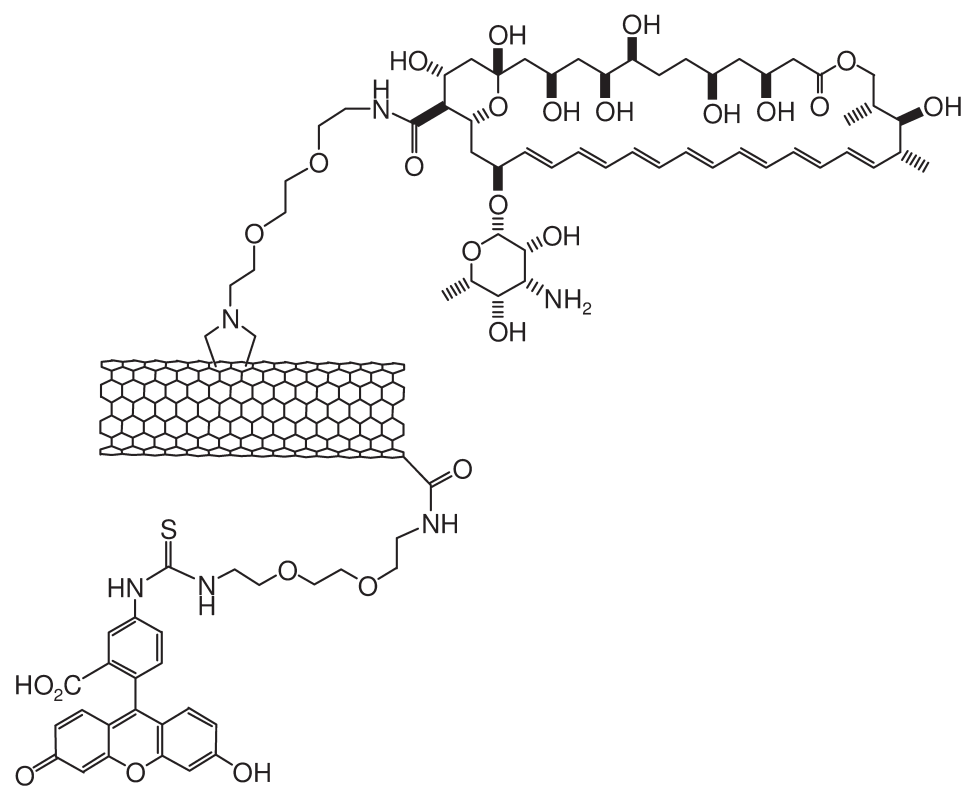

Figure 3.13. Molecular structure of CNTs functionalized with FITC and AmB. 
has been shown that AmB-CNTs were rapidly internalized into Jurkat cells in a dose-dependent manner. The process was nonendocytotoxic since the incubation of the cells at $4{ }^{\circ} \mathrm{C}$ or in the presence of sodium azide did not completely block the uptake. The drug was internalized into mammalian cells with a remarkable reduction of toxicity. Indeed, AmB is widely used, but it suffers from high toxicity. At the highest dose, more than $40 \%$ of cells died by the effect of free AmB, while all cells remained alive following the treatment with AmB covalently conjugated to CNTs. Very interestingly, AmB preserved its high antifungal activity once linked to the nanotubes. Different types of pathogens including Candida albicans, Candida paropsilosis and Cryptococcus neoformans were treated with AmB-CNT conjugates, and the activity was in some cases higher that the drug alone. Although only some hypotheses on the action of the AmB linked to the tubes could be formulated (increase of the solubility of the drug, multipresentation of the drug by CNTs that favor interaction with the fungal membrane), the conjugation of AmB to the tubes modulated its therapeutic effect by decreasing mammalian toxicity and increasing the antifungal activity.

Using another strategy, Hosmane and coworkers prepared SWNTs with a carborane cage for boron neutron capture therapy (BNCT) [216]. CNTs were functionalized with a substituted $\mathrm{C}_{2} \mathrm{~B}_{10}$ carborane derivative via nitrene cycloaddition. Following treatment with sodium hydroxide, a water-soluble CNT conjugate was obtained (Fig. 3.14).

Then, the biodistribution study on different tissues showed that carborane nanotubes were concentrated more in tumor cells than in blood, liver, lung or spleen when administered intravenously. However, the mechanism for this it is not yet understood. The results are preliminary, although promising for future applications of CNTs on delivery of boron-based agents for effective BNCT treatment of cancer, provided that cytotoxicity and more complete biodistribution studies prove the biocompatibility of this system. Another application of CNTs in cancer therapy was shown by Kam and coworkers [217]. The property of CNTs to adsorb NIR irradiation was exploited to kill cancer cells. Pristine SWNTs were wrapped with PEG modified with a PL moiety on one side and folic acid (FA) on the other side. As

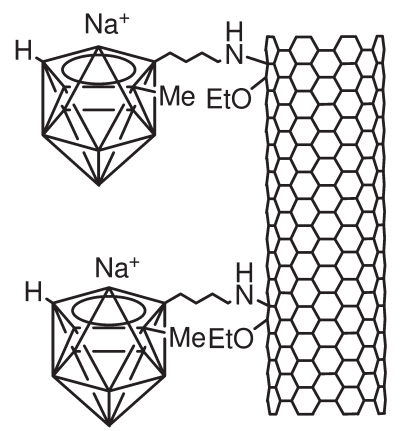

Figure 3.14. Molecular structure of CNTs functionalized with a carborane cage. 


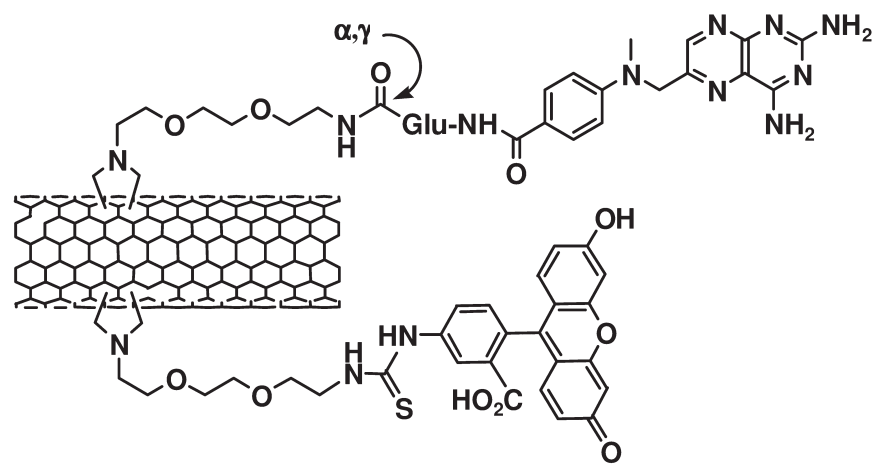

Figure 3.15. Molecular structure of CNTs functionalized with FITC and methotrexate.

tumor cells are known to overexpress folate receptors, the PL-PEG-FA/SWNT construct was mainly taken up by cancer cells, which were then destroyed by using a laser wavelength of $808 \mathrm{~nm}$. Laser pulses induced local heating and consequently death only of those tumor cells that had internalized the CNTs.

Pastorin and coworkers have developed an alternative method to exploit CNTs in cancer [218]. CNTs were doubly functionalized using 1,3-dipolar cycloaddition reaction. Two orthogonally protected amino groups were introduced on the sidewalls and the tips of the tubes. After selective deprotection, an anticancer molecule [methotrexate (MTX)] and a fluorescent probe (FITC) were linked to the tubes (Fig. 3.15).

MTX is a drug widely used against cancer, but it displays a reduced cellular uptake. Therefore, the limited capacity of MTX to cross the cell membrane could be overcome by its conjugation to CNTs, which are able to enhance cell uptake of linked moieties. The presence of fluorescein provided the optical signal for imaging CNT-drug into the cells. Jurkat cells were incubated with different doses of MTX-CNT and the fluorescent tubes were localized around the nuclear membrane in a dose-dependent manner. Preliminary studies have shown that MTX conjugated to the CNTs had the same cytotoxic activity of the drug alone.

Another class of carbon nanomaterials very similar to CNTs called carbon nanohorns were found to be effective systems for delivery of anticancer agents. Singlewalled carbon nanohorns (SWCHs) are spherical aggregates of graphitic tubes with dimensions in the nanorange scale. These nanostructures were loaded with dexamethasone [219]. Binding and release of the drug were subsequently evaluated using two types of nanohorns. It was found that oxidized nanohorns were able to adsorb more dexamethasone than as-grown horns. The analysis of activation of glucocorticoid response in mouse bone marrow cells and induction of alkaline phosphatase in mouse osteoblasts confirmed the biological activity of the drug released from the carbon support. Similarly, carbon nanohorns were used to encapsulate cisplatin (another anticancer agent) [220]. Again, the structure of the drug was preserved into the aggregates. Cisplatin was slowly liberated into water and it was effective in blocking the growth of human lung cancer cells. Unloaded oxi- 
dized carbon nanohorns were instead not active. Therefore, this type of carbon material is potentially useful as a carrier of anticancer agents.

In view of the overall results, functionalized carbon nanostructures represent an emerging and new class of delivery tools for the transport, encapsulation and release of molecules into mammalian cells. However, it will be important in the near future to assess the metabolism, biodistribution and clearance form the body of nanotubes for further development and complete integration in living systems.

\section{7}

\section{CNTs for Gene Transfer}

\subsection{1}

\section{Interaction with DNA and RNA}

In the quest for a useful nonviral gene transfer system, the interaction between a cationic component (liposome, polymer, nanoparticle) and the negatively charged nucleic acids to be delivered is critical for the eventual effectiveness of the gene transfer construct. CNTs have very recently been explored for the first time as novel materials for the complexation and delivery of gene-encoding nucleic acids [191, 221]. However, the physicochemical interactions between CNTs and DNA have been studied under different contexts for much longer, particularly in attempts to disperse non- $f$-CNTs, and for the construction of sensors, nanocircuits, nanocomposites and gene delivery vectors.

Theoretical predictions of DNA interactions with CNTs by molecular dynamics simulations have shown that single-stranded DNA spontaneously inserts into non- $f$-CNTs through a combination of van der Waals and hydrophobic forces [222]. However, a recent molecular modeling simulation has demonstrated that double-stranded DNA can also wrap around non- $f$-CNTs or, the in case of positively charged CNTs in an aqueous environment, DNA molecules could electrostatically adhere onto the CNTs surface [223].

Experimentally, a range of different techniques has been used to understand the CNT-DNA interactions and the ensuing supramolecular structures between the two components. However, most studies agree that the nature and mechanism of such interactions will be highly dependent on the type of CNTs surface functionalization and the characteristics of the nucleic acids.

UV and IR spectroscopy have both been used to show that non- $f$-SWNTs and double-stranded DNA interact through hydrogen bonds [224, 225]. Changes in the electronic levels in the nucleotide bases of the DNA molecule were found in these studies and the DNA acquired a chaotic sphere conformation upon interaction with CNTs. $\pi-\pi$ interactions between the CNT sidewalls and the nucleic acid bases have been proposed as the mechanistic basis for this wrapping effect. Moreover, the ability of DNA to wrap around the CNT surface has been described for both double-stranded DNA [226, 227] and single-stranded DNA [91], and has been utilized to disperse CNTs in solvents of varying polarity. 
As described earlier in this chapter, CNT surface characteristics can be altered through organic and defect functionalization. By strong oxidation, $\mathrm{OH}$ and $\mathrm{C}=\mathrm{O}$ defects are introduced at the tips and sidewalls of CNTs. Several studies describe that these oxidized CNTs (CNT-ox) covalently bond DNA- $\mathrm{NH}_{2}$ in a controllable assembling process $[38,118,228,229]$ or are helically wrapped $(\pi-\pi$ interactions $)$ by double-stranded DNA and single-stranded DNA [230-232]. An alternative functionalization reaction described by Georgakilas and coworkers produces positively charged ammonium- $f$-CNTs $\left(\mathrm{CNT}^{-\mathrm{NH}_{3}}{ }^{+}\right)[146]$. The interaction of $\mathrm{CNT}-\mathrm{NH}_{3}{ }^{+}$ with plasmid DNA (pDNA) was studied in detail in our laboratories [221, 233]. We have found that these $f$-CNTs interact with pDNA to form complexes primarily through electrostatic forces and that the pDNA was condensed around the CNT$\mathrm{NH}_{3}{ }^{+}$. Moreover, these studies have indicated that the total available surface area and the surface charge density of CNTs were critical parameters in the interaction and complexation of pDNA.

With regard to interactions between RNA and CNTs, to our knowledge there has only been one published report describing the interaction between non- $f$-SWNTs and RNA polymer poly(rU) [234]. In this study the RNA polymer poly(rU) was observed in a blob-like conformation when bound at the surface of CNTs as imaged by scanning electron microscopy, resembling the condensation of pDNA strands. These authors suggested that the binding occurs through $\pi$-stacking and hydrophobic interactions; however, no detailed mechanistic study has been published so far describing how the CNT-RNA interactions occur.

\section{7 .2}

\section{Delivery and Expression of Gene-encoding DNA and RNA}

The development of water-soluble CNTs automatically renders them compatible with the biological fluids and milieu. The complex formation between CNTs and nucleic acids in combination with the improved CNT biocompatibility recently achieved allowed for exploration of the hypothesis that CNTs can be used as genedelivery systems. So far, the intracellular translocation and expression of geneencoding nucleic acids (DNA and RNA) involving CNTs have been shown for mammalian cells to bacteria in vitro. The following is a comparative description of the different techniques used to deliver nucleic acids to cells through CNTs.

The first ever study to demonstrate CNT-mediated gene delivery and expression of marker gene-encoding nucleic acids was carried out in our laboratories. Pantarotto and coworkers reported that CNTs covalently functionalized with ammonium groups $\left(\mathrm{CNT}-\mathrm{NH}_{3}{ }^{+}\right)$were able to associate with pDNA through electrostatic interactions [191]. Transmission electron microscopy images of the supramolecular complexes showed the pDNA attaining a condensed globular conformation at the surface of the CNT-NH${ }_{3}{ }^{+}$. The delivery of pDNA and expression of $\beta$-galactosidase (a marker gene) in CHO cells was found to be approximately 10 times higher than naked pDNA. An endosome-independent penetration mechanism was proposed for the complex uptake based on evidence of spontaneous cellular uptake of the $f$-CNTs alone. Similar to other nonviral gene delivery systems based on the elec- 
trostatic supramolecular complex formation between a cationic macromolecule or nanoparticle and nucleic acids, the charge ratio $(+/-)$ CNT- $\mathrm{NH}_{3}{ }^{+}$:pDNA was found to be a critically important factor determining the level of gene expression.

A similar approach was later followed by Liu and coworkers, which reported a noncovalent association of pDNA onto the surface of CNTs functionalized with polyethylenimine (PEI) - a polymer with high density of terminal amine groups [235]. The complexes were tested at different charge ratios in different cell lines (293, COS7 and HepG2 cells) and the level of gene (pCMV-Luc) expression was found to be much higher than those of DNA alone. This study suggested that the uptake mechanism of the CNT-PEI-pDNA conjugates was took place by endocytosis.

Kam and coworkers later used two distinct methods to deliver nucleic acids via CNTs into HeLa cells. In a first study [217], CNTs functionalized with Cy3-labeled single-stranded DNA through noncovalent adsorption were used. These CNTs were excited with NIR light. The release and nuclear translocation of the single-stranded DNA was reported by confocal microscopy only in the case of NIR treatment. In the absence of cell illumination by NIR, the Cy3-DNA was seen by Kam and coworkers to remain in the cytoplasm. This group also suggested an endosomemediated cellular uptake.

In a subsequent study by the same group [93], CNTs were functionalized by noncovalent adsorption of PL molecules, which contained a PEG chain terminating in an amine (CNT-PL-PEG-NH2 ) or maleimide (CNT-PL-PEG-maleimide) group. Then a thiol-containing SH-DNA-Cy3 was covalently linked to the CNTs via a disulfide bond by a heterobifunctional cross-linker. In this way, a complicated CNTPL-PEG-single-stranded DNA-Cy3 complex was formed, sensitive to enzymatic cleavage upon endocytosis and translocation to the lysosomal compartments. It was reported in that study that nuclear localization of Cy3-DNA was possible only in the presence of the disulfide linkage. However, in this study gene-encoding nucleic acids were not used therefore no gene expression was reported at all.

A very different strategy to introduce exogenous pDNA into mammalian cells was described recently by Cai and coworkers [192]. The pDNA was immobilized on the CNTs, which contained Ni particles (CNT-Ni) enclosed and suspended with the surfactant Nanosperse AQ. Then, with a magnetic spearing technique (exposure to an external magnetic field followed by centrifugation) the complexes were added to Bal 17 cells, mouse splenic cells and a primary culture of mice cortical neurons. The expression of the enhanced green fluorescent protein (EGFP) gene was evaluated by fluorescence microscopy and flow cytometry. Gene delivery through CNT-Ni produced $80-100 \%$ fluorescent cells, while CNTs deprived of Ni particles did not produce any fluorescence signal. In this way, another illustration of the possibility to use CNTs to transport intracellularly gene expressing nucleic acids was seen. However, such techniques are only appropriate for in vitro or ex vivo gene transfer.

The delivery of exogenous genes by CNTs has been shown to be also possible in bacterial cultures. Rojas-Chapana and coworkers have demonstrated that oxidized, water-dispersible CNTs deliver pDNA into Escherichia coli through temporary nano- 
channels across the cell envelope [236]. The pUC19-transformed bacteria were examined by optical microscopy, and an efficient transformation between 9 and 32 transformants was observed. The authors achieved that by an electroporation technique using microwave-activated CNTs, which apparently orient their tips in a conformation perpendicular to the bacterial cell membrane.

CNTs have also been shown to transport RNA into mammalian cells. Lu and coworkers have studied the cellular uptake of CNT-RNA polymer poly(rU) hybrids formed through nonspecific binding. MCF7 cells were examined by confocal microscopy after addition of the hybrids, and their translocation in cellular and nuclear membranes reported [237]. In agreement with these findings, Kam and coworkers, in more a recent report, used a complex CNT-small interfering RNA (siRNA) conjugate linked with disulfide bonds (as described above for singlestranded DNA) and have shown preliminary observations of siRNA-mediated gene silencing [93].

All of these studies have been initiated by our initial observations that it was indeed feasible to use $f$-CNTs to complex, deliver and express gene-encoding nucleic acids. The most recent study in this exploratory exercise has been very recently published using GFP-encoding pDNA condensed with $f$-CNTs carrying positive charges [238]. In this way our initial reports and observations were indeed substantiated and reproduced in an independent study. The development of CNTs as delivery systems for nucleic acids is still in its exploratory stage, and many more studies are needed to determine the advantages and limitations offered by these novel materials.

\section{8}

\section{Health Impact of CNTs}

Nanotechnology has been rapidly developing due to the possibility of engineering at nanometer scales. The resulting nanoproducts display physicochemical characteristics that confer electrochemical, mechanical and thermal properties that are very useful in the medical, scientific, commercial and environmental fields. However, it is too early to say whether the "nanostructures" will wean the world from dirty technologies or if they will definitely backfire, basically because the laws of chemistry or physics are different when particles get down to the nanoscale. Even substances that are normally innocuous can trigger intense chemical reactions and biological anomalies as nanospecies [239].

For this reason, there is a heated debate between the desire of introducing nanomaterials in everyday life and the moralistic tendency of blocking the nanotech factory until the risks will be better understood. Currently, available information concerning the relative environmental and health risks of manufactured nanoparticles or nanomaterials is severely absent and defective. In fact, most of nanomaterials (fullerenes, nanoparticles, nanofibers and nanotubes) are made of carbon atoms, with distinct geometries, different surface areas, and diverse physical and chemical 
properties. The existence of such variables produced a lot of contrasting evidence. Doses, effects and cell viability of different carbon nanomaterials are summarized in Tab. 3.1. For example, Adelmann and coworkers have studied the in vitro effect of fullerenes on alveolar macrophages, prepared in an arc between two graphite electrodes [240]. A 60\% reduction in macrophage viability and increased levels of some inflammatory cytokines were found, suggesting that such structures had similar toxicity to quartz particles. Moreover, it was discovered that stable solutions of $\mathrm{C}_{60}$ nanoparticles (nano- $\mathrm{C}_{60}$ ) displayed a high toxicity against bacteria at a concentration of $0.4 \mu \mathrm{g} \mathrm{mL} \mathrm{m}^{-1}$ [241]. Other highly water-soluble nanofullerenes (13$100 \mathrm{mg} \mathrm{mL}^{-1}$ ) showed also a remarkable cytotoxicity both in fibroblasts and in liver carcinoma cells at very low concentrations $\left(50 \mu \mathrm{g} \mathrm{mL}^{-1}\right)$ [242]. It could be deduced that such behavior conveys a common toxicity of all $\mathrm{C}_{60}$ materials [243]. On the contrary, it was observed that the lethal doses varied by seven orders of magnitude, strongly depending on the functionalization of the fullerene surface [242]. Therefore, the further modification at the surface deeply influenced the toxicological profile of the nanomaterials [244].

In contrast, some in vivo studies on fullerene showed that intraperitoneal injections of amounts of $\mathrm{C}_{60}$ up to $2.5 \mathrm{~g} \mathrm{~kg}^{-1}$ in mice and rats had neither lethal effects nor acute toxicity $[245,246]$. What was evident was only a hypertrophy of livers and spleens, which could be ascribed to the high amount of compound injected that had exceeded the absorption capacity of the animal. Similarly, mice subcutaneously implanted with Hat-stacked carbon nanofibers did not show severe inflammatory responses such as necrosis or degeneration after 4 weeks of incubation [247]. However, these encouraging results are not exhaustive in representing the reduced harmfulness of all the different nanomaterials.

\subsection{1}

\section{Parameters of CNTs Related to Health Impact}

The data reported above suggest that, in general, carbon nanoparticles can be considered as dangerous as quartz, only on the basis of the common "starting material", i.e. carbon. In particular, CNTs represent a class of substances which are, at the same time, intriguing (for their characteristics) and doubtful. In fact, they revealed unusual toxicological properties, because their shapes can be both fibers and nanoparticles, and they are often characterized by the presence of metallic components even after their purification. CNTs, both single and multiwalled, are classified as "synthetic graphite" by the National Occupational Safety and Health Administration, on the basis of the same hexagonal/honeycomb pattern. However, such extrapolation might not be protective for exposure to CNTs, because they show physicochemical properties that are often influenced by several variables.

\subsubsection{Purity}

CNTs generally show different levels of purity, which are strictly dependent on the methods employed for their production. The impurities are essentially made up of 
Tab. 3.1. Doses, effects and cell viability of different carbon nanomaterials.

\begin{tabular}{|c|c|c|c|c|c|}
\hline $\begin{array}{l}\text { Type of } \\
\text { nanomaterial }\end{array}$ & $\begin{array}{l}\text { Amount/ } \\
\text { concentration }\end{array}$ & $\begin{array}{l}\text { Cell/animal } \\
\text { target }\end{array}$ & Effect & Possible causes & Ref. \\
\hline Fullerenes & not specified & $\begin{array}{l}\text { alveolar } \\
\text { macrophages }\end{array}$ & $\begin{array}{l}60 \% \text { reduction on } \\
\text { cell viability; } \\
\text { inflammatory } \\
\text { cytokines (IL-6, } \\
\text { IL-8) }\end{array}$ & intrinsic toxicity & 240 \\
\hline Nano $\mathrm{C}_{60}$ & $0.4 \mu \mathrm{g} \mathrm{mL}^{-1}$ & bacteria & growth inhibition & & 241 \\
\hline Nano $\mathrm{C}_{60}$ & $50 \mu \mathrm{g} \mathrm{mL} L^{-1}$ & $\begin{array}{l}\text { fibroblast; liver } \\
\text { carcinoma cells }\end{array}$ & $\begin{array}{l}\text { decreasing } \\
\text { cytotoxicity with } \\
\text { increasing } \\
\text { functionalization } \\
\text { and solubility }\end{array}$ & $\begin{array}{l}\text { oxidative stress; } \\
\text { surface effect }\end{array}$ & 242 \\
\hline $\begin{array}{l}\text { Functionalized gold } \\
\text { nanoparticles }\end{array}$ & $250 \mu \mathrm{M}$ & leukemia cells & $\begin{array}{l}\text { no remarkable cell } \\
\text { death; rapid } \\
\text { internalization }\end{array}$ & & 244 \\
\hline $\mathrm{C}_{60}$ & $2.5 \mathrm{~g} \mathrm{~kg}^{-1}$ & mice and rats & $\begin{array}{l}\text { no acute toxicity; } \\
\text { hypertrophy }\end{array}$ & too high amount & $\begin{array}{l}245 \\
246\end{array}$ \\
\hline $\begin{array}{l}\text { Hat-stacked carbon } \\
\text { nanofibers (H-CNF) }\end{array}$ & not specified & rats & no toxicity & & 247 \\
\hline $\begin{array}{l}\text { SWNTs, MWNTs, } \\
\text { fullerenes }\end{array}$ & $\geq 1.41 \mu \mathrm{g} \mathrm{cm}^{-2}$ & $\begin{array}{l}\text { alveolar } \\
\text { macrophages }\end{array}$ & $\begin{array}{l}20 \% \text { reduction on } \\
\text { cell viability } \\
\text { (SWNTs) }\end{array}$ & low purity & 248 \\
\hline Pristine SWNTs & $0.1-10 \mu \mathrm{g} \mathrm{mL} \mathrm{L}^{-1}$ & $\mathrm{HaCaT}$ cells & increased cell death & $\begin{array}{l}\text { oxidative stress } \\
\text { or solvent (DMF) }\end{array}$ & 249 \\
\hline$f$-SWNTs & $\begin{array}{l}3 \mu \mathrm{g} \mathrm{mL}^{-1}- \\
30 \mathrm{mg} \mathrm{mL}^{-1}\end{array}$ & HDF & $\begin{array}{l}\text { cell death } 50 \% \text { or } \\
\text { below }\end{array}$ & & 252 \\
\hline \multirow[t]{2}{*}{$\begin{array}{l}\text { MWNTs (220 and } \\
825 \mathrm{~nm})\end{array}$} & $\begin{array}{l}50-500 \mathrm{ng} \mathrm{mL}^{-1} \\
\text { (in vitro) }\end{array}$ & $\begin{array}{l}\text { leukemia cells } \\
\text { THP-1 }\end{array}$ & $\begin{array}{l}\text { inflammation } \\
\text { (especially with } \\
\text { 825-nm samples) }\end{array}$ & length & 253 \\
\hline & $\begin{array}{l}0.1 \mathrm{mg} \mathrm{mL} \mathrm{m}^{-1} \\
\text { (in vivo) }\end{array}$ & mice & $\begin{array}{l}\text { granulomatous } \\
\text { inflammation }\end{array}$ & & 253 \\
\hline $\begin{array}{l}\text { HiPCO, CVD- } \\
\text { SWNTs and CVD- } \\
\text { double-walled CNTs }\end{array}$ & $0.62-2.5 \mathrm{mg}$ & red blood cells & $\begin{array}{l}\text { complement } \\
\text { activation }\end{array}$ & $\mathrm{C} 1 \mathrm{q}$ activation & 254 \\
\hline $\begin{array}{l}\text { Arc-SWNTs and } \\
\text { CVD-H-CNF }\end{array}$ & $10 \mu \mathrm{g} \mathrm{mL}-1$ & $\begin{array}{l}\text { leukemia cells } \\
\text { THP-1; mouse } \\
\text { spleen cells }\end{array}$ & immune response & $\begin{array}{l}\text { Induction of } \\
\text { TNF- } \alpha\end{array}$ & 255 \\
\hline
\end{tabular}


Tab. 3.1 (continued)

\begin{tabular}{|c|c|c|c|c|c|}
\hline $\begin{array}{l}\text { Type of } \\
\text { nanomaterial }\end{array}$ & $\begin{array}{l}\text { Amount/ } \\
\text { concentration }\end{array}$ & $\begin{array}{l}\text { Cell/animal } \\
\text { target }\end{array}$ & Effect & Possible causes & Ref. \\
\hline$f$-SWNTs & $<5 \mu \mathrm{M}$ & fibroblasts & $\begin{array}{l}\text { no remarkable cell } \\
\text { death }(90 \%) \text {; rapid } \\
\text { internalization }\end{array}$ & & 190 \\
\hline $\begin{array}{l}f \text {-SWNTs and } f \text { - } \\
\text { MWNTs }+ \text { plasmid } \\
\text { DNA }\end{array}$ & $1 \mathrm{mg} \mathrm{mL}^{-1}$ & HeLa cells & $\begin{array}{l}\text { no remarkable cell } \\
\text { death; efficient } \\
\text { delivery }\end{array}$ & & 191 \\
\hline MWNT-PEI + DNA & $<5 \mu \mathrm{g} \mathrm{mL}-1$ & HEK293 cells & $\begin{array}{l}\text { below } 40 \% \\
\text { reduction on cell } \\
\text { viability }\end{array}$ & $\begin{array}{l}\text { increased PEI } \\
\text { weight }\end{array}$ & 235 \\
\hline SWNT-CpG ODN & $5 \mathrm{ng}-5 \mu \mathrm{g}$ & $\begin{array}{l}\text { mouse } \\
\text { splenocytes }\end{array}$ & $\begin{array}{l}\text { no remarkable cell } \\
\text { death }\end{array}$ & & 204 \\
\hline SWNT-RNA & $\leq 1 \mathrm{mg} \mathrm{mL}^{-1}$ & $\begin{array}{l}\text { breast cancer } \\
\text { cells (MCF7) }\end{array}$ & efficient delivery & & 237 \\
\hline SWNTs & $1-250 \mu \mathrm{g} \mathrm{mL}^{-1}$ & $\begin{array}{l}\text { embryo kidney } \\
\text { cells (HEK293 } \\
\text { cells) }\end{array}$ & $\begin{array}{l}\text { apoptosis; 20/30- } \\
\text { kDa protein } \\
\text { secretion }\end{array}$ & $\begin{array}{l}\text { downregulation } \\
\text { of genes for } \\
\text { adhesion; } \\
\text { upregulation of } \\
\text { genes involved in } \\
\text { apoptosis }\end{array}$ & 256 \\
\hline Pristine MWNTs & $0.1-0.4 \mathrm{mg} \mathrm{mL}^{-1}$ & $\begin{array}{l}\text { embryo kidney } \\
\text { cells (HEK293) }\end{array}$ & inflammation & $\begin{array}{l}\text { production of } \\
\text { IL-8 }\end{array}$ & 257 \\
\hline $\begin{array}{l}\text { Pristine and } \\
\text { oxidized MWNTs }\end{array}$ & $400 \mu \mathrm{g} \mathrm{mL}{ }^{-1}$ & T lymphocytes & $\begin{array}{l}40 \% \text { reduction on } \\
\text { cell viability } \\
\text { (pristine) } 80 \% \\
\text { reduction on cell } \\
\text { viability (oxidation) }\end{array}$ & $\begin{array}{l}\text { better dispersion } \\
\text { of oxidized tubes }\end{array}$ & 258 \\
\hline MWNTs & $0.5,2$ or $5 \mathrm{mg}$ & rats & $\begin{array}{l}\text { upregulation of pro- } \\
\text { inflammatory and } \\
\text { profibrotic } \\
\text { mediators }\end{array}$ & $\begin{array}{l}\text { biopersistence in } \\
\text { the lung }\end{array}$ & 259 \\
\hline $\begin{array}{l}\text { Raw, HiPCO and } \\
\text { arc-SWNTs }\end{array}$ & $\begin{array}{l}0.1 \text { or } 0.5 \mathrm{mg} \text { per } \\
\text { mouse }\end{array}$ & mice & granulomas & intrinsic toxicity & 260 \\
\hline Pristine SWNTs & 1 or $5 \mathrm{mg} \mathrm{kg}^{-1}$ & rats & $\begin{array}{l}\text { pulmonary } \\
\text { inflammation, with } \\
\text { non-dose-dependent } \\
\text { granulomas }\end{array}$ & $\begin{array}{l}\text { blockage of } \\
\text { upper airways }\end{array}$ & 261 \\
\hline
\end{tabular}


Tab. 3.1 (continued)

\begin{tabular}{|c|c|c|c|c|c|}
\hline $\begin{array}{l}\text { Type of } \\
\text { nanomaterial }\end{array}$ & $\begin{array}{l}\text { Amount/ } \\
\text { concentration }\end{array}$ & $\begin{array}{l}\text { Cell/animal } \\
\text { target }\end{array}$ & Effect & Possible causes & Ref. \\
\hline $\begin{array}{l}\text { Fullerenes and } \\
\text { CNTs }\end{array}$ & $\begin{array}{l}0.2 \mathrm{~mL} \text { (not } \\
\text { specified) }\end{array}$ & $\begin{array}{l}\text { four albino } \\
\text { rabbits and } 40 \\
\text { human } \\
\text { volunteers }\end{array}$ & $\begin{array}{l}\text { no remarkable skin } \\
\text { irritation or } \\
\text { allergen risks }\end{array}$ & & $\begin{array}{l}262 \\
263\end{array}$ \\
\hline $\begin{array}{l}\text { Carbon fiber } \\
\text { particles }\end{array}$ & not specified & 341 workers & contact dermatitis & $\begin{array}{l}\text { exposure to } \\
\text { organic } \\
\text { solvents or to } \\
\text { carbonaceous } \\
\text { particles }\end{array}$ & $\begin{array}{l}264 \\
265\end{array}$ \\
\hline $\begin{array}{l}\text { Pristine HiPCO- } \\
\text { SWNTs }\end{array}$ & $\begin{array}{l}0.06,0.12 \text { or } \\
0.24 \mathrm{mg} \mathrm{mL}^{-1}\end{array}$ & HaCaT cells & $\begin{array}{l}\text { alteration of cell } \\
\text { morphology and } \\
\text { surface integrity }\end{array}$ & $\begin{array}{l}\text { transition metal } \\
\text { catalysts }\end{array}$ & 266 \\
\hline $\begin{array}{l}\text { Pristine HiPCO or } \\
\text { laser ablation } \\
\text { SWNTs (aerosol) }\end{array}$ & $15.5 \mathrm{mg}$ & cotton gloves & $\begin{array}{l}\text { deposition on } \\
\text { individual gloves } \\
\text { ranged from } 217 \text { to } \\
6020 \mu \mathrm{g}(\text { aerosol } \\
\left.\text { below } 53 \mu \mathrm{g} \mathrm{m}^{-3}\right)\end{array}$ & ultrafine powders & 267 \\
\hline
\end{tabular}

residual catalysts and amorphous carbon. Their high amount might enhance the toxicity. In this context, Jia and coworkers investigated the cytotoxicity caused by nanostructures such as SWNTs, MWNTs and fullerenes on alveolar macrophages (AM) [248]. The different carbon particles, all with a purity superior than $90 \%$, were suspended in RPMI medium using a Dounce homogenizer and sonicated for $20 \mathrm{~min}$. In this way, a stable suspension was obtained and immediately used to measure the phagocytic ability of AM after a 6-h exposure to carbon materials. The amount of materials used was expressed as $\mu \mathrm{g} \mathrm{cm}^{-2}$, because CNTs are characterized by a wide length distribution. As expected, the tested samples exhibited different cytotoxicity to AM. At low doses $\left(1.41 \mu \mathrm{g} \mathrm{cm}^{-2}\right)$ SWNTs showed a high cytotoxic effect, corresponding to above $20 \%$ inhibition of cell growth with a dosedependent trend. MWNTs and fullerene were instead much less toxic. One possible reason for such a major difference could be attributed to the purity level of SWNTs that was lower than the other samples. Indeed, residual amorphous carbon and trace amounts of metallic catalysts, such as Fe, Ni and Y, were present in SWNT samples. These impurities, even at a low level, can influence cell viability, so ultrapure material should be employed; in any case, human and environmental heath evaluations of different carbon nanomaterials must be considered individually. 


\subsubsection{Solvents}

Any kind of cell evaluation needs a medium to dissolve the sample. Physiological solutions, with the addition of nutritional elements, are the most appropriate, but sometimes the low solubility of the carbon material requires the use of polar, organic solvents. Manna and coworkers investigated the essential mechanism involved in the toxicity of SWNTs [249]. Human keratinocytes (HaCaT cells) were exposed to concentrations between 0.1 and $10 \mu \mathrm{g} \mathrm{mL}^{-1}$ of nanotubes, displaying increased cell death. This observation was attributed to the excess of oxidative stress within the cells and to the associated activation of transcription factor NF$\kappa \mathrm{B}$. However, DMF was used to dissolve the samples and might have induced some alterations of the results. In fact, DMF is a solvent known to be toxic and thus it should be avoided in cell manipulation.

\subsubsection{Surface of CNTs}

Until now, the size cut-off below which particles are surely toxic has not been demonstrated. However, there are at least two main reasons that render CNTs potentially harmful: (i) their large surface area and (ii) the reactivity or intrinsic toxicity of the surface $[250,251]$. The smaller the particles, the more toxic they become. This is due to the fact that there is more surface area per mass unit. As a consequence, any intrinsic toxicity of the surface will deeply influence the toxicological profile of the samples. For example, Sayes and Ausman investigated the effect on human fibroblasts (HDF) of some water-dispersible SWNTs [252]. It was found that cytotoxicity of compounds decreased significantly with the increased degree of functionalization on the surface. In addition, although a dose-response relationship of toxicity in the considered range of concentrations $\left(0.003-30 \mathrm{mg} \mathrm{mL}^{-1}\right)$ was observed, cell death did not exceed $50 \%$, apart from in one case in which $1 \%$ surfactant was employed. This could be justified by the fact that surfactant was coated on the surface of the nanotubes in a noncovalent, reversible way, whereas the functional groups were covalently bound and were not removed in the conditions of the biological tests.

\subsubsection{Length}

Another parameter that was found to influence the toxicity profile of CNTs is their length. Sato and coworkers separated MWNTs of 220 and $825 \mathrm{~nm}$ using controlled strong acid conditions [253]. During a short incubation time, clusters of both samples were shown to be surrounded by macrophages as a consequence of the activation of innate immunity. The shorter tubes displayed a lower inflammatory response. In both cases, no severe effects, such as necrosis or degeneration, were observed around CNTs throughout the experimental period of 4 weeks.

\subsection{2}

\section{In Vitro Effect of CNTs}

SWNTs were investigated to verify if they affected the immune system through the activation of complement [254]. For this purpose, SWNTs in concentrations be- 
tween 0.62 and $2.5 \mathrm{mg}$ were tested in rabbit red blood cells. They displayed a dosedependent potency in complement activation comparable to that of the known, potent activator zymosan. In particular, it seemed that such activation followed the classical pathway, but with high selectivity. This was confirmed by the demonstration of a direct binding of CNTs to the main complement subunit C1q. On the contrary, chemical modifications at the surface of CNTs reduced or even eliminated the complement activation, but further investigations are necessary to confirm this observation.

In a parallel study, SWNTs were evaluated in terms of their capacity to activate mouse spleen cells [255]. Since different cell types (monocytic leukemia THP-1 and spleen cells) and incubation times were employed, it was difficult to compare the obtained results. It has been confirmed that SWNTs induced an immune response, although the stimulating activity resulted to be lower than that of microbial systems.

The effect of functionalized, water-soluble CNTs on cell viability was also analyzed by Pantarotto and coworkers during the study of translocation of bioactive peptides across the cell membrane [190]. 3T6 and 3T3 fibroblasts were treated with 1-10 $\mu \mathrm{M}$ concentration of fluorescent SWNTs. The cytotoxicity was evaluated by flow cytometry, using the markers Annexin $\mathrm{V}$ and propidium iodide as indicators of apoptosis and necrosis, respectively. It was observed that below $5 \mu \mathrm{M}$ almost $90 \%$ of the cell population remained alive, indicating a nontoxic behavior of $f$ CNTs. Low toxicity was not only a characteristic of SWNTs functionalized with peptides. Both $f$-SWNTs and $f$-MWNTs, regardless of cell subtypes, are nontoxic on their own $[90,220]$. HeLa cells, incubated for several hours with about $1 \mathrm{mg} \mathrm{mL}^{-1}$ of CNTs mixed with plasmid DNA in different charge ratios, did not demonstrate signs of apoptosis [191]. In addition, $f$-CNTs complexed to different types of nucleic acids including plasmid DNA, RNA and oligodeoxynucleotides CpG sequences were not toxic for cells like breast cancer cells (MCF7) or splenocytes [204, 235, 237].

Apart from the investigation of the effect of CNTs on cells, it is also important to understand the mechanism involved in their interaction with biological systems. Cui and coworkers evaluated the activity of human embryo kidney cells (HEK293) during 5 days treatment with SWNTs in concentrations between 1 and $250 \mu \mathrm{g} \mathrm{mL}^{-1}$ [256]. It was found that SWNTs were able to inhibit the proliferation of HEK293, and to induce apoptosis in a dose- and time-dependent way. The most interesting finding was that cells actively responded to SWNTs, secreting a series of 20- to 30$\mathrm{kDa}$ proteins able to aggregate and wrap this unknown material, regardless of the uniformity of the starting samples. The possible mechanism for this phenomenon was attributed to a stimuli induced by SWNTs attached at the cell surface, followed by a downregulation of the genes responsible for adhesion. It was also envisaged that SWNTs could determine an upregulation of the genes associated with apoptosis and secretion of small proteins as protection for cells that were preserved from the contact with the tubes. This phenomenon presents a double advantage, since it allows us to investigate the rules at the basis of this interaction and, at the same 
time, it offers the possibility to consider these secreted proteins as potential targets in future medical therapy.

The same type of cells was also used to verify if bigger material, like MWNTs, was able to cross the external membrane and to affect the cell functions. It was shown that unmodified MWNTs were able to enter HEK293 cells and to induce the release of the pro-inflammatory cytokine IL-8 [257]. In addition, it was demonstrated that they were less toxic towards T lymphocytes than chemically functionalized tubes [258]. This was attributed to the fact that oxidized MWNTs were better dispersed in aqueous solution, determining higher weight/volume concentrations and, thus, a deeper impact on toxicity. At the dose of $400 \mu \mathrm{g} \mathrm{mL} \mathrm{m}^{-1}$, oxidized tubes killed more than $80 \%$ of cells in 5 days, while pristine MWNTs decreased the cell viability of less than $40 \%$. However, although it is obvious that CNTs toxicity does not depend only on concentration, the dose used in this study was very high and the same experiments with concentrations below $40 \mu \mathrm{g} \mathrm{mL} \mathrm{m}^{-1}$ did not affect the function of T cells [258].

\section{8 .3}

\section{In Vivo Effects of CNTs}

Apart from in vitro experiments, some CNTs were implanted at the subcutaneous level in rats to study their effects in vivo. Sato and coworkers demonstrated that coagulated MWNTs of $825 \mathrm{~nm}$ determined granulomas, since they were not easily phagocytosed by macrophages in comparison to MWNTs of $220 \mathrm{~nm}$ length [253].

MWNTs were also administrated intratracheally to rats to evaluate their respiratory toxicity due to their biopersistence in the lungs [259]. The results clearly showed that, once they reach the lung, MWNTs have the capacity to induce an overexpression of pro-inflammatory and profibrotic mediators. However, there might be some artifacts on the experimental strategy, since the method of administration presents several limitations, such as the formation of big aggregates that could remain entrapped in the airways. A different mode of administration (e.g. inhalation) and the real ability of these materials to translocate from the respiratory system to other organs would give more reliable data.

Other in vivo studies were conducted by Lam and coworkers [260] and Warheit and coworkers [261] to investigate the pulmonary toxicity of SWNTs in rodents. In particular, Lam and coworkers evaluated histopathological alterations in mice at 7 and 90 days after exposure to three differently manufactured SWNTs that contained varying amounts of residual catalytic metals: (i) raw nanotubes (RNT) and (ii) purified nanotubes (PNT), both iron-containing HiPCO products from Rice University, and (iii) CarboLex's Ni-containing electric-arc nanotubes (CNTs). Carbon black and quartz were employed as low and high pulmonary toxicity controls, respectively [260]. The experiments indicated that the three types of tubes induced dose-dependent lung lesions characterized by interstitial granulomas, regardless of the amount of metal impurities inside the samples. Even the product containing very low quantities ( $2 \%$ by weight) of iron produced granulomas, suggesting that 
CNTs themselves are toxic. However, the methods employed for this study were somehow ambiguous, since the suspension was obtained by briefly shearing and short sonication to avoid any alteration of the nature of SWNTs, but the instillation was performed through a plastic catheter placed in the trachea. Thus, further studies would be needed to elucidate the cause of death. However, it was clear that mice treated with $0.5 \mathrm{mg}$ of nanotubes showed the formation of granulomas, containing macrophages laden with black particles, few lymphocytes, neutrophils, eosinophils and other inflammatory cells. Interestingly, it was encouraging to observe that the lowest dose $(0.1 \mathrm{mg}$ per $30 \mathrm{~kg})$ determined no evident clinical signs. The same (5 mg kg-1), or even a lower $\left(1 \mathrm{mg} \mathrm{kg}^{-1}\right)$, amount of SWNTs was employed in the study of Warheit and coworkers, in which histopathological evaluation of lung tissue was conducted after $24 \mathrm{~h}, 1$ week and 3 months postinstillation [261]. In these experiments, SWNTs and graphite particles, together with the corresponding controls (carbonyl iron and quartz particles) were prepared in a volume of $1 \%$ Tween 80 surfactant and phosphate saline buffer subjected to polytron dispersion. Rats, intratracheally instilled with carbonyl iron or graphite, did not present adverse effects, while no dose-dependent multifocal granulomas where visible after exposure to SWNTs, even if they did not progress beyond 1 month. In $15 \%$ of the rats, the highest dose induced mortality, but the main reason for that was due to mechanical blockage of the upper airways and not to the inner toxicity of SWNTs particulate. The death index was somehow incorrect, because the nanotubes tended to form nanoropes instead of being individually dispersed. A proof was the observation that the surviving animals appeared normal through the whole 3 months. In addition, studies on chemotaxis concerning quartz treatment showed a reduced motility as a consequence of a deficiency in macrophages after 1 week. This phenomenon was not observed in the case of SWNTs, which differed from quartz also in the formation of granulomas in a non-dose-dependent manner.

Additional studies by Huczko and coworkers have contributed to understanding further the impact of nanomaterials on health. They tested the effect of fullerenes and CNTs on skin irritation and allergen risks $[262,263]$. There is only some evidence of contact dermatitis caused by exposure to carbon fibers [264, 265]. The authors applied two protocols that are commonly employed for testing skin irritation, i.e. a patch and a Draize rabbit eye test. In the first case, 40 people showing predisposition to irritation and allergy were treated with a patch of Whatman filter paper saturated with a water suspension of CNTs, and then they were examined for $96 \mathrm{~h}$. In the second method, four albino rabbits were administered with $0.2 \mathrm{~mL}$ of CNT aqueous suspension, and observed after 24, 48 and $72 \mathrm{~h}$. The absence of adverse effects seemed not to be dependent on the time of exposure nor on the type of material used, since there were no differences in comparison with the reference material (which did not contain CNTs). On the whole, the encouraging results in all experiments on skin irritation suggested that no specific precautions should be adopted while handling such nanomaterial [262, 263].

In general, the manufacturing of carbon nanomaterial is based on the use of transition metal catalysts. Therefore, the eventual health hazards are potentially connected with carbon and metals. In fact, free iron or nickel and transition metal 
complexes are known to produce reactive radicals, which could induce radical oxidation and enhance oxidative stress. In order to investigate this aspect, Shvedova and coworkers identified and quantified the reactive species that were produced during the manipulation and evaluated the effects of pristine SWNTs on human epidermal keratinocytes (HaCaT) [266]. SEM and TEM allowed us to verify that oxidative stress, caused by treatment with SWNTs, caused a change in the morphology of cells, besides altering surface integrity. These unwanted effects were reduced by the subsequent use of an iron chelator that displayed a protecting role towards HaCaT cells and, thus, confirmed that cytotoxicity of SWNTs was mainly correlated with iron catalytic effects.

A parallel study investigated the adverse effects recorded by aerosol release obtained through mechanical collisions of as-produced SWNTs with bronze beads [267]. The results were somehow ambiguous, since the production of ultrafine powders was not very efficient and it was not possible to discriminate if such particles were made up mainly of nanotubes or of catalyst. Moreover, although nanotubes tended to agglomerate into nanoropes, thus reducing the formation of an appreciable respirable aerosol, it was possible that such nanoparticles remained in the mouth and nasopharyngeal region, causing a potential health risk.

On the whole, CNTs have shown uncommon and interesting physicochemical properties, which increase their possible biomedical applications; however, at the same time, they might persist in biological systems and, consequently, be responsible for adverse health effects and environmental safety. It is imperative that a clear understanding of what really happens to nanoparticles months and years after their release in needed, since some encouraging evidence is not exhaustive in guaranteeing complete innocuous behavior. For all these very important reasons, further studies are required to investigate if CNTs can be widely used for their useful characteristics as well as if they safely represent a promising beginning of the so-called "next industrial revolution".

\section{9}

\section{General Conclusions}

Although still debatable, the use of CNTs in drug delivery and biosensing is acquiring more and more substantiating evidence for efficient development. It is clear that many important issues have to be faced before CNTs can be proposed for clinical trials. However, CNTs show unusual carrier properties, with a very strong tendency to pass cell membranes and seem to perfectly fit into the new discipline of nanobiotechnology. Although the first toxicological reports on pristine CNTs were very discouraging, labeling CNTs as very dangerous species, it is becoming widely accepted that $f$-CNTs are by far less toxic than non- $f$-CNTs. Therefore, the combination of penetration ability with high loading achievable with CNTs makes these new carbon species promising candidates for innovative therapies. Another aspect that should not be disregarded is that other functions can be introduced on CNTs by using different functionalization methods. 
In conclusion, we do hope that, in a few years, $f$-CNTs will be considered as valuable building blocks for pharmaceutical uses.

\section{Acknowledgments}

The authors are deeply indebted to all their coworkers who have partly contributed to the development of the research described in this chapter and whose names are cited in the references. This work has been supported by the CNRS, MRNT (GenHomme 2003), University of Trieste and MIUR (PRIN 2004, prot. 2004035502). G. P. and W. W. are recipients of a fellowship from MNRT. C. K. is grateful to the Università Italo-Francese/Université Franco-Italienne (VINCI Programme 2003) for financing his international PhD.

\section{References}

1 Allen, T. M., Cullis, P. R. Drug delivery systems: entering the mainstream, Science 2004, 303, 1818-1822.

2 Kostarelos, K. Rational design and engineering of delivery systems for therapeutics: biomedical exercises in colloid and surface science, Adv. Colloid Interface Sci. 2003, 106, 147-168.

3 Merdan, T., Kopecek, J., Kissel, T. Prospects for cationic polymers in gene and oligonucleotide therapy against cancer, Adv. Drug Deliv. Rev. 2002, 54, 715-758.

4 Bianco, A., Kostarelos, K., Partidos, C. D., Prato, M. Biomedical applications of functionalised carbon nanotubes, Chem. Commun. 2005, 571-577.

5 Lin, Y., Taylor, S., Li, H., Fernando, K. A., Qu, L., WANG, W., Gu, L., Zhou, B., Sun, Y. P. Advances toward bioapplications of carbon nanotubes, J. Mater. Chem. 2004, 14, 527-541.

6 Kostarelos, K., Lacerda, L., Partidos, C. D., Prato, M., Bianco, A. Carbon nanotube-mediated delivery of peptides and genes to cells: translating nanobiotechnology to therapeutics, J. Drug Deliv. Sci. Technol. 2005, 15, 41-47.

7 Bianco, A., Hoebeke, J., Kostarelos, K., Prato, M., Partidos, C. D. Carbon nanotubes: on the road to deliver, Curr. Drug Deliv. 2005, 2, 253-259.

8 Pastorin, G., Kostarelos, K., Prato, M., Bianco, A. Functionalized carbon nanotubes: towards the delivery of therapeutic molecules, J. Biomed. Nanotechnol. 2005, 1, 133-142.

9 Katz, E., Willner, I. Biomoleculefunctionalized carbon nanotubes: applications in nanobioelectronics, ChemPhysChem 2004, 5, 1084-1104.

10 Fortina, P., Kricka, L. J., Surrey, S., Grodzinski, P. Nanobiotechnology: the promise and reality of new approaches to molecular recognition, Trends Biotechnol. 2005, 23, 168-173.

11 Yu, M.-F., Files, B. S., Arepalli, S., Ruoff, R. S. Tensile loading of ropes of single wall carbon nanotubes and their mechanical properties, Phys. Rev. Lett. 2000, 84, 5552-5555.

12 Saito, R., Dresselhaus, G., Dresselhaus, M. S. Physical Properties of Carbon Nanotubes. Imperial College Press, London, 1998.

13 Saito, R., Fujita, M., Dresselhaus, G., Dresselhaus, M. S. Electronic structure of chiral graphene tubules, Appl. Phys. Lett. 1992, 60, 2204-2206.

14 Saito, R., Fujita, M., Dresselhaus, G., Dresselhaus, M. S. Electronic structure of graphene tubules based on $\mathrm{C}_{60}$, Phys. Rev. B 1992, 46, 1804-1811. 
15 Hamada, N., Sawada, S., Oshiyama, A. New one-dimensional conductors: graphitic microtubules, Phys. Rev. Lett. 1992, 68, 1579-1581.

16 Kaiser, A. B., Düsberg, G., Roth, S. Heterogeneous model for conduction in carbon nanotubes, Phys. Rev. B 1998, 57, 1418-1421.

17 Dresselhaus, M. S., Dressellaus, G., Eklund, P. C. Science of Fullerenes and Carbon Nanotubes. Academic Press, New York, 1996.

18 IıjıмA, S. Carbon nanotubes: past, present, and future, Physica B 2002, 323, 1-5.

19 Journet, C., Maser, W. K., Bernier, P., Loiseau, A., Lamy de la Chapelle, M., Lefrant, A., Denard, P., Lee, R., Fischer, J. E. Large-scale production of single-walled carbon nanotubes by the electric-arc technique, Nature 1997, 388, 756-758.

20 Rinzler, A. G., Liu, J., Dai, H., Nikolaev, P., Huffman, C. B., Rodriguez-Macias, F. J., Boul, P. J., Lu, A. H., Heymann, D., Colbert, D. T., Lee, R. S., Fischer, J. E., Rao, A. M., Eklund, P. C., Smalley, R. E. Large-scale purification of single-wall carbon nanotubes: process, product, and characterization, Appl. Phys. A 1998, 67, 29-37.

21 Endo, M., Takeuchi, K., Kobori, K., Takahashi, K., Kroto, H. W., SARKAR, A. Pyrolytic carbon nanotubes from vapor-grown carbon fibers, Carbon 1995, 33, 873-881.

22 Nikolaev, P., Bronikowski, M., Bradley, R. K., Rohmund, F., Colbert, D. T., Smith, K., Smalley, R. E. Gas-phase catalytic growth of single-walled carbon nanotubes from carbon monoxide, Chem. Phys. Lett. 1999, 313, 91-97.

23 Ajayan, P. M. Nanotubes from carbon, Chem. Rev. 1999, 99, 1787-1799.

24 Xie, S. S., Chang, B. H., Li, W. Z., Pan, Z. W., Sun, L. F., MaO, J. M., Chen, X. H., Qian, L. X., Zhou, W. Y. Synthesis and characterization of aligned carbon nanotube arrays, Adv. Mater. 1999, 11, 11351138.
25 Dai, L., Mau, A. W. H. Controlled synthesis and modification of carbon nanotubes and $\mathrm{C}_{60}$ : carbon nanostructures for advanced polymeric composite materials, Adv. Mater. 2001, 13, 899-913.

26 Rao, C. N. R., Satishiumar, B. C., Govindaraj, A., Nath, M. Nanotubes, ChemPhysChem 2001, 2, 78-105.

27 Bahr, J. L., Mickelson, E. T., Bronikowski, M. J., Smalley, R. E., Tour, J. M. Dissolution of small diameter single-wall carbon nanotubes in organic solvents?, Chem. Commun. 2001, 193-194.

28 Liu, J., Rinzler, A. G., Dai, H., Hafner, J. H., Bradley, R. K., Boul, P. J., Lu, A., Iverson, T., Shelimov, K., Huffman, C. B., RodriguezMacias, F., Shon, Y.-S., Lee, T. R., Colbert, D. T., Smalley, R. E. Fullerene pipes, Science 1998, 280, 1253-1256.

29 Bandow, S., Rao, A. M., Williams, K. A., Thess, A., Smalley, R. E., Eklund, P. C. Purification of singlewall carbon nanotubes by microfiltration, J. Phys. Chem. B 1997, 101, 8839-8842.

30 Duesberg, G. S., Burghard, M., Muster, J., Philipp, G., Roth, S. Separation of carbon nanotubes by size exclusion chromatography, Chem. Commun. 1998, 435-436.

31 Holzinger, M., Hirsch, A., Bernier, P., Duesberg, G. S., Burghard, M. A new purification method for singlewall carbon nanotubes (SWNTs), Appl. Phys. A 2000, 70, 599-602.

32 Martinez, M., Callejas, M., Benito, A. M., Maser, W. K., Cochet, M., Andres, J. M., Schreiber, J., Chauvet, O., Fierro, J. L. G. Microwave single walled carbon nanotubes purification, Chem. Commun. 2002, 1000-1001.

33 Vazquez, E., Georgakilas, V., Prato, M. Microwave-assisted purification of HIPCO carbon nanotubes, Chem. Commun. 2002, 2308-2309.

34 Harutyunyan, A. R., Pradhan, B. K., Chang, J., Chen, G., Eklund, P. C. Purification of single-wall carbon nanotubes by selective microwave 
heating of catalyst particles, J. Phys.

Chem. B 2002, 106, 8671-8675.

35 Chen, R. J., Zhang, Y., Wang, D., DAI, H. Noncovalent sidewall functionalization of single-walled carbon nanotubes for protein immobilization, J. Am. Chem. Soc. 2001, 123, 3838-3839.

36 Besteman, K., Lee, J.-O., Wiertz, F. G. M., Heering, H. A., Dekker, C. Enzyme-coated carbon nanotubes as single-molecule biosensors, Nano Lett. 2003, 3, 727-730.

37 Xin, H., Woolley, A. T. DNAtemplated nanotube localization, J. Am. Chem. Soc. 2003, 125, 8710-8711.

38 Taft, B. J., Lazareck, A. D., Withey, G. D., Yin, A., Xu, J. M., Kelley, S. O. Site-specific assembly of DNA and appended cargo on arrayed carbon nanotubes, J. Am. Chem. Soc. 2004, 126, 12750-12751.

39 Liu, L., Wang, T., Li, J., Guo, Z., Dai, L., ZHANG, D., ZHU, D. Self-assembly of gold nanoparticles to carbon nanotubes using a thiol-terminated pyrene as interlinker, Chem. Phys. Lett. 2003, 367, 747-752.

40 Cao, L., Chen, H., Wang, M., Sun, J., Zhang, X., Kong, F. Photoconductivity study of modified carbon nanotube/oxotitanium phthalocyanine composites, J. Phys. Chem. B 2002 , 106, 8971-8975.

41 Wang, X., Liu, Y., Qiu, W., Zhu, D. Immobilization of tetra-tertbutylphthalocyanines on carbon nanotubes: a first step towards the development of new nanomaterials, J. Mater. Chem. 2002, 12, 1636-1639.

42 Cao, L., Chen, H.-Z., Zhou, H.-B., Zhu, L., Sun, J.-Z., Zhang, X.-B., Xu, J.-M., WANG, M. Carbon-nanotubetemplated assembly of rare-earth phthalocyanine nanowires, Adv. Mater. 2003, 15, 909-913.

43 Guldi, D. M., Rahman, G. N. A., Ramey, J., Marcaccio, M., Paolucci, D., Paolucci, F., Qin, S., Ford, W. T., Balbinot, D., Jux, N., Tagmatarchis, N., Prato, M. Donor-acceptor nanoensembles of soluble carbon nanotubes, Chem. Commun. 2004, 2034-2035.
44 Guldi, D. M., Rahman, G. M. A., Prato, M., Jux, N., Qin, S., Ford, W. Single-wall carbon nanotubes as integrative building blocks for solarenergy conversion, Angew. Chem. Int. Ed. 2005, 44, 2015-2018.

45 Murakami, H., Nomura, T., NAKashima, N. Noncovalent porphyrin-functionalized single-walled carbon nanotubes in solution and the formation of porphyrin-nanotube nanocomposites, Chem. Phys. Lett. 2003, 378, 481-485.

46 Li, H., Zhou, B., Lin, Y., Gu, L., WANG, W., Fernando, K. A. S., Kumar, S., Allard, L. F., Sun, Y.-P. Selective interactions of porphyrins with semiconducting single-walled carbon nanotubes, J. Am. Chem. Soc. 2004, 126, 1014-1015.

47 Chen, J., Collier, C. P. Noncovalent functionalization of single-walled carbon nanotubes with water-soluble porphyrins, J. Phys. Chem. B 2005, 109, 7605-7609.

48 Satake, A., Miyajima, Y., Kobuke, Y. Porphyrin-carbon nanotube composites formed by noncovalent polymer wrapping, Chem. Mater. 2005, 17, 716-724.

49 Guldi, D. M., Rahman, G. M. A., Jux, N., Tagmatarchis, N., Prato, M. Integrating single-wall carbon nanotubes into donor-acceptor nanohybrids, Angew. Chem. Int. Ed. 2004, 43, 5526-5530.

50 Guldi, D. M., Rahman, G. M. A., Jux, N., Balbinot, D., Tagmatarchis, N., Prato, M. Multiwalled carbon nanotubes in donor-acceptor nanohybrids - towards long-lived electron transfer products, Chem. Commun. 2005, 2038-2040.

51 Guldi, D. M., Taieb, H., Rahman, G. M. A., Tagmatarchis, N., Prato, M. Novel photoactive single-walled carbon nanotube-porphyrin polymer wraps: efficient and long-lived intracomplex charge separation, $A d v$. Mater. 2005, 17, 871-875.

52 Guldi, D. M., Rahman, G. M. A., Jux, N., Balbinot, D., Hartnagel, U., Tagmatarchis, N., Prato, M. Functional single-wall carbon 
nanotube nanohybrids-associating SWNTs with water-soluble enzyme model systems, J. Am. Chem. Soc. 2005, 127, 9830-9838.

53 Chichak, K. S., Star, A., Altoe, M. V. P., Stoddart, J. F. Single-walled carbon nanotubes under the influence of dynamic coordination and supramolecular chemistry, Small 2005, 1, 452-461.

54 TANG, B. Z., Xu, H. Preparation, alignment, and optical properties of soluble poly(phenylacetylene)-wrapped carbon nanotubes, Macromolecules 1999, 32, 2569-2576.

55 Romero, D. B., Carrard, M., de Heer, W., Zuppiroli, L. A carbon nanotube/organic semiconducting polymer heterojunction, Adv. Mater. 1996, 8, 899-902.

56 Ago, H., Petritsch, K., Shaffer, M. S. P., Windle, A. H., Friend, R. H. Composites of carbon nanotubes and conjugated polymers for photovoltaic devices, Adv. Mater. 1999, 11, 1281-1285.

57 Ago, H., Shaffer, M. S. P., Ginger, D. S., Windle, A. H., Friend, R. H. Electronic interaction between photoexcited poly ( $p$-phenylene vinylene) and carbon nanotubes, Phys. Rev. B 2000, 61, 2286-2290.

58 Wery, J., Aarab, H., Lefrant, S., Faulques, E., Mulazzi, E., Perego, R. Photoexcitations in composites of poly(paraphenylene vinylene) and single-walled carbon nanotubes, Phys. Rev. B 2003, 67, 115202 (1-6).

59 Fournet, P., Coleman, J. N., Lahr, B., Drury, A., Blau, W. J., O’Brien, D. F., Horhold, H. H. Enhanced brightness in organic light-emitting diodes using a carbon nanotube composite as an electron-transport layer, J. Appl. Phys. 2001, 90, 969-975.

60 Fournet, P., O'Brien, D. F., Coleman, J. N., Horhold, H. H., Blau, W. J. A carbon nanotube composite as an electron transport layer for M3EH-PPV based lightemitting diodes, Synth. Met. 2001, 121, 1683-1684.

61 Dalton, A. B., Stephan, C., Coleman, J. N., McCarthy, B.,
Ajayan, P. M., Lefrant, S., Bernier, P., Blau, W. J., Byrne, H. J. Selective interaction of a semiconjugated organic polymer with single-wall nanotubes, J. Phys. Chem. B 2000, 104, 10012-10016.

62 Coleman, J. N., Dalton, A. B., Curran, S., Rubio, A., Davey, A. P., Drury, A., McCarthy, B., Lahr, B., Ajayan, P. M., Roth, S., Barklie, R. C., Blau, W. J. Phase separation of carbon nanotubes and turbostratic graphite using a functional organic polymer, Adv. Mater. 2000, 12, 213-216.

63 Star, A., Lu, Y., Bradley, K., Gruner, G. Nanotube optoelectronic memory devices, Nano Lett. 2004, 4, 1587-1591.

64 Murphy, R., Coleman, J. N., Cadek, M., McCarthy, B., Bent, M., Drury, A., Barklie, R. C., Blau, W. J. Highyield, nondestructive purification and quantification method for multiwalled carbon nanotubes, J. Phys. Chem. B. 2002, 106, 3087-3091.

65 Coleman, J. N., O’Brien, D. F., Dalton, A. B., McCarthy, B., Lahr, B., Barklie, R. C., Blau, W. J. Electron paramagnetic resonance as a quantitative tool for the study of multiwalled carbon nanotubes, J. Chem. Phys. 2000, 113, 9788-9793.

66 Star, A., Stoddart, J. F., Steuerman, D., Diehl, M., Boukai, A., Wong, E. W., YAng, X., Chung, S. W., Choi, H., Heath, J. R. Preparation and properties of polymer-wrapped singlewalled carbon nanotubes, Angew. Chem. Int. Ed. 2001, 40, 1721-1725.

67 Steuerman, D. W., Star, A., Narizzano, R., Choi, H., Ries, R. S., Nicolini, C., Stoddart, J. F., Heath, J. R. Interactions between conjugated polymers and single-walled carbon nanotubes, J. Phys. Chem. B 2002, 106, 3124-3130.

68 Star, A., Stoddart, J. F. Dispersion and solubilization of single-walled carbon nanotubes with a hyperbranched polymer, Macromolecules 2002, 35, 7516-7520.

69 Musa, I., Baxendale, M., AmaraTunga, G. A. J., Eccleston, W. 
Properties of regioregular poly(3octylthiophene)/multi-wall carbon nanotube composites, Synth. Met. 1999, 102, 1250.

70 Alexandrou, I., Kymakis, E., Amaratunga, G. A. J. Polymernanotube composites: burying nanotubes improves their field emission properties, Appl. Phys. Lett. 2002, 80, 1435-1437.

71 Valentini, L., Armentano, I., Biagiotti, J., Frulloni, E., Kenny, J. M., Santucci, S. Frequency dependent electrical transport between conjugated polymer and single-walled carbon nanotubes, Diam. Rel. Mater. 2003, 12, 1601-1609.

72 Kymakis, E., Amaratunga, G. A. J. Single-wall carbon nanotube/ conjugated polymer photovoltaic devices, Appl. Phys. Lett. 2002, 80, 112-114.

73 Kymakis, E., Alexandrou, I., Amaratunga, G. A. J. High opencircuit voltage photovoltaic devices from carbon-nanotube-polymer composites, J. Appl. Phys. 2003, 93, 1764-1768.

74 Bhattacharyya, S., Kymakis, E., Amaratunga, G. A. J. Photovoltaic properties of dye functionalized single-wall carbon nanotube/ conjugated polymer devices, Chem. Mater. 2004, 16, 4819-4823.

75 Landi, B. J., Raffaelle, R. P., Castro, S. L., Bailey, S. G. Single-wall carbon nanotube-polymer solar cells, Prog. Photovolt. Res. Appl. 2005, 13, 165-172.

76 O'Connell, M. J., Boul, P., Ericson, L. M., Huffman, C., WanG, Y., Haroz, E., Kuper, C., Tour, J. M., Ausman, K. D., Smalley, R. E. Reversible water-solubilization of single-walled carbon nanotubes by polymer wrapping, Chem. Phys. Lett. 2001, 342, 265-271.

77 Islam, M. F., Rojas, E., Bergey, D. M., Johnson, A. T., Yodh, A. G. High weight fraction surfactant solubilization of single-wall carbon nanotubes in water, Nano Lett. 2003, 3, 269-273.

78 Richard, C., Balavoine, F., Schultz, P., Ebbesen, T. W., Mioskowski, C. Supramolecular self-assembly of lipid derivatives on carbon nanotubes, Science 2003, 300, 775-778.

79 O'Connell, M. J., Bachilo, S. M., Huffman, C. B., Moore, V. C., Strano, M. S., Haroz, E. H., Rialon, K. L., Boul, P. J., Noon, W. H., Kittrell, C., Ma, J., Hauge, R. H., Weisman, R. B., Smalley, R. E. Band gap fluorescence from individual single-walled carbon nanotubes, Science 2002, 297, 593-596.

80 Moore, V. C., Strano, M. S., Haroz, E. H., Hauge, R. H., Smalley, R. E. Individually suspended single-walled carbon nanotubes in various surfactants, Nano Lett. 2003, 3, 1379-1382.

81 Wenseleers, W., Vlasov, I. I., Goovaerts, E., Obraztsova, E. D., LoBACH, A. S., Bouwen, A. Efficient isolation and solubilization of pristine single-walled nanotubes in bile salt micelles, Adv. Funct. Mater. 2004, 14, 1105-1112.

82 Bachilo, S. M., Strano, M. S., Kittrell, C., Hauge, R. H., Smalley, R. E., Weisman, R. B. Structureassigned optical spectra of singlewalled carbon nanotubes, Science 2002, 298, 2361-2366.

83 Hagen, A., Hertel, T. Quantitative analysis of optical spectra from individual single-wall carbon nanotubes, Nano Lett. 2003, 3 , 383-388.

84 Strano, M. S., Doorn, S. K., Haroz, E. H., Kittrell, C., Hauge, R. H., Smalley, R. E. Assignment of $(n, m)$ Raman and optical features of metallic single-walled carbon nanotubes, Nano Lett. 2003, 3, 1091-1096.

85 Weisman, R. B., Bachilo, S. M. Dependence of optical transition energies on structure for singlewalled carbon nanotubes in aqueous suspension: an empirical Kataura plot, Nano Lett. 2003, 3, 1235-1238.

86 Dyкe, C. A., Tour, J. M. Unbundled and highly functionalized carbon nanotubes from aqueous reactions, Nano Lett. 2003, 3, 1215-1218.

87 Dieckmann, G. R., Dalton, A. B., Johnson, P. A., Razal, J., Chen, J., Giordano, G. M., MuŇoz, E., 
Musselman, I. H., Baughman, R. H., Draper, R. K. Controlled assembly of carbon nanotubes by designed amphiphilic peptide helices, J. Am. Chem. Soc. 2003, 125, 1770-1777.

88 Zorbas, V., Ortiz-Acevedo, A., Dalton, A. B., Yoshida, M. M., Dieckmann, G. R., Draper, R. K., Baughman, R. H., Jose-Yacaman, M., Musselman, I. H. Preparation and characterization of individual peptidewrapped single-walled carbon nanotubes, J. Am. Chem. Soc. 2004, 126, 7222-7227.

89 Zorbas, V., Smith, A. L., Xie, H., Ortiz-Acevedo, A., Dalton, A. B., Dieckmann, G. R., Draper, R. K., Baughman, R. H., Musselman, I. H. Importance of aromatic content for peptide/single-walled carbon nanotube interactions, J. Am. Chem. Soc. 2005, 127, 12323-12328.

90 KAM, N. W. S., DAI, H. Carbon nanotubes as intracellular protein transporters: generality and biological functionality, J. Am. Chem. Soc. 2005, 127, 6021-6026.

91 Zheng, M., Jagota, A., Semke, E. D., Diner, B. A., Mclean, R. S., Lustig, S. R., Richardson, R. E., Tassi, N. G. DNA-assisted dispersion and separation of carbon nanotubes, Nat. Mater. 2003, 2, 338-342.

92 Zheng, M., Jagota, A., Strano, M. S., Santos, A. P., Barone, P., Chou, S. G., Diner, B. A., Dresselhaus, M. S., Mclean, R. S., Onoa, G. B., Samsonidze, G. G., Semke, E. D., Usrey, M., Walls, D. J. Structurebased carbon nanotube sorting by sequence-dependent DNA assembly, Science 2003, 302, 1545-1548.

93 Kam, N. W. S., Liu, Z., Dai, H. Functionalization of carbon nanotubes via cleavable disulfide bonds for efficient intracellular delivery of siRNA and potent gene silencing, J. Am. Chem. Soc. 2005, 127, 12492-12493.

$94 \mathrm{HiRsCH}$, A. Functionalization of single-walled carbon nanotubes, Angew. Chem. Int. Ed. 2002, 41, 1853-1859.

95 Banerjee, S., Hemraj-Benny, T., Wong, S. S. Covalent surface chemistry of single-walled carbon nanotubes, Adv. Mater. 2005, 17, 17-29.

96 Hamon, M. A., Chen, J., Hu, H., Chen, Y., Itkis, M. E., Rao, A. M., Eklund, P. C., Haddon, R. C. Dissolution of single-walled carbon nanotubes, Adv. Mater. 1999, 11, 834-840.

97 Kunovecz, A., Kramberger, C., Holzinger, M., Kuzmany, H., Schalko, J., Mannsberger, M., Hirsch, A. On the stacking behavior of functionalized single-wall carbon nanotubes, J. Phys. Chem. B 2002, 106, 6374-6380.

98 Chen, J., Rao, A. M., Lyuksyutov, S., Itkis, M. E., Hamon, M. A., Hu, H., Cohn, R. W., Eklund, P. C., Colbert, D. T., Smalley, R. E., HAdDon, R. C. Dissolution of fulllength single-walled carbon nanotubes, J. Phys. Chem. B 2001, 105, 2525-2528.

99 Niyogi, S., Hamon, M. A., Hu, H., Zhao, B., Bhowmik, P., Sen, R., ItKis, M. E., Haddon, R. C. Chemistry of single-walled carbon nanotubes, Acc. Chem. Res. 2002, 35, 1105-1113.

100 Hiura, H., Ebbesen, T. W., Tanigaki, $\mathrm{K}$. Opening and purification of carbon nanotubes in high yields, Adv. Mater. 1995, 7, 275-276.

101 Ajayan, P. M., Ebbesen, T. W., Ichihashi, T., Iijima, S., Tanigaki, K., Hiura, H. Capillarity-induced filling of carbon nanotubes, Nature 1993, 361, 333-334.

102 Chen, J., Hamon, M. A., Hu, H., Chen, Y., Rao, A. M., Eklund, P. C., HADDON, R. C. Solution properties of single-walled carbon nanotubes, Science 1998, 282, 95-98.

103 Lago, R. M., Tsang, S. C., Lu, K. L., Chen, Y. K., Green, M. L. H. Filling carbon nanotubes with small palladium metal crystallites: the effect of surface acid groups, Chem. Commun. 1995, 1355-1356.

104 Lu, K. L., Lago, R. M., Chen, Y. K., Green, M. L. H., Harris, P. J. F., TsANG, S. C. Mechanical damage of carbon nanotubes by ultrasound, Carbon 1996, 34, 814-816. 
105 Monthioux, M., Smith, B. W., Burteaux, B., Claye, A., Fischer, J. E., Luzzi, D. E. Sensitivity of singlewall carbon nanotubes to chemical processing: an electron microscopy investigation, Carbon 2001, 39, 1251-1272.

106 Koshio, A., Yudasaka, M., Zhang, M., Irjima, S. A simple way to chemically react single-wall carbon nanotubes with organic materials using ultrasonication, Nano Lett. 2001, 1, 361-363.

107 Qin, Y., Shi, J., Wu, W., Li, X., Guo, Z., ZHu, D. Concise route to functionalized carbon nanotubes, J. Phys. Chem. B 2003, 107, 12899-12901.

108 Chen, Y., Haddon, R. C., Fang, S., Rao, A. M., Eklund, P. C., Lee, W. H., Dickey, E. C., Grulke, E. A., Pendergrass, J. C., Chavan, A., Haley, B. E., Smalley, R. E. Chemical attachment of organic functional groups to single-walled carbon nanotube material, J. Mater. Res. 1998, 13, 2423-2431.

109 Sun, Y.-P., Huang, W., Lin, Y., Fu, K., Kitaygorodskiy, A., Riddle, L. A., Yu, Y. J., Carroll, D. L. Soluble dendron-functionalized carbon nanotubes: preparation, characterization, and properties, Chem. Mater. 2001, 13, 2864-2869.

110 Fu, K., Huang, W., Lin, Y., Riddle, L. A., Carroll, D. L., Sun, Y.-P. Defunctionalization of functionalized carbon nanotubes, Nano Lett. 2001, 1 , 439-441.

111 Sun, Y.-P., Fu, K., Lin, Y., Huang, W. Functionalized carbon nanotubes: properties and applications, Acc. Chem. Res. 2002, 35, 1096-1104.

112 Kong, H., GaO, C., Yan, D. Controlled functionalization of multiwalled carbon nanotubes by in situ atom transfer radical polymerization, J. Am. Chem. Soc. 2004, 126, 412413.

113 Qin, S., Qin, D., Ford, W. T., Resasco, D. E., Herrera, J. E. Polymer brushes on single-walled carbon nanotubes by atom transfer radical polymerization of $n$-butyl methacrylate, J. Am. Chem. Soc. 2004, 126, 170-176.

114 Huang, W., Taylor, S., Fu, K., Lin, Y., Zhang, D., Hanks, T. W., Rao, A. M., Sun, Y.-P. Attaching proteins to carbon nanotubes via diimideactivated amidation, Nano Lett. 2002 , 2, 311-314.

115 Kam, N. W. S., Jessop, T. C., Wender, P. A., DAI, H. Nanotube molecular transporters: internalization of carbon nanotube-protein conjugates into mammalian cells, J. Am. Chem. Soc. 2004, 126, 6850-6851.

116 Yim, T., Liu, J., Lu, Y., Kane, R. S., Dordick, J. S. Highly active and stable DNAzyme-carbon nanotube hybrids, J. Am. Chem. Soc. 2005, 127, 12200-12201.

117 Baker, S. E., Cai, W., Lasseter, T. L., Weidkamp, K. P., Hamers, R. J. Covalently bonded adducts of deoxyribonucleic acid (DNA) oligonucleotides with single-wall carbon nanotubes: synthesis and hybridization, Nano Lett. 2002, 2, 1413-1417.

118 Hazani, M., NaAman, R., Hennrich, F., Kappes, M. M. Confocal fluorescence imaging of DNA-functionalized carbon nanotubes, Nano Lett. 2003, 3, 153-155.

119 Williams, K. A., Veenhuizen, P. T. M., De la Torre, B. G., Eritja, R., DekKer, C. Nanotechnology: carbon nanotubes with DNA recognition, Nature 2002, 420, 761.

120 Tasis, D., Tagmatarchis, N., Bianco, A., Prato, M. Chemistry of carbon nanotubes, Chem. Rev. 2006, 106, 1105-1136.

121 Jorio, A., Dresselhaus, G., Dresselhaus, M. S., Souza, M., Dantas, M. S. S., Pimenta, M. A., Rao, A. M., Saito, R., Liu, C., Cheng, H. M. Polarized Raman study of single-wall semiconducting carbon nanotubes, Phys. Rev. Lett. 2000, 85, 2617-2620.

122 Holden, J. M., Zhou, P., Bi, X., Eklund, P. C., Bandow, S., Jishi, R. A., Chowdhury, K. D., Dresselhaus, G., Dresselhaus, M. S. Raman scattering from nanoscale carbons 
generated in a cobalt-catalyzed carbon plasma, Chem. Phys. Lett. 1994, 220, 186-191.

123 Bahr, J. L., Tour, J. M. Covalent chemistry of single-wall carbon nanotubes, J. Mater. Chem. 2002, 12, 1952-1958.

124 Mickelson, E. T., Huffman, C. B., Rinzler, A. G., Smalley, R. E., Hauge, R. H., Margrave, J. L. Fluorination of single-wall carbon nanotubes, Chem. Phys. Lett. 1998, 296, 188-194.

125 Mickelson, E. T., Chiang, I. W., Zimmerman, J. L., Boul, P. J., Lozano, J., Liu, J., Smalley, R. E., Hauge, R. H., Margrave, J. L. Solvation of fluorinated single-wall carbon nanotubes in alcohol solvents, J. Phys. Chem. B 1999, 103, 4318-4322.

126 Boul, P. J., Liu, J., Mickelson, E. T., Huffman, C. B., Ericson, L. M., Chiang, I. W., Smith, K. A., Colbert, D. T., Hauge, R. H., Margrave, J. L., Smalley, R. E. Reversible sidewall functionalization of buckytubes, Chem. Phys. Lett. 1999, 310, 367-372.

127 Khabashesku, V. N., Billups, W. E., Margrave, J. L. Fluorination of single-wall carbon nanotubes and subsequent derivatization reactions, Acc. Chem. Res. 2002, 35, 1087-1095.

128 Holzinger, M., Vostrowsky, O., Hirsch, A., Hennrich, F., Kappes, M., Weiss, R., Jellen, F. Sidewall functionalization of carbon nanotubes, Angew. Chem. Int. Ed. Engl. 2001, 40, 4002-4005.

129 Bahr, J. L., Yang, J., Kosynkin, D. V., Broniskowski, M. J., Smalley, R. E., Tour, J. M. Functionalization of carbon nanotubes by electrochemical reduction of aryl diazonium salts: a bucky paper electrode, J. Am. Chem. Soc. 2001, 123, 6536-6542.

130 Bahr, J. L., Tour, J. M. Highly functionalized carbon nanotubes using in situ generated diazonium compounds, Chem. Mater. 2001, 13, 3823-3824.

131 Dyкe, C. A., Tour, J. M. Solvent-free functionalization of carbon nanotubes,
J. Am. Chem. Soc. 2003, 125,

1156-1157.

132 Ying, Y., Saini, R. K., Liang, F., Sadana, A. K., Billups, W. E.

Functionalization of carbon nanotubes by free radicals, Org. Lett. 2003, 5, 1471-1473.

133 Peng, H., Reverdy, P., Khabashesku, V. N., Margrave, J. L. Sidewall functionalization of single-walled carbon nanotubes with organic peroxides, Chem. Comm. 2003, 362-363.

134 Strano, M. S., Dyke, C. A., Usrey, M. L., Barone, P. W., Allen, M. J., Shan, H., Kittrell, C., Hauge, R. H., Tour, J. M., Smalley, R. E. Electronic structure control of single-walled carbon nanotube functionalization, Science 2003, 301, 1519-1522.

135 Hamon, M. A., Itkis, M. E., Niyogi, S., Alvaraez, T., Kuper, C., Menon, M., Haddon, R. C. Effect of rehybridization on the electronic structure of single-walled carbon nanotubes, J. Am. Chem. Soc. 2001, 123, 11292-11293.

136 Viswanathan, G., Chakrapani, N., YANG, H., Wei, B., Chung, H., Cho, K., Ryu, C. Y., Ajayan, P. M. Singlestep in situ synthesis of polymergrafted single-wall nanotube composites, J. Am. Chem. Soc. 2003, 125, 9258-9259.

137 Wu, W., Zhang, S., Li, Y., Li, J., Lu, L., Qin, Y., Guo, Z., DAI, L., Ye, C., ZHu, D. PVK-modified single-walled carbon nanotubes with effective photoinduced electron transfer, Macromolecules 2003, 36, 6286-6288.

138 Pekker, S., Salvetat, J.-P., Jakab, E., Bonard, J.-M., Forro, L. Hydrogenation of carbon nanotubes and graphite in liquid ammonia, J. Phys. Chem. B 2001, 105, 7938-7943.

139 Tagmatarchis, N., Georgakilas, V., Prato, M., Shinohara, H. Sidewall functionalization of single-walled carbon nanotubes through electrophilic addition, Chem. Commun. 2002, 2010-2011.

140 Coleman, K. S., Bailey, S. R., Fogden, S., Green, M. L. H. Functionalization of single-walled 
carbon nanotubes via the Bingel reaction, J. Am. Chem. Soc. 2003, 125 , 8722-8723.

141 Worsley, K. A., Moonoosawmy, K. R., KRUSE, P. Long-range periodicity in carbon nanotube sidewall functionalization, Nano Lett. 2004, 4, 1541-1546.

142 Moghaddam, M. J., Taylor, S., Gao, M., Huang, S., Dai, L., McCall, M. J. Highly efficient binding of DNA on the sidewalls and tips of carbon nanotubes using photochemistry, Nano Lett. 2004, 4, 89-93.

143 Georgakilas, V., Kordatos, K., Prato, M., Guldi, D. M., Holzinger, M., Hirsch, A. Organic functionalization of carbon nanotubes, J. Am. Chem. Soc. 2002, 124, 760-761.

144 Lu, X., Tian, F., Xu, X., Wang, N., ZHANG, Q. Theoretical exploration of the 1,3-dipolar cycloadditions onto the sidewalls of $(n, n)$ armchair single-wall carbon nanotubes, J. Am. Chem. Soc. 2003, 125, 10459-10464.

145 Yao, Z., Braidy, N., Botton, G. A., Adronov, A. Polymerization from the surface of single-walled carbon nanotubes - preparation and characterization of nanocomposites, J. Am. Chem. Soc. 2003, 125, 16015-16024.

146 Georgakilas, V., Tagmatarchis, N., Pantarotto, D., Bianco, A., Briand, J.-P., Prato, M. Amino acid functionalization of water soluble carbon nanotubes, Chem. Commun. 2002, 3050-3051.

147 Georgakilas, V., Voulgaris, D., Vazquez, E., Prato, M., Guldi, D. M., Kukovecz, A., Kuzmany, H. Purification of HiPCO carbon nanotubes via organic functionalization, J. Am. Chem. Soc. 2002, 124, 14318-14319.

148 Pantorotto, D., Partidos, C. D., Graff, R., Hoebeke, J., Briand, J.-P., Prato, M., Bianco, A. Synthesis, structural characterization, and immunological properties of carbon nanotubes functionalized with peptides, J. Am. Chem. Soc. 2003, 125 , 6160-6164.

149 Bianco, A., Prato, M. Can carbon nanotubes be considered useful tools for biological applications?, Adv. Mater. 2003, 15, 1765-1768.

150 Chopra, N., Majumder, M., Hinds, B. J. Bifunctional carbon nanotubes by sidewall protection, Adv. Funct. Mater. 2005, 15, 858-864.

151 Lee, K. M., Li, L., DaI, L. Asymmetric end-functionalization of multi-walled carbon nanotubes, J. Am. Chem. Soc. 2005, 127, 4122-4123.

152 Wu, W., Wieckowski, S., Pastorin, G., Benincasa, M., Klumpp, C., Briand, J.-P., Gennaro, R., Prato, M., Bianco, A. Targeted delivery of amphotericin B to cells using functionalized carbon nanotubes, Angew. Chem. Int. Ed. 2005, 44, 6358-6362.

153 Scheller, F. W., Wollenberger, U., WARsinke, A., LisdAT, F. Research and development in biosensors, Curr. Opin. Biotechnol. 2001, 12, 35-40.

154 Meadows, D. Recent developments with biosensing technology and applications in the pharmaceutical industry, Adv. Drug. Deliv. Rev. 1996, 21, 179-189.

155 Tess, M. E., Cox, J. A. Chemical and biochemical sensors based on advances in materials chemistry, J. Pharm. Biomed. Anal. 1999, 19, 55-68.

156 Popov, V. N. Carbon nanotubes: properties and application, Mater. Sci. Eng. 2004, R43, 61-102.

157 Special Issue on Carbon Nanotubes, Acc. Chem. Res. 2002, 35, 997-1113.

158 Tans, S. J., Verschueren, A. R. M., DEKKER, C. Room-temperature transistor based on a single carbon nanotube, Nature 1998, 393, 49-52.

159 Davis, J. J., Green, M. L. H., Hill, H. A. O., Leung, Y. C., Sloan, J., Sadler, P. J., Xavier, A. V., Tsang, S. C. The immobilisation of proteins in carbon nanotubes, Inorg. Chim. Acta 1998, 272, 261-266.

160 Snow, E. S., Perkins, F. K., Houser, E. J., Badescu, S. C., Reinecke, T. L. Chemical detection with a singlewalled carbon nanotube capacitor, Science 2005, 307, 1942-1945.

161 Qian, K., Yan, B., Lin, Y., Xu, D., Cai, B., Chen, T., Sun, Z. Research 
on carbon nanotube array field emission pressure sensors, Electron. Lett. 2005, 41, 824-825.

162 Postma, H. W. C., Teepen, T., Yao, Z., Grifoni, M., Dekker, C. Carbon nanotube single-electron transistors at room temperature, Science 2001, 293, 76-79.

163 Merkoçi, A., Pumera, M., Llopis, X., Pérez, B., Del Valle, M., Alegret, S. New materials for electrochemical sensing VI: carbon nanotubes, Trends Anal. Chem. 2005, 24, 826-838.

164 Martel, R., Schmidt, T., Shea, H. R., Hertel, T., Avouris, P. Single- and multi-wall carbon nanotube field-effect transistors, Appl. Phys. Lett. 1998, 73, 2447-2449.

165 Li, J., Koehne, J. E., Cassell, A. M., Chen, H., NG, H. T., Ye, Q., Fan, W., Han, J., MeyYappan, M. Inlaid multiwalled carbon nanotube nanoelectrode arrays for electroanalysis, Electroanalysis 2005, 17, 15-27.

166 Avouris, P. Molecular electronics with carbon nanotubes, Acc. Chem. Res. 2002, 35, 1026-1034.

167 DAI, H. Carbon nanotubes: synthesis, integration, and properties, Acc. Chem. Res. 2002, 35, 1035-1044.

168 Johnston, D. E., Islam, M. F., Yodh, A. G., Johnson, A. T. Electronic devices based on purified carbon nanotubes grown by high-pressure decomposition of carbon monoxide, Nat. Mater. 2005, 4, 589-592.

169 Niyogi, S., Hu, H., Hamon, M. A., Bhowmik, P., Zhao, B., Rozenzhak, S. M., Chen, J., Itkis, M. E., Meier, M. S., Haddon, R. C. Chromatographic purification of soluble singlewalled carbon nanotubes (s-SWNTs), J. Am. Chem. Soc. 2001, 123, 733-734.

170 Zhao, B., Hu, H., Niyogi, S., Itkis, M. E., Hamon, M. A., Bhowmik, P., Meier, M. S., Haddon, R. C. Chromatographic purification and properties of soluble single-walled carbon nanotubes, J. Am. Chem. Soc. 2001, 123, 11673-11677.

171 Dyke, C. A., Stewart, M. P., Tour, J. M. Separation of single-walled carbon nanotubes on silica gel. Materials morphology and Raman excitation wavelength affect data interpretation, J. Am. Chem. Soc. 2005, 127, 4497-4509.

172 So, H.-M., Won, K., Kim, Y. H., Kim, B.-K., Ryu, B. H., NA, P. S., Kim, H., LEE, J.-O. Single-walled carbon nanotube biosensors using aptamers as molecular recognition elements, J. Am. Chem. Soc. 2005, 127, 11906-11907.

173 Takeda, S., Sbagyo, A., Sakoda, Y., Ishit, A., Sawamura, M., Sueoka, K., Kida, H., Mukasa, K., Matsumoto, K. Application of carbon nanotubes for detecting anti-hemagglutinins based on antigen-antibody interaction, Biosensors Bioelectron. 2005, 21, 201-205.

174 Stait, C., Johnson Jr., A. T., Chen, M., Gelperin, A. DNA-decorated carbon nanotubes for chemical sensing, Nano Lett. 2005, 5, 17741778.

175 Chen, R. J., Choi, H. C., Bangsaruntip, S., Yenilmez, E., TANG, X., Wang, Q., Chang, Y.-L., DAI, H. An investigation of the mechanisms of electronic sensing of protein adsorption on carbon nanotube devices, J. Am. Chem. Soc. 2004, 126, 1563-1568.

176 Chen, R. J., Bangsaruntip, S., Drouvalakis, K. A., Kam, N. W. S., Shim, M., Li, Y., Kim, W., Utz, P. J., DAI, H. Noncovalent functionalization of carbon nanotubes for highly specific electronic biosensors, Proc. Natl Acad. Sci. USA 2003, 100, 4984-4989.

177 Collins, P. G., Arnold, M. S., Avouris, P. Engineering carbon nanotubes and nanotube circuits using electrical breakdown, Science 2001, 292, 706-709.

178 Kong, J., Franklin, N. R., Zhou, C., Chapline, M. G., Peng, S., Cho, K., DAI, H. Nanotube molecular wires as chemical sensors, Science 2000, 287, 622-625.

179 Feng, X., Irle, S., Witek, H., Morokuma, K., Vidic, R., Borguet, E. Sensitivity of ammonia interaction with single-walled carbon nanotube bundles to the presence of defect sites 
and functionalities, J. Am. Chem. Soc. 2005, 127, 10533-10538.

180 Lucci, M., Regoliosi, P., Reale, A., Di Carlo, A., Orlanducci, S., Tamburri, E., Terranova, M. L., Lugli, P., Di Natale, C., D’Amico, A., Paolesse, R. Gas sensing using single wall carbon nanotubes ordered with dielectrophoresis, Sensors Actuators B 2005, 111-112, 181-186.

181 Zhang, B., Fu, R. W., Zhang, M. Q., Dong, X. M., LAN, P. L., QIU, J. S. Preparation and characterization of gas-sensitive composites from multiwalled carbon nanotubes/polystyrene, Sensors Actuators, B 2005, 109, 323-328.

182 Gooding, J. J., Wibowo, R., LiU, J., YANG, W., Losic, D., Orbons, S., Mearns, F. J., Shapter, J. G., Hibbert, D. B. Protein electrochemistry using aligned carbon nano-tube arrays, $J$. Am. Chem. Soc. 2003, 125, 9006-9007.

183 Patolsky, F., Weizmann, Y., WILLNER, I. Long-range electrical contacting of redox enzymes by SWCNT connectors, Angew. Chem. Int. Ed. 2004, 43, 2113-2117.

184 Lin, Y., Lu, F., Tu, Y., Ren, Z. Glucose biosensors based on carbon nanotube nanoelectrode ensembles, Nano Lett. 2004, 4, 191-195.

185 Kerman, K., Morita, Y., Takamura, Y., TAmiYa, E. Escherichia coli singlestrand binding protein-DNA interactions on carbon nanotubemodified electrodes from a label-free electrochemical hybridization sensor, Anal. Bioanal. Chem. 2005, 381, 1114-1121.

186 Li, G., Liao, J. M., Hu, G. Q., Ma, N. Z., Wu, P. J. Study of carbon nanotube modified biosensor for monitoring total cholesterol in blood, Biosensors Bioelectron. 2005, 20, 2140-2144.

187 Wang, J., Musameh, M., Lin, Y. Solubilization of carbon nanotubes by nafion toward the preparation of amperometric biosensors, J. Am. Chem. Soc. 2003, 125, 2408-2409.

188 Balavoine, F., Schultz, P., Richard, C., Mallouh, V., Ebbesen, T. W., Mıоsкowsкi, C. Helical crystallization of proteins on carbon nanotubes: a first step towards the development of new biosensors, Angew. Chem. Int. Ed. 1999, 38, 1912-1915.

189 Shim, M., Kam, N. W. S., Chen, R. J., LI, Y., DAI, H. Functionalization of carbon nanotubes for biocompatibility and biomolecular recognition, Nano Lett. 2002, 2, 285-288.

190 Pantarotto, D., Briand, J.-P., Prato, M., Bianco, A. Translocation of bioactive peptides across cell membranes by carbon nanotubes, Chem. Commun. 2004, 16-17.

191 Pantarotto, D., Singh, R., McCarthy, D., Erhardt, M., Briand, J.-P., Prato, M., Kostarelos, K., Bianco, A. Functionalised carbon nanotubes for plasmid DNA gene delivery, Angew. Chem. Int. Ed. 2004, 43, 5242-5246.

192 Cai, D., Mataraza, J. M., Qin, Z. H., Huang, Z., Huang, J., Chiles, T. C., Carnahan, D., Kempa, K., Ren, Z. Highly efficient molecular delivery into mammalian cells using carbon nanotube spearing, Nat. Methods 2005, 2, 449-454.

193 Cherukuri, P., Bachilo, S. M., Litovsky, S. H., Weisman, R. B. Nearinfrared fluorescence microscopy of single-walled carbon nanotubes in phagocytic cells, J. Am. Chem. Soc. 2005, 127, 15638-15639.

194 Kaм, N. W. S., Liu, Z., Dai, H. Carbon nanotubes as intracellular transporters for proteins and DNA: an investigation of the uptake mechanism and pathway, Angew. Chem. Int. Ed. 2006, 46, 577-581.

195 Acharya, T., Kennedy, R., DaAr, A. S., Singer, P. A. Biotechnology to improve health in developing countries - a review, Mem. Inst. Oswaldo Cruz 2004, 99, 341-350.

196 Miconnet, I., Koenig, S., Speiser, D., Krieg, A., Guillaume, P., Cerottini, J. C., Romero, P. CpG are efficient adjuvants for specific CTL induction against tumor antigenderived peptide, J. Immunol. 2002, 168, 1212-1218.

197 Klinman, D. M., Currie, D., Gursel, I., Verthelyi, D. Use of CpG 
oligodeoxynucleotides as immune adjuvants, Immunol. Rev. 2004, 199, 201-216

198 Klinman, D. M. Immunotherapeutic uses of CpG oligodeoxynucleotides, Nat. Rev. Immunol. 2004, 4, 249-258.

199 Klinman, D. M., Verthelyi, D., Takeshita, F., Ishit, K. J. Immune recognition of foreign DNA: a cure for bioterrorism?, Immunity 1999, 11, 123-129.

200 Krieg, A. M. CpG motifs in bacterial DNA and their immune effects, Annu. Rev. Immunol. 2002, 20, 709-760.

201 Hemmi, H., Takeuchi, O., Kawai, T., Kaisho, T., Sato, S., Sanjo, H., Matsumoto, M., Hoshino, K., Wagner, H., Takeda, K., Akira, S. A. A Toll-like receptor recognizes bacterial DNA, Nature 2000, 408, $740-745$.

202 Hoffmann, J. A., Kafatos, F. C., Janeway, C. A., Ezekowitz, R. A. B. Phylogenetic perspectives in innate immunity, Science 1999, 284, 13131318.

203 Krieg, A. M. The role of CpG motifs in innate immunity, Curr. Opin. Immunol. 2000, 12, 35-43.

204 Bianco, A., Hoebeke, J., Godefroy, S., Chaloin, O., Pantarotto, D., Briand, J.-P., Muller, S., Prato, M., Partidos, C. D. Cationic carbon nanotubes bind to $\mathrm{CpG}$ oligodeoxynucleotides and enhance their immunostimulatory properties, J. Am. Chem. Soc. 2005, 127, 58-59.

205 Leist, T. P., Сobbold, S. P., Waldmann, H., Aguet, M., ZinkeRnAGEL, R. M. Functional analysis of $\mathrm{T}$ lymphocyte subsets in antiviral host defense, J. Immunol. 1987, 138, 2278-2281.

206 Matloubian, M., Concepcion, R. J., Ahmed, R. CD4 ${ }^{+}$T cells are required to sustain $\mathrm{CD}^{+}$cytotoxic T-cell responses during chronic viral infection, J. Virol. 1994, 68, 80568063.

207 Mosmann, T. R., Coffman, R. L. T 1 and $\mathrm{T}_{\mathrm{H}} 2$ cells: different patterns of lymphokine secretion lead to different functional properties, Annu. Rev. Immunol. 1989, 7, 145-173.
208 Barchet, W., Oehen, S., Klennerman, P., Wodarz, D., Bocharov, G., Lloyd, A. L., Nowak, M. A., Hengartner, H., Zinkernagel, R. M., EhL, S.

Direct quantitation of rapid elimination of viral antigen-positive lymphocytes by antiviral CD ${ }^{+} \mathrm{T}$ cells in vivo, Eur. J. Immunol. 2000, 30, 1356-1363.

209 Partidos, C. D. Peptide mimotopes as candidate vaccines, Curr. Opin. Mol. Ther. 2000, 2, 74-79.

210 Francis, M. J. Peptide vaccines for viral diseases, Sci. Prog. 1990, 74, 115-130.

211 Pantarotto, D., Partidos, C. D., Hoebeke, J., Brown, F., Kramer, E., Briand, J.-P., Muller, S., Prato, M., BiAnCO, A. Immunization with peptide-functionalized carbon nanotubes enhances virus-specific neutralizing antibody responses, Chem. Biol. 2003, 10, 991-966.

212 Francis, M. J., Hastings, G. Z., Syred, A. D., McGinn, B., Brown, F. Rowlands, D. J. Non-responsiveness to a foot-and-mouth disease virus peptide overcome by addition of foreign helper T-cell determinants, Nature 1987, 330, 168-170.

213 Partidos, C. D., Obeid, O. E., Steward, M. W. Antibody responses to non-immunogenic synthetic peptides induced by co-immunization with immunogenic peptides, Immunology 1992, 77, 262-266.

214 Schutze, M. P., Leclerc, C., Jolivet, M., Audibert, F., Chedid, L. Carrierinduced epitopic suppression, a major issue for future synthetic vaccines, J. Immunol. 1985, 135, 2319-2322.

215 Pouton, C. W., Seymour, L. W. Key issues in non-viral gene delivery, Adv. Drug. Deliv. Rev. 2000, 46, 187-203.

216 Yinghuai, Z., Peng, A. T., Carpenter, K., Maguire, J. A., Hosmane, N. S., TAKagaki, M. Substituted carborane-appended watersoluble single-wall carbon nanotubes: New approach to boron neutron capture therapy drug delivery, J. Am. Chem. Soc. 2005, 127, 9875-9880.

217 Kam, N. W. S., O'Connell, M., Wisdom, J. A., DAI, H. Carbon 
nanotubes as multifunctional biological transporters and nearinfrared agents for selective cancer cell destruction, Proc. Natl Acad. Sci. USA 2005, 102, 11600-11605.

218 Pastorin, G., Wu, W., Wieckowski, S., Briand, J.-P., Kostarelos, K., Prato, M., Bianco, A. Double functionalization of carbon nanotubes for multimodal drug delivery, Chem. Commun. 2006, 1182-1184.

219 Murakami, T., Ajima, K., Miyawaki, J., Yudasaka, M., Iijima, S., Shibe, K. Drug-loaded carbon nanohorns: adsorption and release of dexamethasone in vitro, Mol. Pharm. 2004, 1, 399-405.

220 Ajima, K., Yudasaka, M., Murakami, T., Maigné, A., Shiba, K., Iıjima, S. Carbon nanohorns as anticancer drug carriers, Mol. Pharm. 2005, 2, 475480.

221 Singh, R., Pantarotto, D., McCarthy, D., Chaloin, O., Hofbeke, J., Partidos, C. D., Briand, J.-P., Prato, M., Bianco, A., Kostarelos, K. Binding and condensation of plasmid DNA onto functionalized carbon nanotubes: towards the construction of nanotubebased gene delivery vectors, J. Am. Chem. Soc. 2005, 127, 4388-4396.

222 GaO, H., Kong, Y., Cui, D. X., OzKan, C. S. Spontaneous insertion of DNA oligonucleotides into carbon nanotubes, Nano Lett. 2003, 3, 471-473.

223 Lu, G., Maragakis, P., Kaxiras, E. Carbon nanotube interaction with DNA, Nano Lett. 2005, 5, 897-900.

224 Matyshevska, O. P., Karlash, A. Y., Shtogun, Y. V., Benilov, A., Kirgizov, Y., GorchinskyY, K. O., Buzaneva, E. V., Prylutskyy, Y. I., ScharfF, P. Self-organizing DNA/ carbon nanotube molecular films, Mater. Sci. Eng. C 2001, 15, 249-252.

225 Buzaneva, E., Karlash, A., Yakovkin, K., Shtogun, Y., Putselyk, S., Zherebetskiy, D., Gorchinskiy, A., Popova, G., Prilutska, S., Matyshevska, O., Prilutskyy, Y., Lytvyn, P., Scharff, P., EKLUND, P. C. DNA nano- technology of carbon nanotube cells: physico-chemical models of selforganization and properties, Mater. Sci. Eng. C 2002, 19, 41-45.

226 Dovbeshio, G. I., Repnytska, O. P., Obraztsova, E. D., Shtogun, Y. V. DNA interaction with single-walled carbon nanotubes: a SEIRA study, Chem. Phys. Lett. 2003, 372, 432437.

227 Nepal, D., Sohn, J. I., Aicher, W. K., Lee, S., Geckeler, K. E. Supramolecular conjugates of carbon nanotubes and DNA by a solid-state reaction, Biomacromolecules 2005, 6, 29192922.

228 Dwyer, C., Guthold, M., Falvo, M., Washburn, S., Superfine, R., Erie, D. DNA-functionalized single-walled carbon nanotubes, Nanotechnology 2002, 13, 601-604.

229 Guo, M. L., Chen, J. H., Liu, D. Y., Nie, L. H., YAO, S. Z. Electrochemical characteristics of the immobilization of calf thymus DNA molecules on multi-walled carbon nanotubes, Bioelectrochemistry 2004, 62, 29-35.

230 Nakashima, N., Okuzono, S., Murakami, H., NaKai, T.,

Yoshikawa, K. DNA dissolves singlewalled carbon nanotubes in water, Chem. Lett. 2003, 32, 456-457.

231 Rajendra, J., Baxendale, M., Dit Rap, L. G., Rodger, A. Flow linear dichroism to probe binding of aromatic molecules and DNA to single-walled carbon nanotubes, J. Am. Chem. Soc. 2004, 126, 11182-11188.

232 Rajendra, J., Rodger, A. The binding of single-stranded DNA and PNA to single-walled carbon nanotubes probed by flow linear dichroism, Chem. Eur. J. 2005, 11, 4841-4847.

233 Lacerda, L., Pastorin, G., Wu, W., Prato, M., Bianco, A., Kostarelos, $\mathrm{K}$. Luminescence of functionalized carbon nanotubes as a tool to monitor bundle formation and dissociation in water: the effect of plasmid-DNA complexation, Adv. Funct. Mater. 2006, 16, 1839-1846.

234 Rao, R., Lu, Q., Keskar, G., Freedman, K. O., Floyd, W. C., Rao, A. M., Ke, P. C. Single-molecule 
fluorescence microscopy and Raman spectroscopy studies of RNA bound carbon nanotubes, Appl. Phys. Lett. 2004, 85, 4228-4230.

235 LiU, Y., Wu, D. C., ZhanG, W. D., JiAnG, X., He, C. B., Chung, T. S., Goh, S. H., Leong, K. W. Polyethylenimine-grafted multiwalled carbon nanotubes for secure noncovalent immobilization and efficient delivery of DNA, Angew. Chem. Int. Ed. 2005, 44, 4782-4785.

236 Rojas-Chapana, J., Troszczynska, J., Firkowska, I., Morsczeck, C., Giersig, M. Multi-walled carbon nanotubes for plasmid delivery into Escherichia coli cells, Lab on a Chip 2005, 5, 536-539.

237 Lu, Q., Moore, J. M., Huang, G., Mount, A. S., Rao, A. M., Larcom, L. L., KE, P. C. RNA Polymer translocation with single-walled carbon nanotubes, Nano Lett. 2004, 4, 2473-2477.

238 GaO, L., Nie, L., Wang, T., Qin, Y., Guo, Z., YanG, D., Yan, X. Carbon nanotube delivery of the GFP gene into mammalian cells, ChemBioChem. 2006, 7, 239-242.

239 Weiss, R. Nanotech poses big unknowns, Washington Post, February 2004, A01.

240 Adelmann, P., Baierl, T., Drosselmeyer, E., Politis, C., Polzer, G., Seidel, A., SchweglerBerry, D., Steinleitner, C. Effects of fullerenes on alveolar macrophages in vitro, in Toxic and Carcinogenic Effects of Solid Particles in the Respiratory Tract. U. Mohr, D. L. Dungworth, J. Mauderly, G. Oberdoerster, (Eds.). ILSI Press, Washington, DC, 1994, pp. 405-407.

241 Fortner, J. D., Lyon, D. Y., SAyes, C. M., Boyd, A. M., Falkner, J. C., Hotze, M., Alemany, L. B., TaO, Y. J., Guo, W., Ausman, K. D., Colvin, V. L., Huges, J. B. $\mathrm{C}_{60}$ in water: nanocrystal formation and microbial response, Environ. Sci. Technol. 2005 , 39, 4307-4316.

242 Sayes, C. M., Fortner, J. D., Guo, W., Lyo, D., Boyd, A. M., Ausman, K. D., Tao, Y. J., Sitharaman, B.,
Wilson, L. J., Huges, J. B., West, J. L., Colvin, V. L. The differential cytotoxicity of water-soluble fullerenes, Nano Lett. 2004, 4, 1881-1887.

243 Colvin, V. L. The potential environmental impact of engineered nanomaterials, Nat. Biotechnol. 2003, 21, 1166-1170.

244 Connor, E. E., Mwamuka, J., Gole, A., Murphy, C. J., Wyatt, M. D. Gold nanoparticles are taken up by human cells but do not cause acute cytotoxicity, Small 2005, 1, 325-327.

245 Moussa, F., Pressac, M., Hadchouel, M., Arbeille, B., Chrétien, P., Trivin, F., CÉolin, R., Szwarc, H. $\mathrm{C}_{60}$ fullerene toxicity: preliminary account of an in vivo study, Electrochemical Soc. Proc. 1997, 5, 332-336.

246 Gharbi, N., Pressac, M., Hadchouel, M., Szwarc, H., Wilson, S. R., Moussa, F. [60]Fullerene is a powerful antioxidant in vivo with no acute or subacute toxicity, Nano Lett. 2005, 5, 2578-2585.

247 Yokoyama, A., Sato, Y., Nodasaka, Y., Yamamoto, S., Kawasaki, T., Shindoh, M., Kohgo, T., AKasaka, T., Uo, M., Watari, F., Tohji, K. Biological behavior of hat-stacked carbon nanofibers in the subcutaneous tissue in rats, Nano Lett. 2005, 5, 157-161.

248 Jia, G., WanG, H., Yan, L., WAnG, X., Pei, R., Yan, T., Zhao, Y., Guo, X. Cytotoxicity of carbon nanomaterials: single-wall nanotube, multi-wall nanotube, and fullerene, Environ. Sci. Technol. 2005, 39, 1378-1383.

249 Manna, S. K., Sarkar, S., Barr, J., Wise, K., Barrera, E. V., Jejelowo, O., Rice-Ficht, A. C., Ramesh, G. T. Single-walled carbon nanotube induces oxidative stress and activates nuclear transcription factor- $\kappa \mathrm{B}$ in human keratinocytes, Nano Lett. 2005, 5, 1676-1684.

250 Donaldson, K., Stone, V., Tran, C. L., Kreyling, W., Borm, P. J. A. Nanotoxicology, Occup. Environ. Med. 2004, 61, 727-728.

251 Tran, C. L., Buchanan, D., Cullen, R. T., Searl, A., Jones, A. D., DonALDSON, K. Inhalation of poorly 
soluble particles. II. Influence of particle surface area on inflammation and clearance, Inhal. Toxicol. 2000, 12, 113-126.

252 Sayes, C. M., Liang, F., Hudson, J. L., Mendez, J., Guo, W., Beach, J. M., Moore, V. C., Doyle, C. D., West, J. L., Billups, W. E., Ausman, K. D., Colvin, V. L. Functionalization density dependence of single-walled carbon nanotubes cytotoxicity in vitro, Toxicol. Lett. 2006, 161, 135-142.

253 Sato, Y., Yokoyama, A., Shibata, K., Акimoto, Y., Ogino, S., Nodasaka, Y., Kohgo, T., Tamura, K., Akasaka, T., Uo, M., Мотомiya, K., Jeyadevan, B., Ishiguro, M., Hatakeyama, R., Watari, F., Tohji, K. Influence of length on cytotoxicity of multi-walled carbon nanotubes against human acute monocytic leukemia cell line THP-1 in vitro and subcutaneous tissue of rats in vivo, Mol. BioSyst. 2005, 1, 176-182.

254 Salvador-Morales, C., Flahaut, E., Sim, E., Sloan, J., Green, M. L. H., Sim, R. B. Complement activation and protein adsorption by carbon nanotubes, Mol. Immunol. 2006, 43, 193-201.

255 Kiura, K., Sato, Y., Yasuda, M., Fugetsu, B., Watari, F., Tohj, K., Shibata, K. Activation of human monocytes and mouse splenocytes by single-walled carbon nanotubes, J. Biomed. Nanotechnol. 2005, 1, 359-364.

256 Cui, D., Tian, F., Ozkan, S., Wang, M., GAO, H. Effect of single wall carbon nanotubes on human HEK293 cells, Toxicol. Lett. 2005, 155, 73-85.

257 Monteiro-Riviere, N. A., Nemanich, R. J., INMAN, A. O., WANG, Y. Y., Riviere, J. E. Multi-walled carbon nanotube interactions with human epidermal keratinocytes, Toxicol. Lett. 2005, 155, 377-384.

258 Bottini, M., Bruckner, S., Nika, K., Bottini, N., Bellucci, S., Magrini, A., Bergamaschi, A., Mustelin, T. Multi-walled carbon nanotubes induce T lymphocyte apoptosis, Toxicol. Lett. 2005, 160, 121-126.
259 Muller, J., Huaux, F., Moreau, N., Misson, P., Heilier, J.-F., Delos, M., Arras, M., Fonseca, A., Nagy, J. B., Lison, D. Respiratory toxicity of multiwall carbon nanotubes, Toxicol. Appl. Pharmacol. 2005, 207, 221-231.

260 Lam, C. W., James, J. T., McCluskey, R., Hunter, R. L. Pulmonary toxicity of single-wall carbon nanotubes in mice 7 and 90 days after intratracheal instillation, Toxicol. Sci. 2004, 77, 126-134.

261 Warheit, D. B., Laurence, B. R., Reed, K. L., Roach, D. H., Reynolds, G. A. M., Webb, T. R. Comparative pulmonary toxicity assessment of single-wall carbon nanotubes in rats, Toxicol. Sci. 2004, 77, 117-125.

262 Huczko, A., Lange, H., Calko, E. Fullerenes: experimental evidence for a null risk of skin irritation and allergy, Fullerene Sci. Technol. 1999, 7, 935-939.

263 Huczko, A., Lange, H. Carbon nanotubes: experimental evidence for a null risk of skin irritation and allergy, Fullerene Sci. Technol. 2001, 9, 247-250.

264 Eedy, D. J. Carbon-fibre-induced airbone irritant contact dermatitis, Contact Derm. 1996, 35, 362-363.

265 Kasparov, A. A., Popova, T. B., Lebedeva, N. V., Gladkova, E. V., Gurvich, E. B. Evaluation of the carcinogenic hazard in the manufacture of graphite articles, Vopr. Onkol. 1989, 35, 445-450.

266 Shyedova, A. A., Kisin, E. R., Murray, A. R., Gandelsman, V. Z., Maynard, A. D., Baron, P. A., Castranova, V. Exposure to carbon nanotube material: Assessment of nanotube cytotoxicity using human keratinocytes cells, J. Toxicol. Environ. Health A 2003, 66, 19091926.

267 Maynard, A. D., Baron, P. A., Foley, M., Shvedova, A. A., Kisin, E. R., Castranova, V. Exposure to carbon nanotube material: aerosol release during the handling of unrefined single-walled carbon nanotube material, J. Toxicol. Environ. Health A 2004, 67, 87-107. 